\title{
Functional properties of ceramic-Ag nanocomposite coatings produced by magnetron sputtering
}

\author{
S. Calderon Velasco ${ }^{\mathrm{a}, \mathrm{b}, *}$, A. Cavaleiro ${ }^{\mathrm{b}}$, S. Carvalho ${ }^{\mathrm{a}, \mathrm{b}}$ \\ a GRF-CFUM, Physics Department, University of Minho, 4800-058 Guimarães, Portugal \\ ${ }^{\mathrm{b}}$ SEG-CEMUC Mechanical Engineering Department, University of Coimbra, 3030-788 Coimbra, Portugal
}

\section{A R T I C L E I N F O}

\section{Article history:}

Received 6 December 2015

Received in revised form 9 September 2016

Accepted 18 September 2016

Available online 24 September 2016

\section{Keywords:}

Nanocomposite

Ceramic coatings

Silver nanoparticles

Magnetron sputtering

Antimicrobial

Mechanical

Tribological

Corrosion

Electrochemical

Optical properties

\begin{abstract}
A B S T R A C T
In recent years, the use of nanocomposite materials to functionalize surfaces has been investigated, taking advantage of the complementary properties of the nanocomposite constituents. Among this family of materials, ceramic-Ag coatings have been widely studied due to the large variety of functionalities that silver possesses and the possibility of tuning the coating's practical features by selecting the proper matrix to support this noble metal. Therefore, this review focuses on the effects of silver nanoparticles on the functional properties of ceramic-Ag nanocomposites. The chemistry, structure, morphology and topography of the coatings are analyzed with respect to the changes produced by the silver nanoparticles' distribution, amount and sizes and by altering production process variables. To offer a clear understanding of the functionalities of these materials, the optical, electrical, mechanical, tribological, electrochemical and biological properties reported in the last decade are reviewed, focusing on the ability to tune such properties by modifying the silver distribution, morphology and composition. In particular, the surface plasmon resonance, self-lubricating ability and antibacterial effect of silver are covered in detail, establishing their correlation with factors such as silver diffusion, segregation and ionization.
\end{abstract}

(c) 2016 Elsevier Ltd. All rights reserved.

\section{Contents}

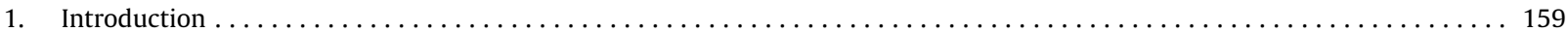

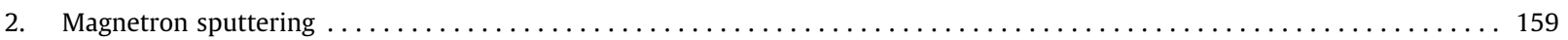

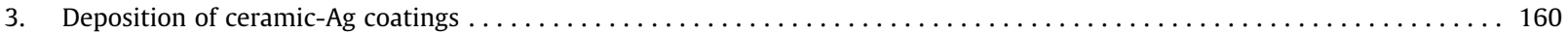

4. Chemical, structural, morphological and topographical properties of ceramic-Ag coatings $\ldots \ldots \ldots \ldots \ldots$

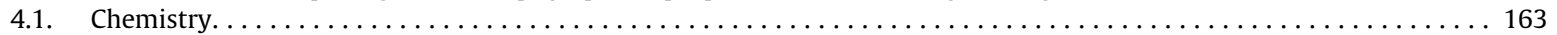

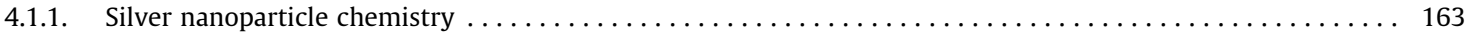

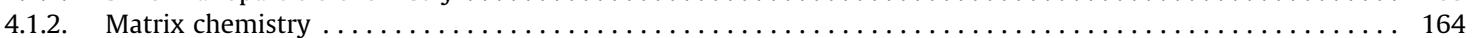

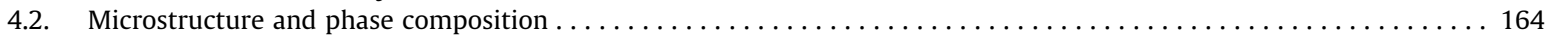

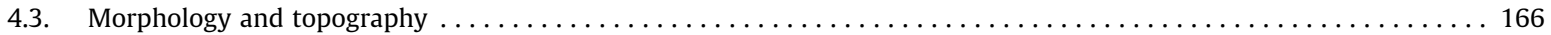

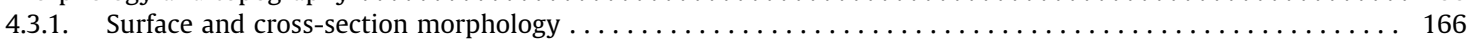

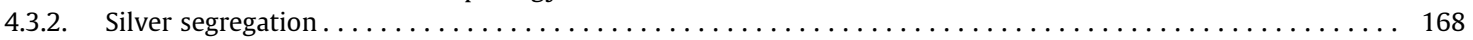

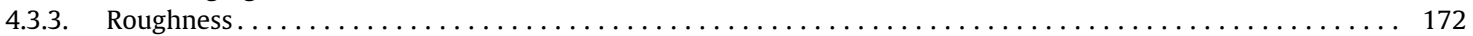

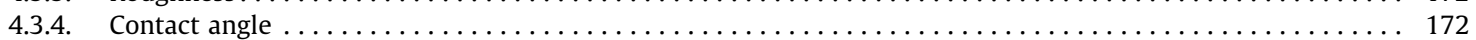

\footnotetext{
* Corresponding author at: Universidade do Minho, Dept. Física, Campus de Azurém, 4800-058 Guimarães, Portugal.

E-mail address: secave44@gmail.com (S. Calderon Velasco).
} 


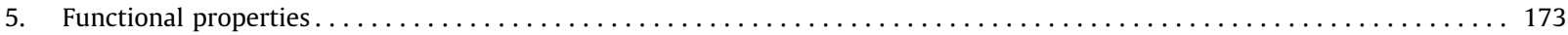

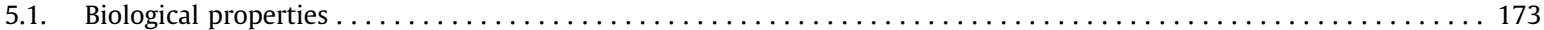

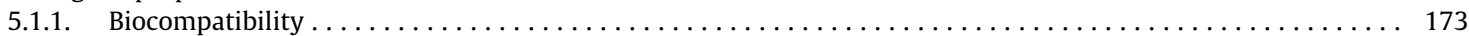

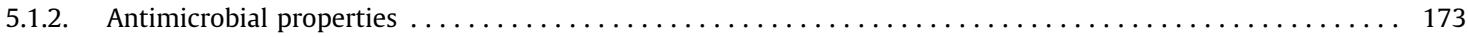

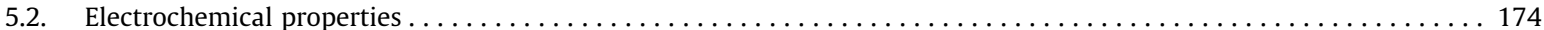

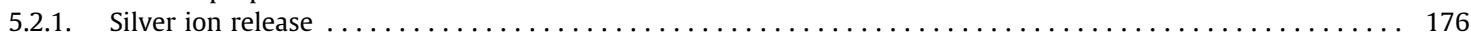

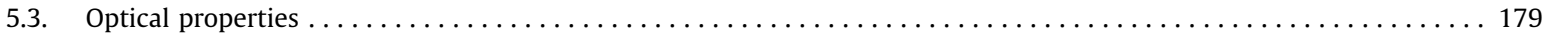

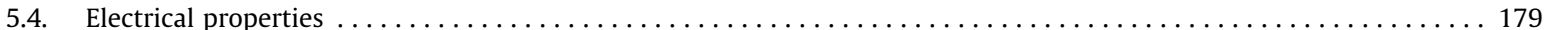

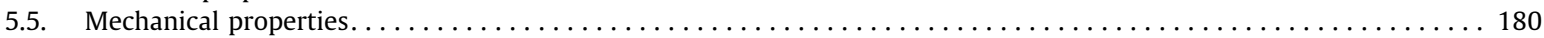

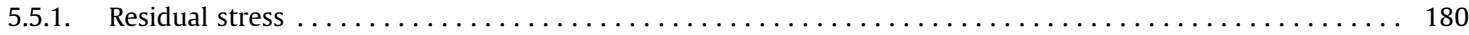

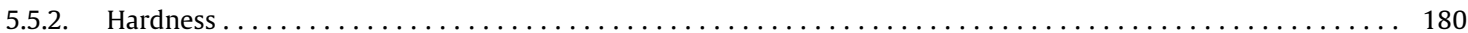

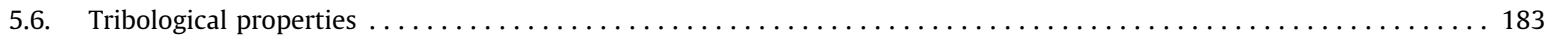

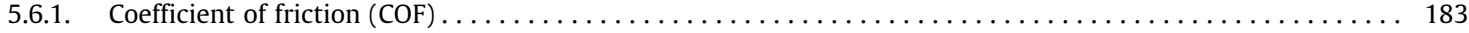

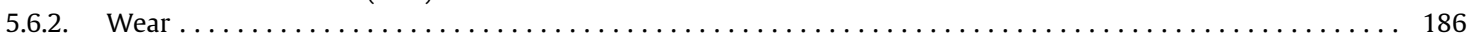

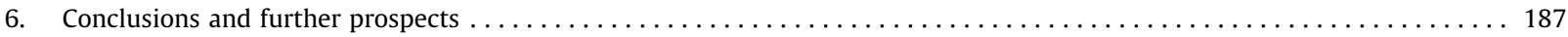

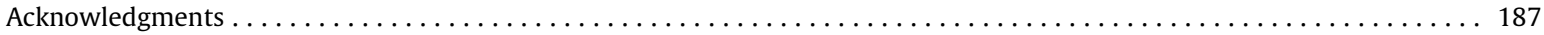

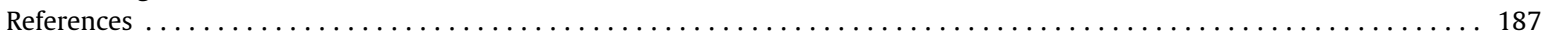

\section{Introduction}

Ceramic-Ag coatings are part of a large collection of protective and functional coatings used to modify the properties of the base material. In these coatings, ceramic phases such as oxides, carbides, nitrides and carbonitrides are mixed with metallic silver to enhance the functionality of the system. These coatings have attracted a considerable amount of attention due to their large range of applications. Their multi-phase character confers independent characteristics from each immiscible phase (ceramic or metallic) in the system, providing multiple functional properties, including antibacterial effects [122] wear resistance [2,4,23-37], corrosion resistance [18,29,38-42] and light absorption enhancement [43-52], among others. One of the most interesting features of these materials is the possibility of tailoring their functionality by selecting the appropriate type, distribution and size of the constituent phases.

A large number of techniques have been used to produce ceramic-Ag coatings, including electrochemical methods, physical vapor deposition (PVD) (e.g., [53]), chemical vapor deposition (CVD) (e.g., [54]) and sol-gel (e.g., [55]) techniques. However, to produce a detailed review of ceramic films with embedded silver nanoparticles and their effect on the coatings' properties, the present review focuses on coatings consisting of silver nanoparticles in ceramic matrices deposited by magnetron sputtering (MS), one of the most commonly used physical vapor deposition techniques. In fact, the diversity of properties exhibited by this group of materials is mainly dominated by the diffusion and growth of the silver nanoparticles in the matrix and the structural nature and the morphological characteristics of the coatings, which are therefore a fundamental factor in the coatings' behavior. These characteristics are strongly affected by the production conditions, resulting in a myriad of outcomes, which is why this review is limited to the MS technique.

\section{Magnetron sputtering}

MS is a deposition technique belonging to a large group of sputtering processes included among PVD technologies. Briefly, for the sputtering process, an electric field is created between two plates (electrodes) within a vacuum chamber. A nonreactive gas (usually $\mathrm{Ar}$ ) is injected into the chamber, is positively ionized due to the electric field and bombards the negative pole of the electric field, the cathode of the discharge. The collisions of $\mathrm{Ar}^{+}$ions with the material located in the cathode, known as the target, cause the ejection of atoms/molecules from the surface toward the substrates [56].

The ionization and collision rates of argon in sputtering systems are generally low, resulting in very slow deposition rates and poor film densities. Thus, a variation of the sputtering technique was introduced in 1930 [57] to increase the ionization rate in the vicinity of the target and increase the deposition rate of the films. This modification, MS, consists of a set of magnets placed beneath the target, which provide a magnetic field to trap the secondary electrons emitted by the target into the discharge, increasing the ionization of argon around the target and, consequently, increasing the target bombardment. All of these components are schematized in Fig. 1a.

MS can be either unbalanced or balanced, which refers to the magnitude of the magnetic field between the poles of the magnets that form the magnetron. Balanced magnetrons possess the same strength in terms of the magnetic field between the south and north poles of the magnet, generating closed field lines between these poles [58]. In the unbalanced mode, by contrast, the strengthened magnetic field in the poles in the exterior of the magnetron allows the magnetic field lines to be directed toward the substrate. These two types of magnetrons are schematized in Fig. $1 \mathrm{~b}$.

In addition to magnetic field balancing, the film features can be modified by altering several parameters in the production process, such as the number of magnetrons, the type of power supply, the current density, the distance between the magnetron and the substrate, the pressure in the chamber (known as the discharge pressure) and the temperature of the 
a) Magnetron sputtering

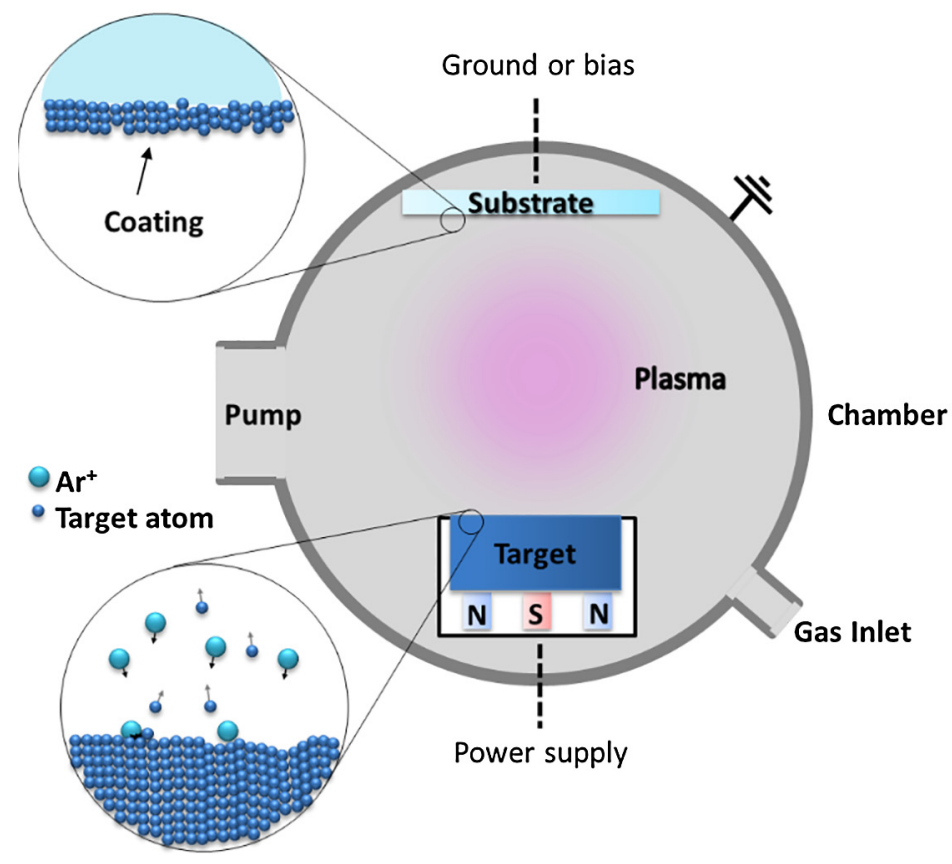

b) Type of magnetrons
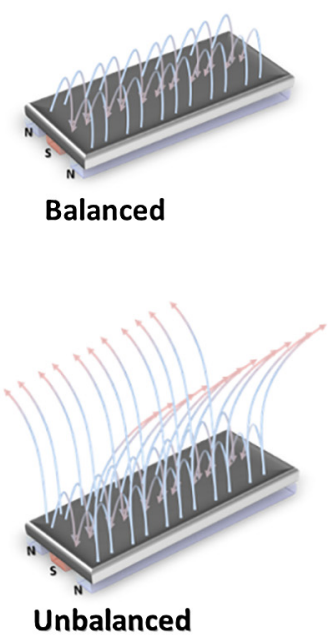

Fig. 1. (a) Magnetron sputtering scheme and (b) balanced and unbalanced types of magnetron configurations used in MS.

chamber/substrate, among others parameters, making this technique very versatile [59]. Moreover, the incorporation of reactive gases into the production chamber, such as oxygen, nitrogen, methane, and acetylene, creates countless possibilities to form compounds between the target and the gases, thus altering the chemical, structural and morphological properties of the films.

The electric field that establishes the discharge may be applied by different types of power supplies, including radio frequency (RF), direct current (DC), pulsed (P) or microwave, depending on the target conductivity or its tendency to react with the injected gas in reactive processes [59]. The temperature in MS provides kinetic energy to the species being deposited, thus adding mobility to the adatoms and consequently modifying the morphology and structure of the films.

Finally, an additional bias potential may be applied to the substrate to make $\mathrm{Ar}^{+}$ions collide with the substrate surface, thereby producing significant changes in the morphology, structure and composition of the films by adding energy to the species deposited or re-sputtering some species from the growing film. Most of these variables were considered when analyzing the various MS techniques used to produce ceramic-Ag coatings in this review.

\section{Deposition of ceramic-Ag coatings}

The production of ceramic films with embedded silver nanoparticles can be divided into five classes based on the nature of the matrix: nitrides, carbides, carbonitrides, carbon-based films (diamond-like carbon or DLC) and oxides.

Nitrides, carbides and carbonitrides with different stoichiometries are easily deposited by reactive MS using $\mathrm{N}_{2}$ and hydrocarbon $\left(\mathrm{C}_{2} \mathrm{H}_{2}\right.$ and $\left.\mathrm{CH}_{4}\right)$ gases to react with a transition metal $\left(\mathrm{Me}\right.$ ) element $\left(\mathrm{Al}, \mathrm{Cr}, \mathrm{Ti}, \mathrm{Nb}, \mathrm{Zr}, \mathrm{Mo}, \mathrm{V}\right.$ or Ta) to form $M e \mathrm{~N}_{\mathrm{x}}$, $M e C_{\mathrm{x}}$ or $M e \mathrm{C}_{1-\mathrm{x}} \mathrm{N}_{\mathrm{x}}$ phases. By increasing the content of the reactive gas(es) and varying the target power density, it is possible to change from a film rich in the metal component (which is known as the metallic mode) to a film rich in reactive gas elements (known as the reactive mode). In addition, for very high reactive gas contents, poisoning of the target is reached, forming a stable phase on its surface (nitride, carbide or carbonitride).

For processes with C-containing reactive gases, such as those for obtaining carbides, carbonitrides or pure carbon-based coatings, carbon amorphous phases can also be deposited in a process very similar to plasma-enhanced chemical vapor deposition. In these cases, hydrogen is incorporated into the coatings; this hydrogen is often not quantified but greatly alters the properties of these amorphous phases, as exemplified in [60,61]. C-based matrices can also be achieved by MS using a graphite target, allowing the deposition of single C coatings, usually known as DLCs [29,62]. As above, if the C-target is sputtered in a reactive $\mathrm{C}-\mathrm{H}$ atmosphere, $\mathrm{H}$ is present in the deposited film.

Oxide matrices, by contrast, are mainly produced by non-reactive MS combining silver and oxide targets. A summary of the conditions and different types of matrices found in the literature is presented in Table 1.

Incorporation of silver is achieved using a separate target in the system or by placing silver pellets on the working target, as shown in Fig. 2a and b, respectively. In the first case, the silver content may be increased by intensifying the power density 
Table 1

Deposition conditions for different types of ceramic-Ag films obtained by MS. (MS = Magnetron Sputtering; P = Pulsed; DC = Direct current; RF = Radio frequency; U = Unbalanced; Mu = Multi-target.)

\begin{tabular}{|c|c|c|c|c|c|c|c|c|}
\hline Matrix & Method & Temperature $^{a}$ & Target element & $\begin{array}{l}\text { Gas type and flux } \\
(\mathrm{sccm})\end{array}$ & $\begin{array}{l}\text { Target power } \\
\left(\mathrm{W} \mathrm{cm}^{-2}\right)\end{array}$ & $\begin{array}{l}\text { Ag target power } \\
\left(\mathrm{W} \mathrm{cm}^{-2}\right)\end{array}$ & $\begin{array}{l}\text { Working } \\
\text { pressure }^{\mathrm{a}}(\mathrm{Pa})\end{array}$ & $\operatorname{Bias}^{\mathrm{a}}(\mathrm{V})$ \\
\hline AIN [63] & MS-Mu-DC & NM & $\mathrm{Al}$ & $\begin{array}{l}\mathrm{Ar}=12 \\
\mathrm{~N}_{2}=8\end{array}$ & $\begin{array}{l}0.74^{\mathrm{d}} \\
4.93^{\mathrm{d}}\end{array}$ & $\begin{array}{l}0.148,0.74 \text { and } \\
1.23^{\mathrm{d}}\end{array}$ & & NM \\
\hline $\begin{array}{l}\mathrm{CrN}[2,23,25,27 \\
\quad 30,31,37,64,65]\end{array}$ & $\begin{array}{l}\text { MS, MS-DC, MS-U-DC, } \\
\text { MS-U-P-DC, MS-U-RF, MS-P }\end{array}$ & $190-700$ & $\mathrm{Cr}$ & $\mathrm{Ar}$ and $\mathrm{N}_{2}$ & $\begin{array}{l}3.3,10.2, \sim 23 \\
3 \mathrm{~A} \\
5.3 \mathrm{~kW}\end{array}$ & $\begin{array}{l}0-8.15 \\
0.2-2 \mathrm{~A} \\
0.1 \text { and } 0.2 \mathrm{~kW}\end{array}$ & $2 \times 10^{-5}$ to 15 & $\begin{array}{l}-150 \text { to }-30 \\
\text { ground }\end{array}$ \\
\hline $\operatorname{MoN}[34,66,67]$ & MS-Mu and MS-U & 350 & Mo & Ar and $N_{2}$ & $9.2-10.2$ & $0-7.4$ & $0.34-1$ & $\begin{array}{l}-30 \\
-60\end{array}$ \\
\hline $\mathrm{NbN}[68]$ & MS-U & 350 & $\mathrm{Nb}$ & $\begin{array}{l}\mathrm{Ar}=0.533 \mathrm{~Pa} \\
\mathrm{~N}_{2}=0.08 \mathrm{~Pa}\end{array}$ & $200 \mathrm{~W}$ & $30 \mathrm{~W}$ & NM & -60 \\
\hline $\operatorname{TaN}[5,32,33,69-71]$ & MS-U and MS-Mu & 100 & $\mathrm{Ta}$ & $\mathrm{Ar}$ and $\mathrm{N}_{2}$ & $7.6-12.7$ & $0-1.10$ & $0.65-1.1$ & $40 \mathrm{~W},-40$ \\
\hline TiN $[1,2,10,12,35,72-74]$ & MS-U-P-DC & $100-325$ & 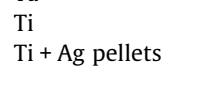 & $\mathrm{Ar}$ and $\mathrm{N}_{2}$ & $\begin{array}{l}3-6.2 \\
1.5 \mathrm{~kW} \\
10 \mathrm{~mA} \mathrm{~cm}^{-2}\end{array}$ & $\begin{array}{l}0-7.1 \\
120 \mathrm{~W} \\
\text { Combined target }\end{array}$ & $0.24-0.6$ & $\begin{array}{l}-200 \text { to } \\
\text { ground }\end{array}$ \\
\hline VN [75] & MS-U & 350 & $\mathrm{~V}$ & $\begin{array}{l}\mathrm{Ar}=0.3 \mathrm{~Pa} \\
\mathrm{~N}_{2}=0.04 \mathrm{~Pa}\end{array}$ & $10.2^{\mathrm{d}}$ & $0-3.8^{d}$ & 0.34 & -60 \\
\hline $\operatorname{ZrN}[2,3,18,45,76-78]$ & $\begin{array}{l}\text { MS-U-DC, MS-P-DC and } \\
\text { MS-DC }\end{array}$ & $\begin{array}{l}\text { Room } \\
\text { Temperature } \\
\text { (RT) }\end{array}$ & $\mathrm{Zr}$ & Ar and $\mathrm{N}_{2}$ & $\begin{array}{l}5 \\
70 \mathrm{~W}\end{array}$ & $\begin{array}{l}0-0.77 \\
0-18 \mathrm{~W}\end{array}$ & $0.21-0.5$ & -30 to -170 \\
\hline HfC [79] & MS-RF-Mu & 200 & $\mathrm{HfC}$ & $\mathrm{Ar}$ & $250 \mathrm{~W}$ & $0-42 \mathrm{~W}$ & 1.33 & NM \\
\hline $\mathrm{SiC}[79]$ & MS-Mu & 200 & $\mathrm{SiC}$ & $\mathrm{Ar}$ & $200 \mathrm{~W}$ & $0-25 \mathrm{~W}$ & 1.33 & NM \\
\hline $\operatorname{TiC}[80,81]$ & MS-RF and MS-U & $180-275$ & $\mathrm{TiC}, \mathrm{Ti}+$ Ag bars & $\mathrm{Ar}$ and $\mathrm{CH}_{4}$ & $2 \mathrm{~A}$ & Combined target & $1-1.33$ & -500 \\
\hline $\mathrm{Ti}(\mathrm{Si}, \mathrm{Ge}$ or $\mathrm{Sn}) \mathrm{C}[82]$ & MS-DC & 300 & $\begin{array}{l}\mathrm{TiC}, \mathrm{Si} \text { and } \mathrm{Ge} \text { or } \\
\mathrm{Sn}\end{array}$ & $\mathrm{Ar}$ & NM & NM & 0.53 & -50 \\
\hline TiSiC $[82,83]$ & MS and MS-DC & 230 and 300 & $\mathrm{Ti}_{3} \mathrm{SiC}_{2}$ & $\mathrm{Ar}$ & NM & NM & NM & NM \\
\hline WC [84] & MS-RF & 275 & WC & $\mathrm{Ar}$ & NM & NM & 1.33 & NM \\
\hline MoCN [85] & MS & 300 & Mo and C & $\mathrm{Ar}$ and $\mathrm{N}_{2}$ & $\begin{array}{l}4.4 \mathrm{~mA} \mathrm{~cm}^{-2} \text { for } \\
\text { Mo and } \mathrm{C}\end{array}$ & NM & 0.2 & -50 \\
\hline $\operatorname{TiCN}[4,26,86-89]$ & MS-U-DC, MS-DC & $100-300$ & $\begin{array}{l}\mathrm{Ti} \\
\mathrm{Ti}+\text { Ag pellets }\end{array}$ & $\mathrm{Ar}, \mathrm{N}_{2}$ and $\mathrm{C}_{2} \mathrm{H}_{2}$ & $3.5-10 \mathrm{~mA} \mathrm{~cm}^{-2}$ & $0-7 \mathrm{~mA} \mathrm{~cm}^{-2}$ & $0.2-0.47$ & -50 to -70 \\
\hline $\mathrm{ZrCN}[40,90,91]$ & MS-U-DC & 100 & $\begin{array}{l}\mathrm{Zr} \\
\mathrm{Zr}+\text { Ag pellets }\end{array}$ & $\mathrm{Ar}, \mathrm{C}_{2} \mathrm{H}_{2}$ and $\mathrm{N}_{2}$ & $1.83-3.75^{\mathrm{d}}$ & $0-1.78$ & $0.2-0.71$ & -50 \\
\hline $\begin{array}{l}\operatorname{DLC}[19,28,29,46, \\
\quad 62,92-104]\end{array}$ & $\begin{array}{l}\text { MS-DC, MS-U-DC, Microwave } \\
\text { sputteringMS-P-AC-Mu } \\
\text { MS-U-DC, MS-PECVD, } \\
\text { MS-U-AC, MS-RF and MS-RF-DC }\end{array}$ & RT to 200 & $\mathrm{C}+\mathrm{Ag}$ pellets & $\mathrm{Ar}, \mathrm{CH}_{4}$ and $\mathrm{C}_{2} \mathrm{H}_{2}$ & $\begin{array}{l}3.5-7.5 \\
400 \mathrm{~W} \\
3-14 \mathrm{~A}\end{array}$ & $\begin{array}{l}5-10 \\
0-14 \mathrm{~A} \\
2.2-6.6 \mathrm{~mA} \mathrm{~cm}{ }^{-2} \\
16-400 \mathrm{~W}\end{array}$ & $0.08-20$ & $\begin{array}{l}-600 \text { to } \\
\text { ground }\end{array}$ \\
\hline ZrON $[9,105]$ & MS-P-U, MS-U & RT to 110 & $\mathrm{Zr}$ & $\mathrm{Ar}, \mathrm{N}_{2}$ and $\mathrm{O}_{2}$ & $4.6-10.2$ & $1.02-13.75$ & $0.1-1.2$ & -40 \\
\hline TaON $[6,7]$ & MS-DC & RT and 300 & Тa & $\mathrm{Ar}, \mathrm{N}_{2}$ and $\mathrm{O}_{2}$ & 9.7 & 0.92 & 0.65 & $40 \mathrm{~W}(\mathrm{RF})$ \\
\hline TiON [9] & MS-DC & NM & $\mathrm{Ti}$ & $\mathrm{Ar}, \mathrm{N}_{2}$ and $\mathrm{O}_{2}$ & $6.5^{\mathrm{d}}$ & $7.1^{\mathrm{d}}$ & NM & NM \\
\hline $\mathrm{Al}_{2} \mathrm{O}_{3}[9]$ & MS-U-Mu and MS-Mu & RT & $\begin{array}{l}\mathrm{Al}_{2} \mathrm{O}_{3} \\
\mathrm{Al}\end{array}$ & $\mathrm{Ar}=30$ & 2.15 and $115 \mathrm{~W}$ & $\begin{array}{l}0.039-0.083 \\
9 \mathrm{~W}\end{array}$ & 0.22 and 3.2 & NM \\
\hline $\mathrm{ZnO}[51,106-110]$ & MS-RF and MS-Mu & RT to 750 & $\begin{array}{l}\mathrm{ZnO} \\
\mathrm{Zn}+\mathrm{Ag} \text { pellets } \\
\mathrm{ZnO} \text { doped with } \\
\mathrm{AgNO}_{3}\end{array}$ & Ar and $\mathrm{O}_{2}$ & $100-1000 \mathrm{~W}$ & $3-13 \mathrm{~W}$ & $0.5-4$ & NM \\
\hline
\end{tabular}




\begin{tabular}{|c|c|c|c|c|c|c|c|c|}
\hline Matrix & Method & Temperature $^{\mathrm{a}}$ & Target element & $\begin{array}{l}\text { Gas type and flux } \\
(\mathrm{sccm})\end{array}$ & $\begin{array}{l}\text { Target power } \\
\left(\mathrm{W} \mathrm{cm}^{-2}\right)\end{array}$ & 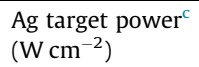 & $\begin{array}{l}\text { Working } \\
\text { pressure }^{\mathrm{a}}(\mathrm{Pa})\end{array}$ & $\operatorname{Bias}^{\mathrm{a}}(\mathrm{V})$ \\
\hline YSZ [111-113] & $\begin{array}{l}\text { MS } \\
\text { MS + PVD-Arc } \\
\text { MS + PLD }\end{array}$ & 150 & $\mathrm{Ag}$ & $\mathrm{Ar}$ & Produced by PLD & $1-5$ & 1.6 & -150 \\
\hline $\mathrm{ZrO}_{2}[17]$ & MS-U-P & 110 & $\mathrm{Zr}$ & $\begin{array}{l}\mathrm{Ar}=75 \\
\mathrm{O}_{2}=0-0.6 \mathrm{~Pa}\end{array}$ & $10.18^{\mathrm{d}}$ & $1.53^{\mathrm{d}}$ & 0.6 & -40 \\
\hline $\mathrm{Bi}_{2} \mathrm{O}_{3}[44]$ & MS-Mu & 150 & $\mathrm{Bi}_{2} \mathrm{O}_{3}$ and $\mathrm{Ag}$ & $\mathrm{Ar}$ & NM & NM & 0.4 & NM \\
\hline $\mathrm{NiO}_{2}[114]$ & MS-DC & 200 & $\mathrm{Ni}+\mathrm{Ag}$ pellets & $\mathrm{O}_{2}=0.01-0.09 \mathrm{~Pa}$ & $1.3^{\mathrm{d}}$ & Combined target & 0.2 & NM \\
\hline $\mathrm{SiO}_{2}[16,21,22,50,115-117]$ & MS-RF, MS-RF-Mu, MS-Mu & 100 & $\begin{array}{l}\mathrm{SiO}_{2}+\mathrm{Ag} \text { pellets } \\
\mathrm{SiO}_{2}\end{array}$ & $\mathrm{Ar}$ & $\begin{array}{l}1.1 \\
100-200 \mathrm{~W}\end{array}$ & 0.2 & 0.5 and 1.33 & NM \\
\hline $\mathrm{TiO}_{2}[11,13-15,20,118,119]$ & $\begin{array}{l}\text { MS-Mu, MS-P-DC, MS-DC, } \\
\text { MS-DC-RF-Mu, MS and MS-RF }\end{array}$ & $100-150$ & $\begin{array}{l}\mathrm{Ti} \\
\mathrm{Ti}+\mathrm{Ag} \text { pellets } \\
\mathrm{Ag} \text { doped } \mathrm{Ti}\end{array}$ & Ar and $\mathrm{O}_{2}$ & $\begin{array}{l}10 \\
25-90 \mathrm{~W} \\
2.5 \mathrm{~kW} \\
100 \mathrm{~mA} \mathrm{~cm}^{-2}\end{array}$ & $\begin{array}{l}1-2.5 \\
6-330 \mathrm{~W}\end{array}$ & $0.7-1.7$ & $\begin{array}{l}-100 \text { to } \\
\text { ground }\end{array}$ \\
\hline ZnS $[120,121]$ & MS-RF and MS-DC-RF-Mu & $\mathrm{RT}$ and 300 & $\begin{array}{l}\mathrm{ZrS}-\mathrm{Ag} \\
\mathrm{Zn} \\
\mathrm{In}-\mathrm{Ag}\end{array}$ & Ar and $\mathrm{H}_{2} \mathrm{~S}$ & $1.97-2.96$ & $2.5-2.8$ & $0.7-0.8$ & NM \\
\hline $\mathrm{WS}_{2}[36,122,123]$ & MS-RF and MS-Mu & RT & $\begin{array}{l}\mathrm{WS}_{2} \\
\mathrm{WS}_{2} \text {-Ag } \\
\text { composite }\end{array}$ & $\mathrm{Ar}$ & $\begin{array}{l}1.2-6.4 \\
150 \mathrm{~W}\end{array}$ & $\begin{array}{l}3 \\
0-40 W\end{array}$ & 0.4 and 2 & -50 and 120 \\
\hline TiCaPCON [38] & MS + ion source & NM & $\mathrm{TiC}_{0.5} \mathrm{Ca}_{3}\left(\mathrm{PO}_{4}\right)_{2}$ & Ar and $\mathrm{N}_{2}$ & $900 \mathrm{~W}$ & $50 \mathrm{~mA}$ & NM & NM \\
\hline
\end{tabular}

a "NM" is used when the variable is not mentioned.

b When provided.

c Power, current or current density are given when the information for power density is not provided.

d Calculated from the data. 

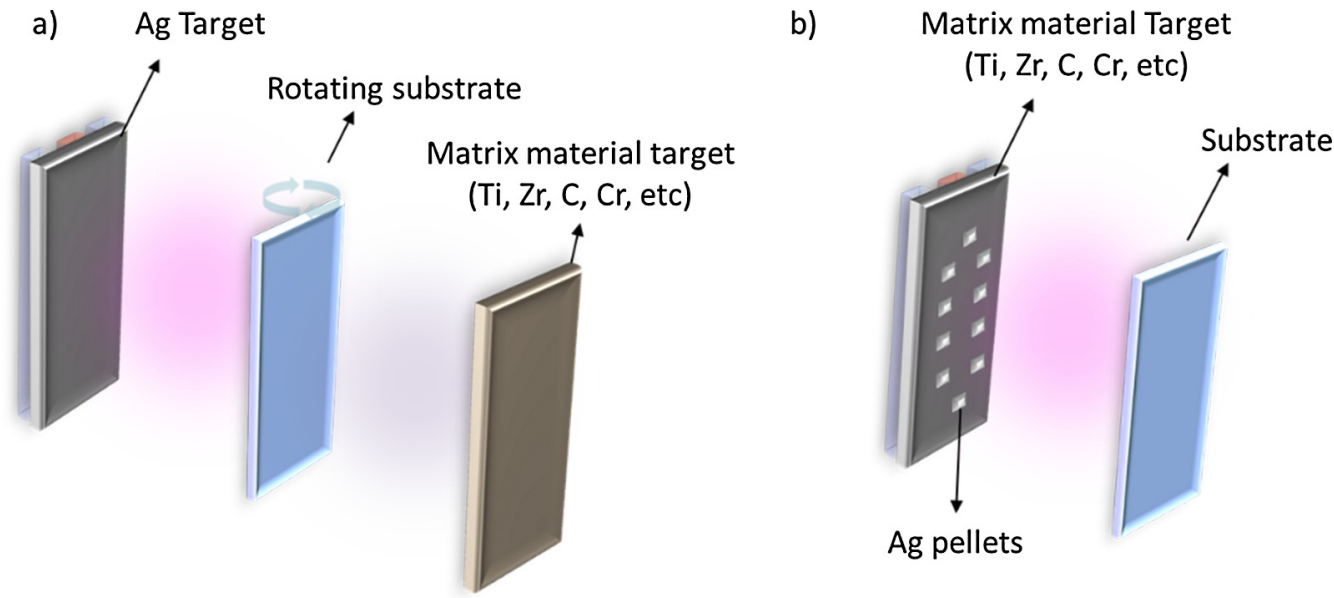

Fig. 2. System scheme used to incorporate silver nanoparticles into ceramic films. (a) Two independent targets and (b) a compound target of Ag and matrix material.

applied to the silver target [19,29,30,35,42,93,103,112,121]; due to the very high sputtering rate of Ag, small changes in the silver target power lead to large variations in the silver content in the films [29,42]. When pellets are used, the number of Ag pellets controls the amount of silver (i.e., the ratio between the Ag and ceramic target areas) $[4,51,73,117,88]$. These approaches produce different behaviors in the deposition rates and poisoning of the targets. For a pure silver target, as expected, the deposition rate increases when more power density is applied to the silver target [93,112], even though the same total power is applied to the discharge. This observation is in agreement with the much higher sputtering yield of silver compared to most of the ceramic and metallic targets reported here. However, for Ag pellets in the ceramic/metallic target configuration (Fig. 2b), controversial results are observed in the literature. In some cases, the expected increase in the deposition rate is observed when the number of Ag pellets increases [28], but in other cases, an unexpected decrease in the deposition rates is observed for a large $\mathrm{Ag} /$ ceramic ratio $[73,88]$. This behavior may be explained by contamination of the ceramic/ metallic part of the target with silver near the pellets, which can modify the deposition rate and the target impedance depending on the power applied in the discharge.

Properly controlling the silver content with these two approaches is only possible if other parameters, such as the flow rates of the reactive gases and the substrate bias potential, remain constant. Otherwise, for example, the Ag atomic percentage can be decreased either by reducing the mean free path of the species and reinforcing the poisoning of the Ag target (i.e., by increasing the reactive gas) $[20,46,95,99,104,114,88]$ or by increasing the negative bias potential applied to the substrate, which is responsible for preferentially re-sputtering the silver from the coatings [76,99].

\section{Chemical, structural, morphological and topographical properties of ceramic-Ag coatings}

The incorporation of a metallic phase $(\mathrm{Ag})$ into ceramic films is expected to produce structural, morphological and chemical changes in the ceramic matrix. Because silver is a noble metal and the metallic state is thus thermodynamically more stable than most silver compounds that can be produced in the solid state by MS, the formation of silver nitrides, carbides, carbonitrides or even some types of oxides is very unlikely. Therefore, the modifications caused by silver largely depend on its amount, particle size and distribution within the ceramic matrix, with consequent influences on the crystallinity, texture and chemical phase distribution.

\subsection{Chemistry}

To evaluate the bonding states of the elements, such as the (transition) metal used for the ceramic phase and the nitrogen, carbon, oxygen or silver, X-ray photoelectron spectroscopy (XPS) analysis is usually employed.

\subsubsection{Silver nanoparticle chemistry}

Silver is considered a very poor nitride- and carbide-forming element [124] and is therefore expected to be in the metallic state or to form oxides or sulfides, depending on the matrix. The majority of reports support this belief, describing the formation of $\mathrm{Ag}$ metallic phases, with the $\mathrm{Ag} 3 \mathrm{~d}$ core level peak located at binding energies of approximately 368.2-368.6 eV $[26,34,63,70,77,81,93,88,125]$. In fact, the silver oxidized state is not always observed when reactive oxygen is introduced, with silver observed in the metallic state for some cases, such as $\mathrm{TiO}_{2}, \mathrm{ZnO}, \mathrm{NiO}$ and $\mathrm{SiO}_{2}$. However, when silver is oxidized to form $\mathrm{Ag}_{2} \mathrm{O}$ and $\mathrm{AgO}$, the $\mathrm{Ag}$ 3d peak is located close to $367.7 \mathrm{eV}$ and $367.2 \mathrm{eV}$, respectively [105]. In spite of silver's low 
affinity for oxygen, silver oxide is usually avoided by increasing the power density applied to the Ag target [77,110] to avoid any poisoning of the target.

Conversely, films with elements that are highly reactive with silver, such as sulfur, have been demonstrated to possess silver oxidized states; however, the lack of a detailed spectrum at the $S 2$ p peak limits the analysis of the results and prevents

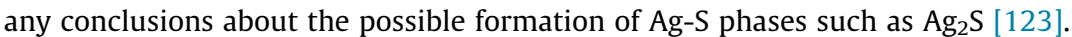

In addition to the Ag metallic state, some authors [26,63,125] have observed that the deconvolution of the silver peak results in an additional much broader peak shifted to higher binding energies and assigned to silver clusters ( $<4$ nm), explained by the size-dependent shift of the Fermi level. This clustered phase has a constant composition of 4 at.\% in AlN-Ag coatings for different silver contents [63], whereas in $\mathrm{ZrCN}-\mathrm{Ag}$ coatings, this phase increases with the silver content, maintaining a constant cluster/metallic silver ratio [126]. The difference in these results may indicate that the solubility of the silver varies in different matrices.

\subsubsection{Matrix chemistry}

The main changes in the matrices' chemical bonding due to silver incorporation are reported for carbon-containing films. DLC coatings, for instance, revealed that the $\mathrm{sp}^{2} / \mathrm{sp}^{3}$ ratio of $\mathrm{C}-\mathrm{C}$ bonds changes as silver is incorporated [29,92,96,104], which was hypothetically explained by the reduction of the residual stress induced by silver addition and consequent prevention of densification of the carbon network. For carbides and carbonitrides, the segregation of carbon (from the hydrocarbon reactive gas) that does not react with the transition metal element is usually reported. In these films, if the Me is completely consumed by other elements such as $\mathrm{N}, \mathrm{C}$ or $\mathrm{O}$, the excess of $\mathrm{C}$ forms amorphous carbon phases (a-C) in a process similar to plasma-enhanced CVD $[85,90,88]$. Such phase formation is enhanced by the increase in the silver target power, which induces a decrease in the relative Me content and potentiates the PE-CVD for the hydrocarbon gas. In fact, the consequent higher global discharge power due to powering on the Ag target increases the decomposition of the hydrocarbon gas, producing films with larger amounts of amorphous carbon phases [4,26,81,88,125,126].

Conversely, no significant changes in the nitride matrices were observed with silver incorporation [70], as shown by XPS analysis.

In a few studies, an unexpected increase in the oxygen content in the films was reported when the power density on the silver target was increased. In particular, an oxygen increment has been observed for processes in which $\mathrm{C}_{2} \mathrm{H}_{2}$ is used as the reactive gas, but no satisfactory explanation for this phenomenon has been obtained [42,46,102]. Note that even when oxygen is used as the reactive gas to produce $\mathrm{Ni}, \mathrm{Zn}, \mathrm{Si}$ and $\mathrm{Ti}$ oxides, among others, no silver oxide has been reported $[15,51,114,119]$, probably due to the lower enthalpy of formation of silver oxide compared to matrix oxides, as mentioned previously.

\subsection{Microstructure and phase composition}

Ceramic-Ag coatings exhibit a combination of different types of phases, including crystalline, nanocrystalline or amorphous phases, as schematized in Fig. 3. These microstructures differ among the nitride, carbide, carbon-based and oxide phases, and their evolution with the incorporation of silver is mainly affected by their crystalline character. Table 2 shows the main crystalline and amorphous phases reported for ceramic-Ag coatings and the grain size for the crystalline phases.

In general, both transmission electron microscopy (TEM) and X-ray diffraction (XRD) have indicated that silver is in the face-centered cubic phase (FCC), with more or less diffuse rings/peaks depending on its grain size, which is calculated to vary between 2 and $80 \mathrm{~nm}$ (more commonly smaller than $25 \mathrm{~nm}$ ) [62,88]. This crystalline silver phase is difficult to identify for grain sizes $<2 \mathrm{~nm}$, which demonstrate very diffuse diffraction rings or the absence of diffraction peaks in SAED and XRD, respectively.

An increase in the silver content produces well-defined diffraction patterns (SAED and XRD) indicating an FCC phase, evidencing an increment in the silver grain size when incorporated into crystalline ( $\mathrm{MeN}$ [25,32,34,45,63,68,70,71,73,75-77, 106], MeO [14,49,105,108-110,112]) or amorphous (C-based [28,96,103,104,121,125]) matrices. The silver grain size increment is accompanied by a decrease in the matrix grain size for crystalline matrices. This reduction is caused by (i) hindrance of matrix grain growth due to silver segregation to the boundaries and/or (ii) the increased number of nucleation sites provided by silver particles/atoms. A further increase in the Ag content can lead to amorphization of the matrix [63,77].

Conversely, when the matrix is composed of a mixture of crystalline and amorphous phases (i.e., $\mathrm{MeCN}$ or MeC), a synergetic effect between the silver nanoparticles and the amorphous phases (mainly a-C) contributes to reducing the grain size of the crystalline part of the ceramic matrix. The $\mathrm{C}$ phase increases the nucleation rate of the ceramic phase $(\mathrm{MeC}(\mathrm{N}))$ and prevents its grain growth $[4,26,40,42,81,83,90,88,130,131]$. In $\mathrm{Zr}-\mathrm{C}-\mathrm{N}-\mathrm{Ag}$ coatings, for instance, amorphous carbon phases have a higher impact on the reduction of the grain sizes due to their ability to encapsulate both silver nanoparticles and ZrCN grains [126], as shown in Fig. 4.

Furthermore, in some studies, the preferential growth of silver and the crystalline matrix has been reported to depend on the deposition conditions. Meškinis et al. [99], for instance, reported that in the MS process, for high gas flows $\left(\mathrm{C}_{2} \mathrm{H}_{2}\right)$, the XRD pattern only indicated a ( $\left.\begin{array}{lll}1 & 1 & 1\end{array}\right)$ Ag diffraction peak, whereas for low $\mathrm{C}_{2} \mathrm{H}_{2}$ flows, all of the Ag diffraction peaks were observed. These results demonstrate that the preferential growth of silver is modified by changing the mean free path in the chamber and, consequently, the overall energy of the silver, as previously mentioned in the section on deposition. In 


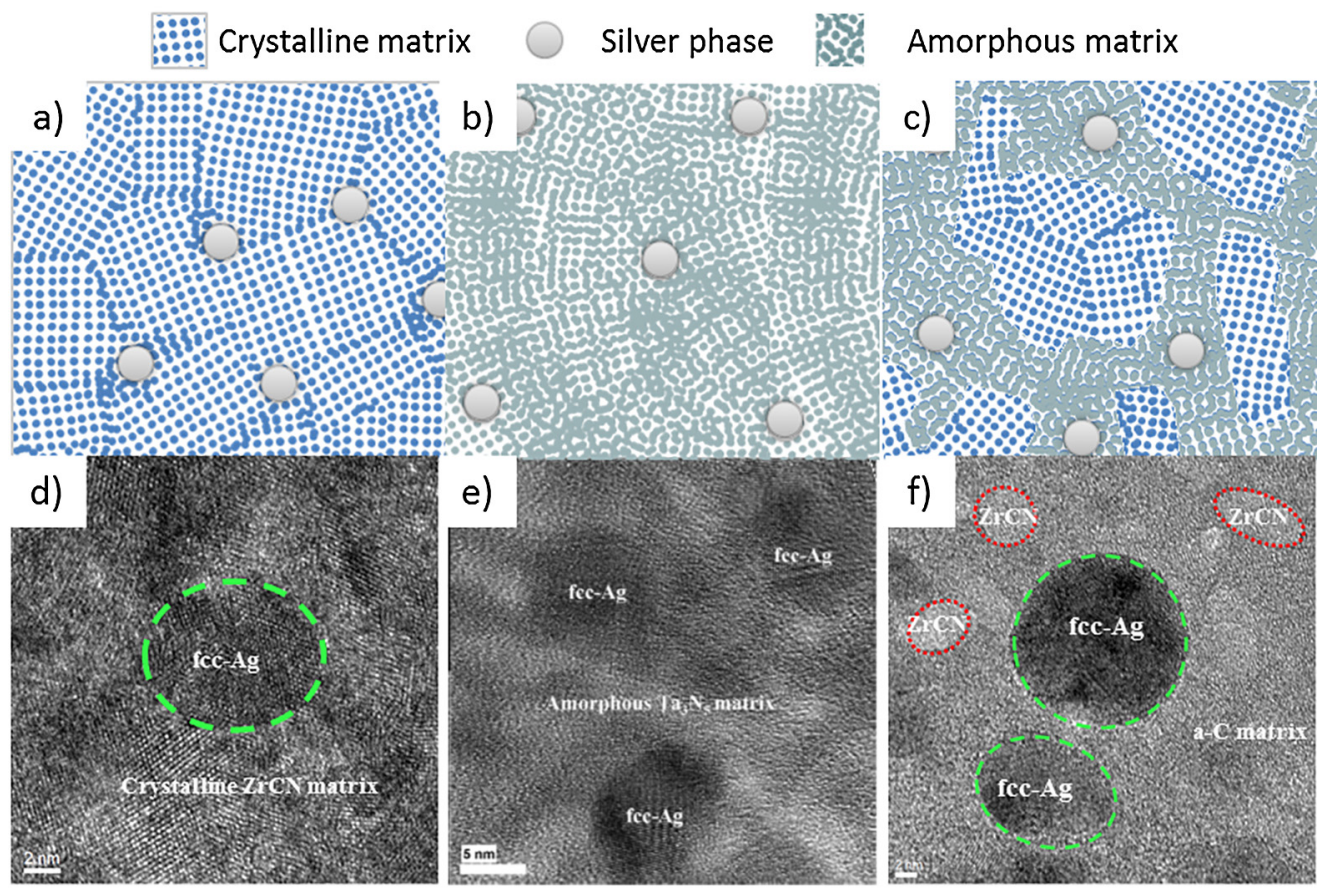

Fig. 3. Structural scheme of ceramic-Ag coatings: (a) crystalline matrix with silver nanoparticles, (b) amorphous matrix with silver nanoparticles, and (c) mixture of crystalline and amorphous matrices with silver nanoparticles. (d) [127], (e) [70] and (f) [127] show phase contrast images exemplifying the schemes in (a), (b) and (c), respectively (adapted from the corresponding reference).

Table 2

Ceramic matrix and silver crystalline structures and grain sizes reported in the literature.

\begin{tabular}{|c|c|c|c|}
\hline & Ag grain size $(\mathrm{nm})$ & Ceramic phase & Grain size $(\mathrm{nm})$ \\
\hline \multicolumn{4}{|l|}{ Nitrides (MeN) } \\
\hline AlN [63] & $1.5-4.5$ & FCC AlN & $0-32$ \\
\hline $\operatorname{CrN}[25,27,64,65]$ & $9-23$ & FCC CrN & $12-25$ \\
\hline MoN $[34,66,67]$ & - & Tetragonal and cubic $\mathrm{Mo}_{2} \mathrm{~N}$ & $7-20$ \\
\hline $\mathrm{NbN}[68]$ & _- & Cubic NbN & - \\
\hline TaN $[32,33,69-71]$ & - & Orthorhombic $\mathrm{Ta}_{3} \mathrm{~N}_{5}$ and FCC TaN & $5.4-7.3$ \\
\hline TiN $[1,35,73,74,128]$ & $6-78$ & FCC TiN & $12-80$ \\
\hline VN [75] & - & Tetragonal VN & 36 \\
\hline $\mathrm{ZrN}[45,77]$ & - & FCC ZrN & $3-25$ \\
\hline \multicolumn{4}{|c|}{ Carbides and carbonitrides ( $\mathrm{MeC}$ and $\mathrm{MeCN}$ ) } \\
\hline $\mathrm{HfC}[79]$ & - & FCC HfC & - \\
\hline $\mathrm{SiC}[79]$ & - & Amorphous SiC & - \\
\hline TiSiC $[82,83]$ & $5-9$ & FCC $\mathrm{TiC}+$ amorphous $\mathrm{SiC}$ & $5-15$ \\
\hline TiC $[80,81]$ & - & FCC TiC & - \\
\hline WC [84] & - & WC & - \\
\hline MoCN [85] & - & Mixture of carbides and nitrides & - \\
\hline $\operatorname{TiCN}[4,26,88,89]$ & $5-20$ & FCC TiCN + amorphous C & $5-45$ \\
\hline $\operatorname{ZrCN}[40,41,90,126]$ & $3.4-4.2$ & FCC $\mathrm{ZrCN}+$ amorphous C & $3-14$ \\
\hline \multicolumn{4}{|l|}{ C-based } \\
\hline DLC $[28,46,95,97,99,121,129]$ & $2-26$ & Amorphous DLC & - \\
\hline \multicolumn{4}{|l|}{ Oxides } \\
\hline $\mathrm{NiO}_{2}[114]$ & - & FCC NiO & $7.6-9.0$ \\
\hline $\mathrm{SIO}_{2}[16,21,50]$ & $8.5-17.5$ & Amorphous $\mathrm{Si}-\mathrm{O}$ & - \\
\hline $\mathrm{Al}_{2} \mathrm{O}_{3}[48,49]$ & $3-8$ & Amorphous $\mathrm{Al}-\mathrm{O}$ & - \\
\hline $\mathrm{TiO}_{2}[11,14,118,119]$ & $12.5-20$ & Amorphous $\mathrm{Ti}-\mathrm{O}$ or tetragonal $\mathrm{TiO}_{2}$ (anatase) & - \\
\hline $\mathrm{ZnO}[106,110]$ & - & Hexagonal ZnO & - \\
\hline YSZ [111,112] & - & Tetragonal $\mathrm{ZrO}_{2}$ & - \\
\hline $\mathrm{ZrO}_{2}[17]$ & - & Tetragonal & - \\
\hline \multicolumn{4}{|l|}{ Sulfides } \\
\hline $\mathrm{WS}_{2}[123]$ & - & $\mathrm{HCP} \mathrm{WS}_{2}$ & - \\
\hline $\mathrm{ZnS}[120,121]$ & - & $\mathrm{BCC}$ and hexagonal $\mathrm{ZnS}$ & $8-15$ \\
\hline
\end{tabular}


a) $\mathrm{Ag}-\mathrm{ZrCN}$

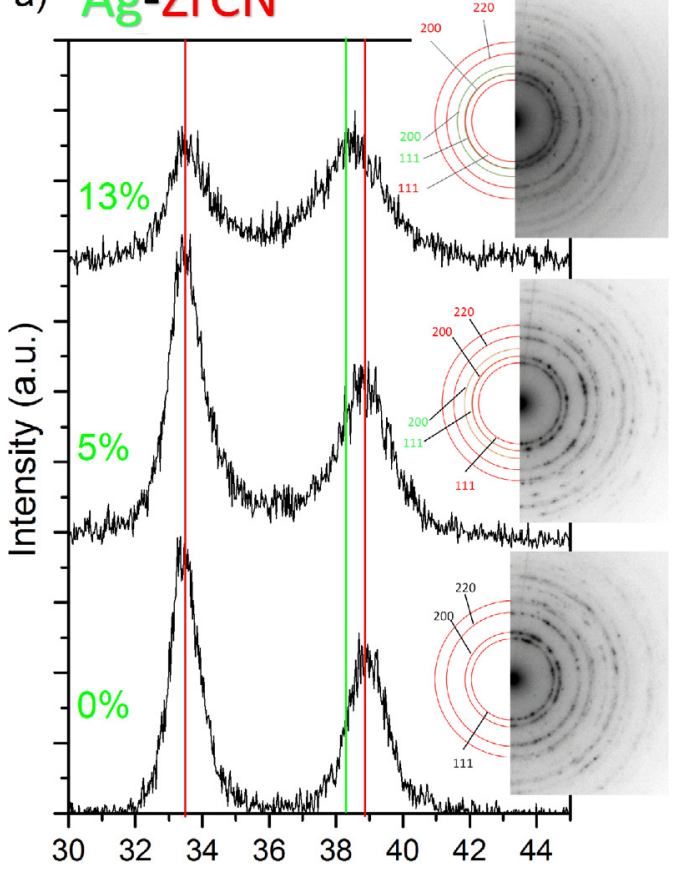

$2 \theta$ (degrees) b) $\mathrm{Ag}-\mathrm{ZrCN}-\mathrm{aC}$

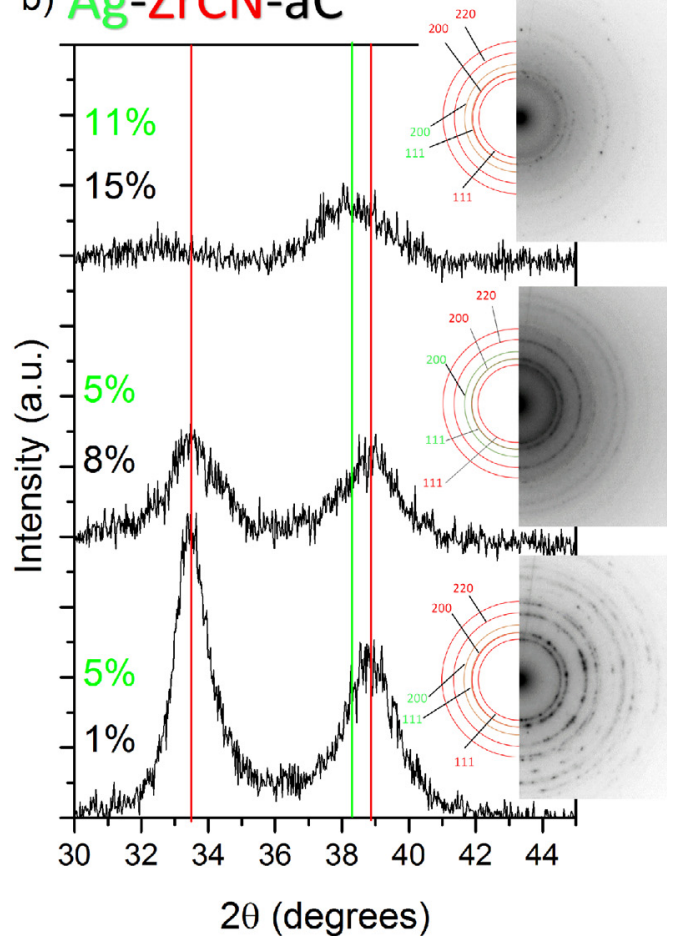

Fig. 4. XRD and selected area diffraction for the Ag-ZrCN-a-C system. (a) Evolution of the diffraction patterns as a function of silver content in the crystalline $\mathrm{ZrCN}$ matrix, and (b) evolution of the microstructure in mixed matrix (crystalline-amorphous) $\mathrm{ZrCN}-\mathrm{aC}$ as a function of silver and amorphous carbon content [126] (adapted from the corresponding reference).

the case of CrAlN [27] and VN [75], a strong (1 111 ) preferential orientation of the ceramic matrix is achieved when silver is incorporated.

Finally, some authors have reported phase transformation in ceramic-Ag systems due to the incorporation of silver. For example, Aouadi et al. [66] reported on a Mo-N-Ag system in which the $\mathrm{Mo}_{2} \mathrm{~N}$ phase transforms from tetragonal to cubic. In some Ag-oxides systems, the oxide's XRD diffraction peaks shift to lower angles when silver is incorporated into the lattice [106-109], in contrast to what has been observed for other matrices. For example, the incorporation of silver transforms $\mathrm{ZrO}_{2}$ from the monoclinic to the tetragonal phase [17], probably due to the relaxation of the lattice.

\subsection{Morphology and topography}

\subsubsection{Surface and cross-section morphology}

The morphology of the coatings, in both surface and cross-section analyses, is usually evaluated by electron microscopy (scanning (SEM) or transmission (TEM)), focusing on the architecture, type of film growth, and phase segregations, among other features. The most common architectures for ceramic-Ag films deposited by MS are shown in Fig. 5. Depending on the configurations, properties such as the density, porosity and phase segregation can be controlled, thus influencing the functional properties. Fig. 5a, for instance, describes the simplest architecture for a ceramic-Ag coating deposited directly onto a substrate surface. To improve the adhesion of the ceramic-Ag films, a thin metallic layer is often deposited between the substrate and the film (Fig. 5b). Another way to improve the adhesion is to use a graded thin film with a composition that varies from a metallic to a ceramic state that matches the ceramic phase in the functional coatings (Fig. $5 \mathrm{c}$ ). Finally, Fig. 5d and e shows more elaborate architectures in which multilayer designs are used to control silver segregation or functional properties such as surface plasmon resonance and the self-lubricating properties of silver nanoparticles, which will be described in more detail in upcoming sections.

In the majority of architectures and matrices, silver is present in the form of spherical nanoparticles; however, cylindrical particles can also be observed [76]. The particle size varies from two up to hundreds of nanometers [27,35,70,81,95,104] and, in some cases (e.g., a-C), is directly correlated with the content of silver in the matrix [19,95,101,104]. In other cases, no correlation is observed (e.g., TiN-Ag) [35]. Such behavior suggests that the nature of the matrix (amorphous or crystalline) plays a role in the growth mechanism of the silver nanoparticles in ceramic matrices, likely due to the more homogeneous distribution of silver in the amorphous matrices, such as oxides or carbon-based films $[70,110,118]$, in which the proximity of the particles allows them to grow by coalescence. In crystalline matrices, the silver nanoparticles are located in the grain bound- 
a)

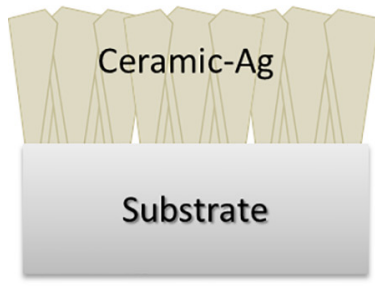

d)

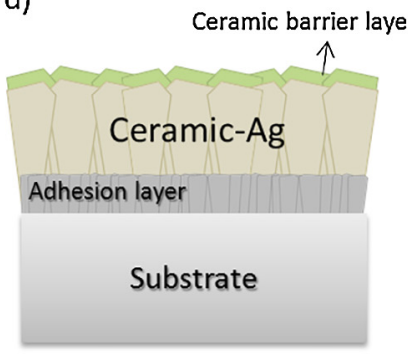

b)

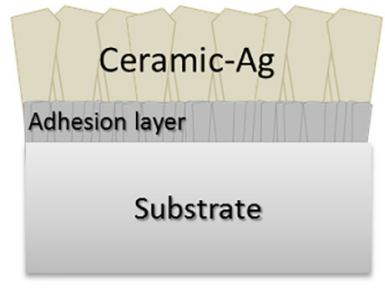

e) c)

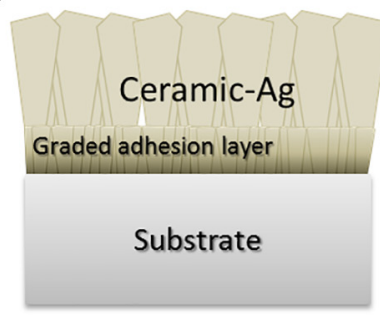

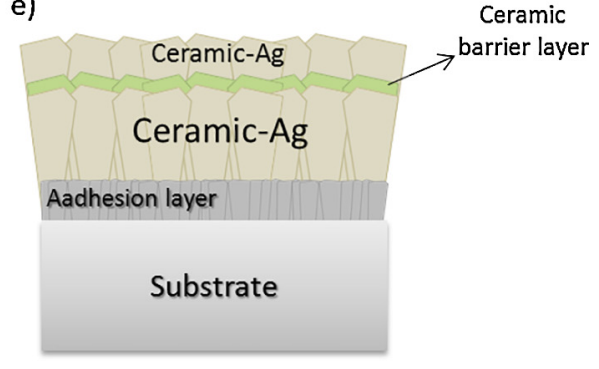

Fig. 5. Common architectures of ceramic-Ag films. (a) Pure ceramic-Ag; (b) transition metal interlayer between the ceramic-Ag coatings and the substrate; (c) architecture (b) with a ceramic barrier layer; (d) graded interlayer between the substrate and ceramic-Ag; and (e) architecture (c) with an additional ceramic-Ag layer.

aries [35], decreasing nanoparticle proximity and, consequently, their coalescence. Additionally, some authors have demonstrated an increase in particle sizes in the film growth direction [19,117], as shown in Fig. 6.

Although the morphology of the coatings may depend on a variety of parameters, such as the substrate bias potential, substrate temperature and working pressure, both the surface and cross-section morphologies exhibit large dependencies on the film's composition (type of matrix and silver content). For example, nitrides and carbonitrides display columnarlike growth, although the latter can display granular-like features, depending on the amount of carbon phases. The typical cross-section morphology of C-based films, as well as oxides, is featureless, and sulfides display a very specific acicular-like morphology (cf. Fig. 7).

In pure nitride and carbonitride (with low carbon content) films, columnar growth is usually reported and is maintained for low silver contents ( $<8$ at.\%) [37,73], as observed in Fig. 7a and b. As the silver content increases, the columnar growth is gradually destroyed, and a granular aspect is achieved $[2,3,40,73,83,84,90,128,130]$, as shown in Fig. 8 . Silver interrupts columnar growth when it segregates to the grain and column boundaries. Large agglomerates can then be formed, obstructing the continuity of the column and promoting the re-nucleation of the nitrides around the silver particles.

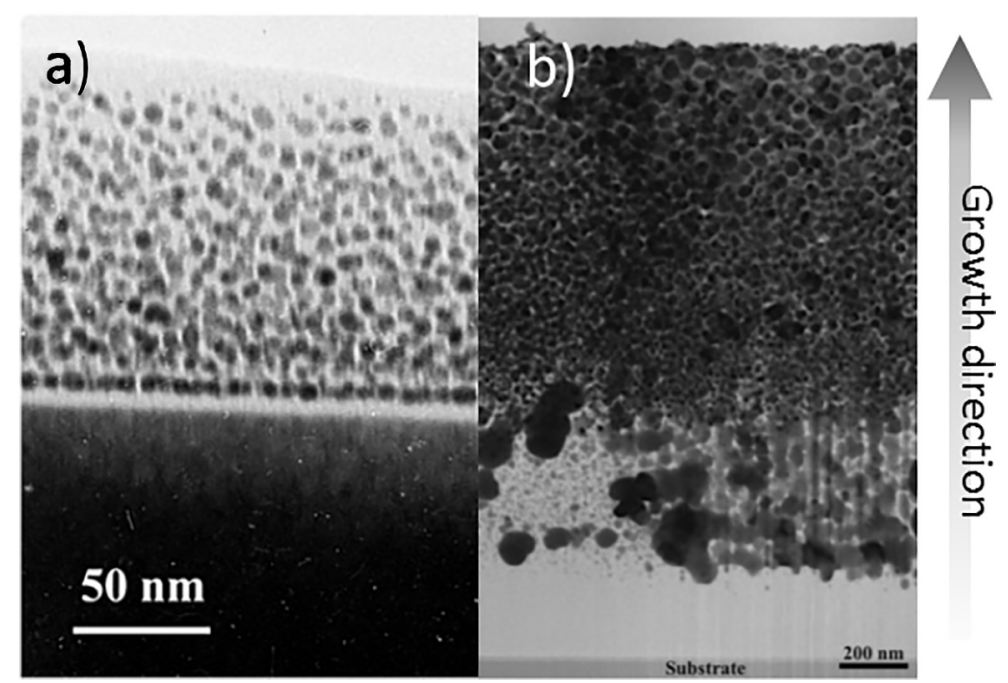

Fig. 6. Silver nanoparticles sizes in cross-sectional TEM images for (a) $\mathrm{SiO}_{2}$ [117] and (b) DLC [19] (adapted from the corresponding reference). 


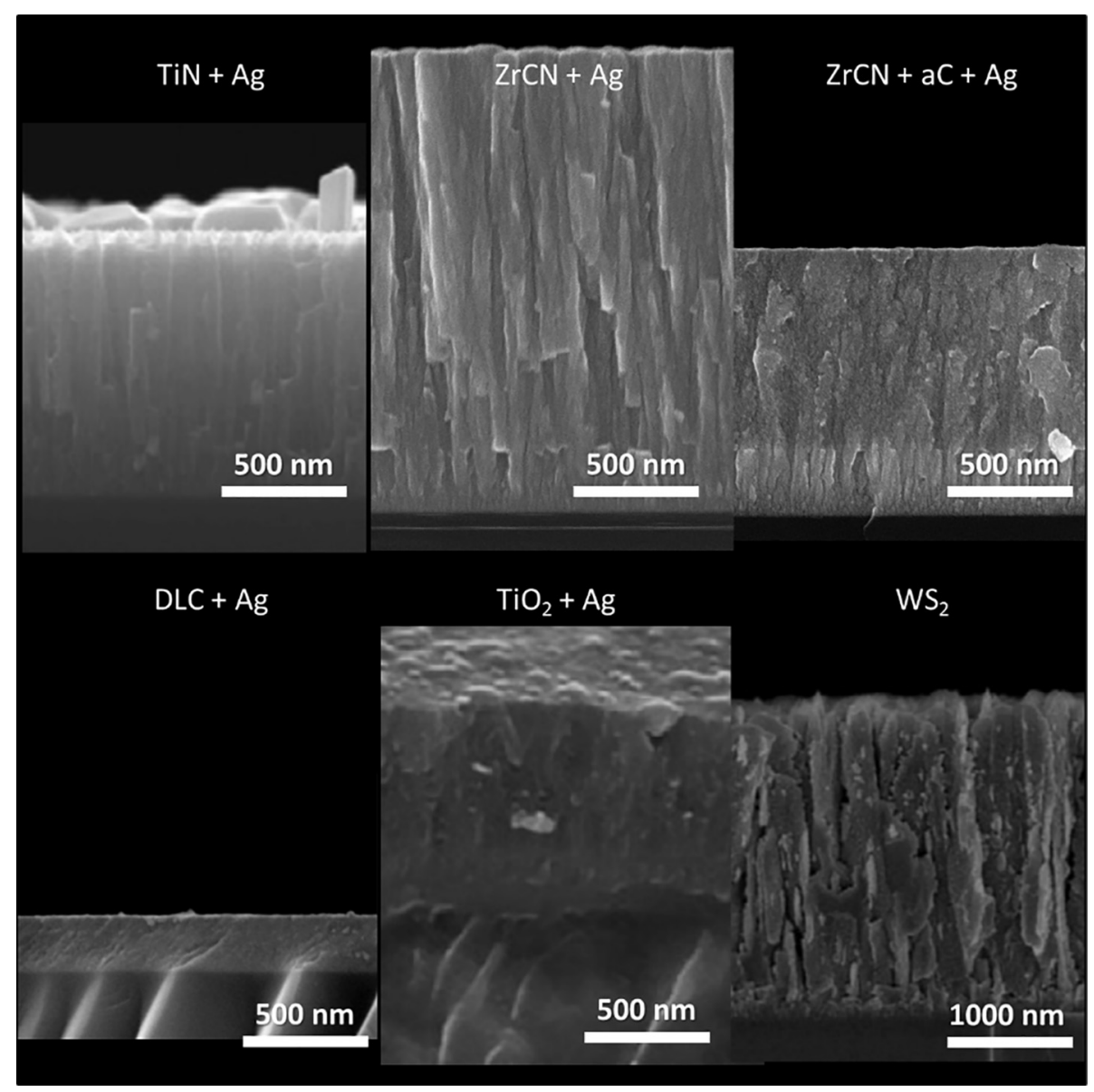

Fig. 7. Cross-section morphology of representative ceramic matrices with similar contents of silver: (a) TiN-Ag with $\sim 4.5$ at.\% [73]; (b) ZrCN-Ag with 6 at.\% [130]; (c) $\mathrm{ZrCN}+\mathrm{aC}-\mathrm{Ag}$ with 7 at.\% [130]; (d) DLC-Ag with 20 at.\% [97]; (e) $\mathrm{TiO}_{2}-\mathrm{Ag}$ with 6 at.\% [20]; and (f) WS $\mathrm{WS}_{2}-\mathrm{Ag}$ with 5.5 at.\% [123] (adapted from the corresponding reference).

\section{Silver at .\% increases}

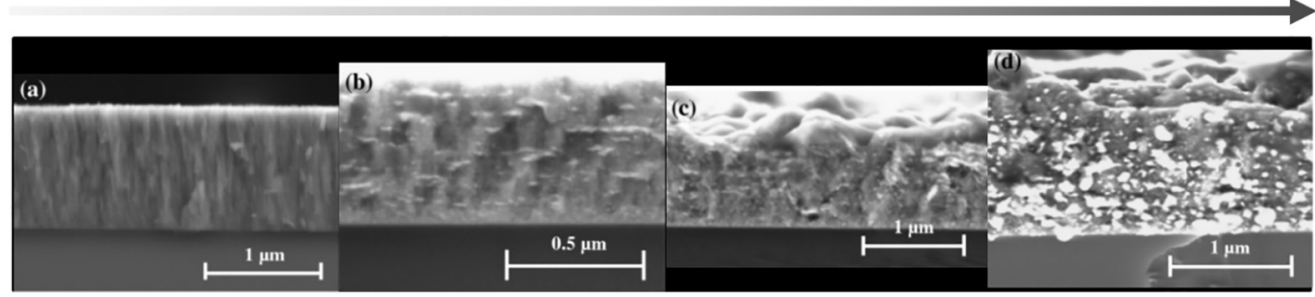

Fig. 8. Cross-section SEM images of TiSiC-Ag films with increasing silver content [83] (adapted from the corresponding reference).

Conversely, for carbonitride and carbide coatings, in addition to an increase in the silver content, an increase in the amorphous carbon phase also contributes to the loss of the columnar growth of the films because the carbon phases can surround the ceramic matrix grains and/or Ag crystallites and form a composite-like configuration. For DLC matrices, the addition of the silver modifies the featureless characteristics, leading to a more granular-like morphology and thus an increase in the roughness of the films [19].

\subsubsection{Silver segregation}

Segregation of silver to the surface has been commonly reported for most matrices, as shown in Fig. 9. In general, for different types of matrices, self-assembled silver is observed on the coating surface. The form of the silver varies and includes lamellar structures [132], small dots $(<20 \mathrm{~nm})[1,3,38,81,112,115,125,130]$, fibers [97], rods and spheres [32,33]. The silver 


\section{Variable increment}

a)

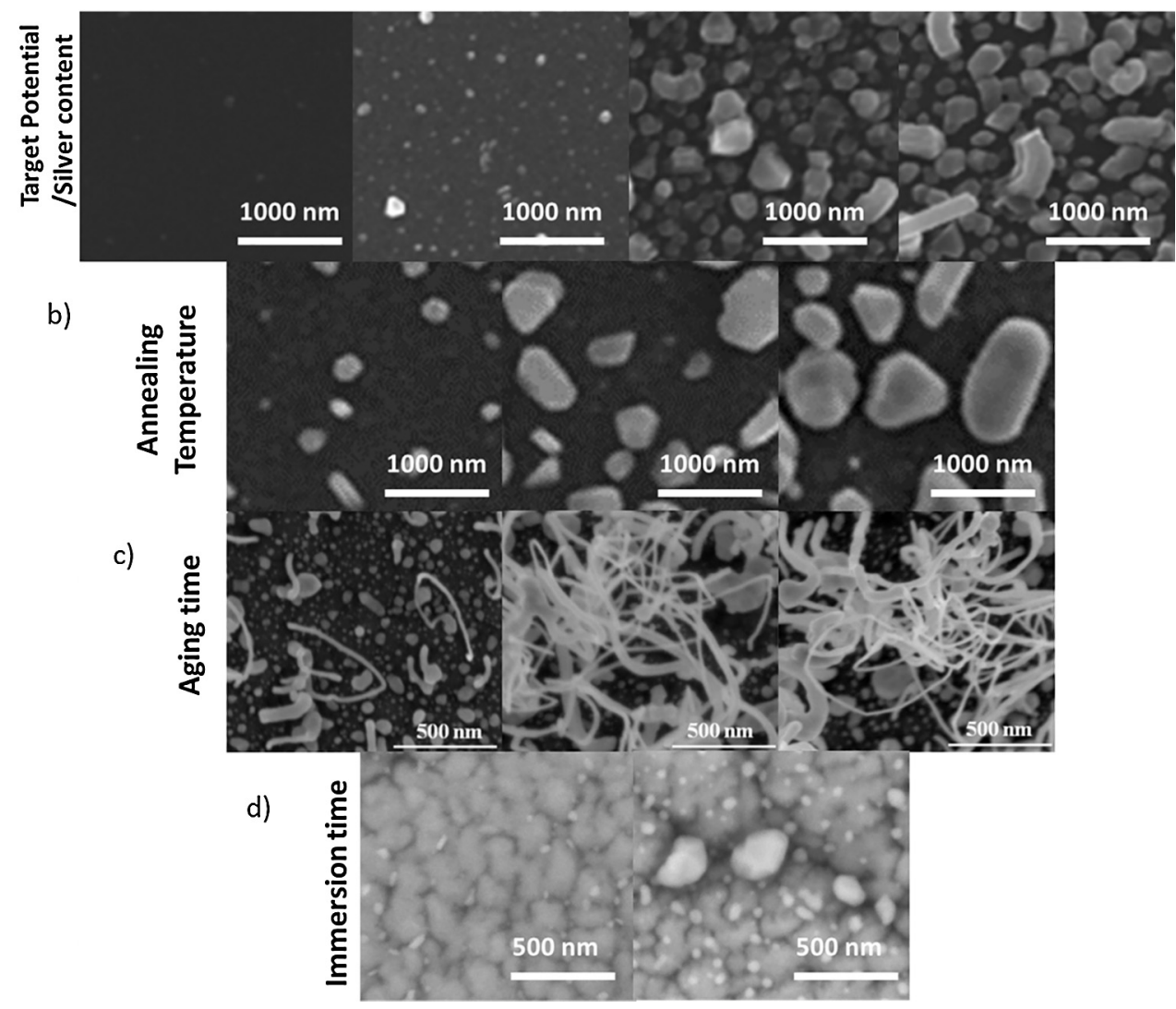

Fig. 9. Evolution of film morphology and silver segregation depending on (a) silver target power or silver content for $\mathrm{CrAlN}-\mathrm{Ag}$ [27], (b) annealing temperature for $\mathrm{CrN}-\mathrm{Ag}$ [23], (c) aging time for DLC-Ag [97], and (d) immersion time in a salt solution for $\mathrm{ZrCN}-\mathrm{Ag}$ (adapted from the corresponding reference).

amount and distribution are dependent on the silver content (and, therefore, on the power density on the silver target), with larger silver segregation achieved by increasing the noble metal content in the matrix $[4,71-73,79,119,88]$ (see Fig. 9a). For a low Ag content, the segregation is less perceptible, indicating that a threshold content is required to start the agglomeration, depending on the matrix.

In addition to the silver target power, silver segregation can be activated by other deposition parameters, including the substrate bias and the deposition/substrate temperature. Song et al. [15], for instance, showed that by applying a $-100 \mathrm{~V}$ bias potential to the substrates during the deposition of $\mathrm{TiO}_{2}$, a higher number of particles was observed compared to unbiased depositions. Thermal annealing has been often used to enhance $\mathrm{Ag}$ segregation and agglomeration in $\mathrm{Ag}$-ceramic films. The temperature improves the mobility of silver, promoting its diffusion to the surface, its aggregation and crystal growth $[25,27,31,62,63,112,132]$. Mulligan et al. $[24,64]$ reported that silver nanoparticles were stable and homogeneously distributed throughout the coatings up to $500^{\circ} \mathrm{C}$ but segregated to the surface when higher temperatures were used $\left(600^{\circ} \mathrm{C}\right.$ and $700{ }^{\circ} \mathrm{C}$ ). Similar behavior has been observed by other authors upon either changing the deposition temperature or annealing the samples at increasing temperatures, from RT up to $800^{\circ} \mathrm{C}$. Thermal treatments appear to be more efficient than deposition with a heated substrate [23].

The driving force triggering the mobility of embedded silver toward the coating surface can be considered the synergy of several energy sources: (i) chemical potential, (ii) surface energy, (iii) strain energy and (iv) thermal energy. However, no study has reported the isolated effects of each of these energies on silver segregation due to the complexity of designing an experiment that avoids the presence of one of these sources.

The low reactivity of silver with the matrix prevents the formation of strong bonds between the ceramic and silver, thus permitting Ag mobility and increasing the segregation. This mobility is potentiated by compressive stress and morphology in PVD films. Compressive stress occurs due to the thermal expansion mismatch between the substrate and the coatings and provides strain energy to the system, thus promoting the plastic deformation of silver and stimulating strain-induced segregation to the surface. The morphology of the coatings plays a crucial role in this process because the morphological features, such as grain boundaries, column boundaries and pores, determine the diffusion paths for silver aggregation. The 
most common morphologies in ceramic-Ag films are columnar-like and granular-like morphologies, which possess clear diffusion paths that facilitate the silver diffusion and segregation to the surface $[25,63]$. The silver that segregates to these boundaries fills the diffusion channels [25], moves to more open spaces (outer column boundaries) and exits to the surface of the material, thus releasing the stress of the films, as will be demonstrated later in this text. This process is therefore enhanced by high temperatures that provide additional energy or by larger amounts of Ag particles in the boundary regions (diffusion path). The latter effect explains why agglomeration is difficult to observe for low silver contents because fewer silver areas are interconnected, reducing the transport rate [25]. Silver segregation has also been observed to decrease when silver establishes chemical bonds with elements in the films, such as S or Ti $[66,133]$, confirming that the low affinity between $\mathrm{Ag}$ and the matrices, such as nitrides or C-based coatings [93], facilitates silver mobility and aggregation.

Finally, silver aggregates on the surface to reduce the large surface energy of small nanoparticles, thus promoting the agglomeration of the metal. This process occurs in the final stage of the coating production or later. During the steady state of the deposition process, there is a constant flow of sputtered species from the target that continuously enrobe the nucleated silver particles, preventing their agglomeration (see Fig. 10a). However, at the end of deposition, when no new species are arriving at the growing film, the Ag mobility is unrestricted, allowing the silver nanoparticles to move over the free surface (Fig. 10b) and their agglomeration to lower the surface energy $[97,134]$.

This process is, to some extent, corroborated by the experimental observation that applying a barrier layer of the same ceramic matrix on top of the surface (see Fig. 5d) can partially control the silver aggregation $[48,97,135]$. The efficiency of this layer depends on its thickness [65] and morphology [119] because thinner or columnar films offer inferior barrier properties compared to thicker or denser films.

Diffusion has also been observed in cross-section analyses, demonstrating the mobility of silver in the films [111], not only on the free surface but also in bulk [31,132]. After a few hours of annealing, a continuous top layer of silver that completely covers the surface is formed [31,111,112]. Additionally, Mulligan et al. [132] have demonstrated that, for $\mathrm{CrN}-\mathrm{Ag}$ films, the diffusion of silver from the bulk to the surface leaves a porous microstructure behind, as shown in Fig. 11.

Furthermore, silver diffusion on the surface has been reported, with aggregates growing in size and reducing in number as the temperature increases, resembling an Ostwald ripening process [7,16,32,33,48,87,128], as shown in Fig. 9b. When the films are deposited onto substrates with a rough topography (e.g., unpolished stainless steel), the silver segregation and agglomeration are more pronounced on the topographical features of the substrate, such as grain boundaries [11]. These features indicate that silver diffuses first on free surfaces in the interior of the films (less dense column boundaries originated by shadowing film growth) and then segregates to the top surface. The images also demonstrate that the silver not only agglomerates but also coalesces, forming large grains instead of silver nanoparticle agglomerates [128]. Silver agglomeration at the surface has also been observed in cross-sectional images by TEM [117], as shown in Fig. 12.

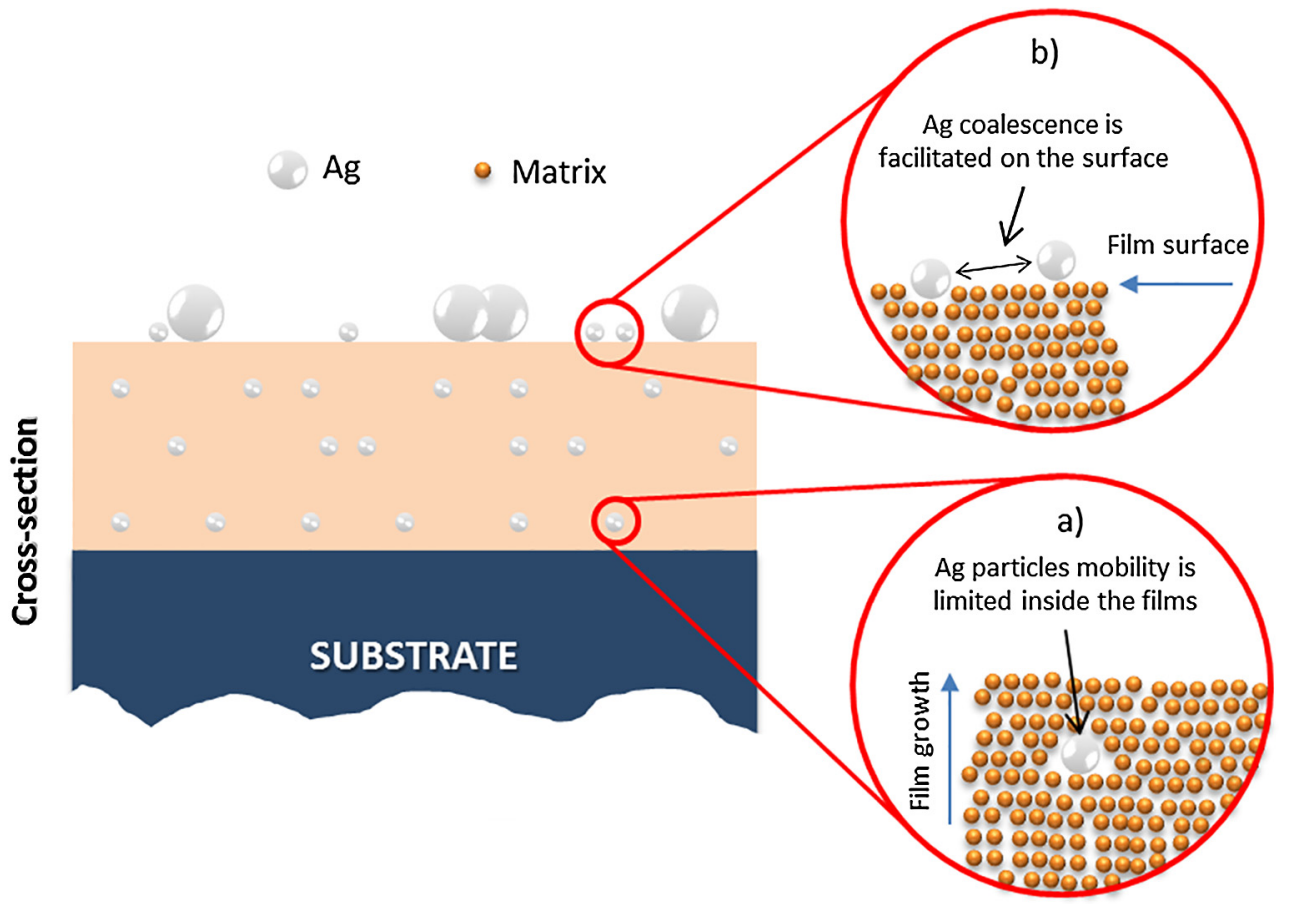

Fig. 10. Schematic ceramic-Ag film cross-sections: (a) the first stage of the coating growth, in which the silver nanoparticle are surrounded by the matrix; (b) silver nanoparticles on the coating surface. 
Surface silver particles have been observed to grow when the ceramic-Ag coatings are exposed to humid environments [97] or electrolytes [125] (Fig. 9c and d). In humid atmospheres, the segregation of the silver is observed to be whisker-like for a-C films, but the phenomenon is not yet well understood [97]. In the case of $\mathrm{Cl}$-containing electrolytes, $\mathrm{Cl}^{-}$ions are believed to promote the release of silver by forming $\mathrm{AgCl}$ with small unstable $\mathrm{Ag}$ particles. Thereafter, $\mathrm{AgCl}$ dissociates to release silver ions. These ions subsequently attach to stable Ag particles, which consequently grow, similar to an Ostwald

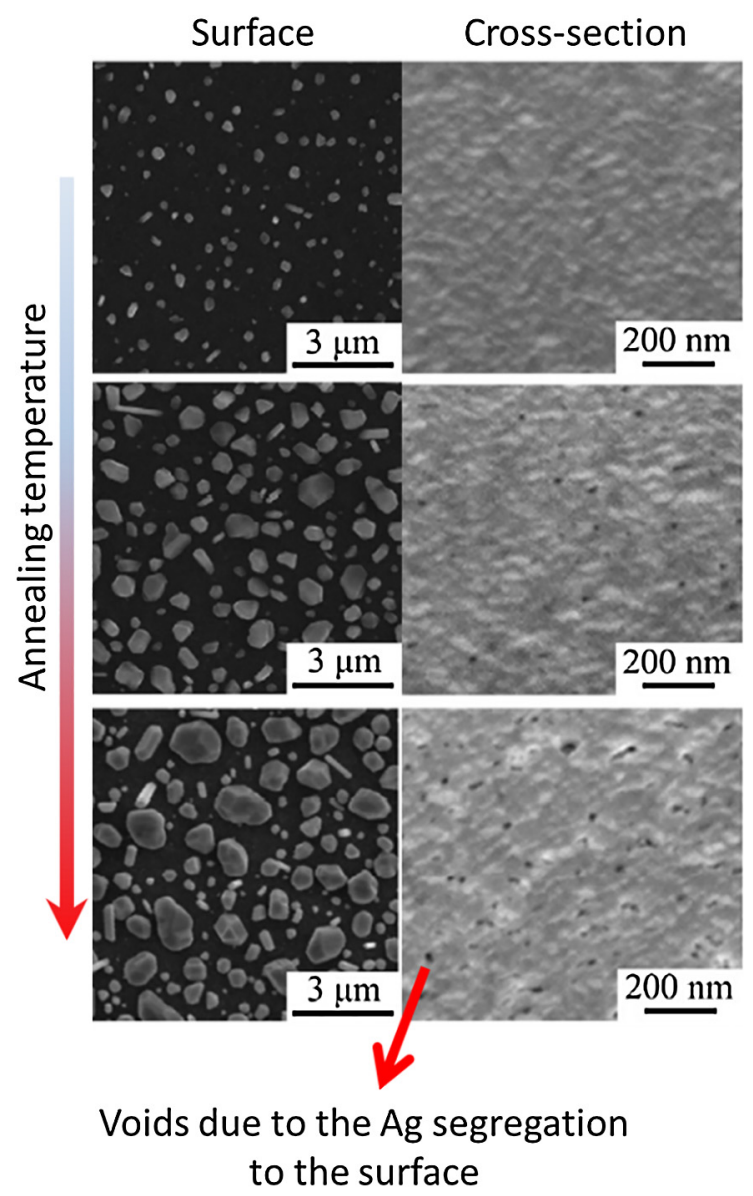

Fig. 11. Silver segregation effect on the surface and cross-section morphology in $\mathrm{CrN}-\mathrm{Ag}$ [132] (adapted from the corresponding reference).

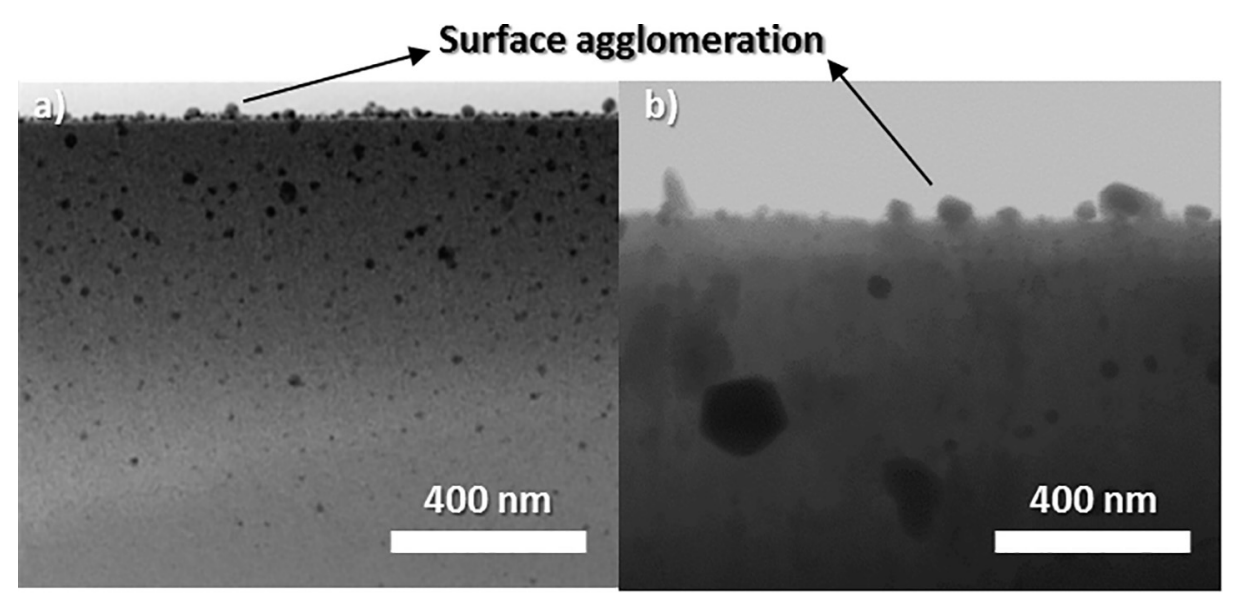

Fig. 12. Silver surface agglomeration observed by TEM or STEM imaging for (a) DLC-Ag [19] and (b) ZrCN-aC-Ag [41] (adapted from the corresponding reference). 
ripening process. In this process, silver chloride does not precipitate due to the low silver ion release, which impedes $\mathrm{Ag}^{+}$ from reaching the solubility constant $\left(1.77 \times 10^{-10} \mathrm{~K} \mathrm{~s}\right)$ threshold needed for stable $\mathrm{AgCl}$ crystal formation.

\subsubsection{Roughness}

The topography changes in the films due to silver incorporation are highly related to the silver diffusion to the surface and morphological changes promoted by the metal. For a sufficiently large silver content, an overall increase in the surface roughness may be observed due to silver segregation to the surface $[35,49,75,93,94,114]$ or more granular-like morphology $[19,49,121]$. However, when the silver content is insufficient to form large agglomerates, the incorporation of silver may produce smoother surfaces due to the refinement of the structure $[4,29,40,76,93]$ and silver segregation to the grain and column boundaries $[4,26,40]$. Both scenarios are schematically shown in Fig. 13.

\subsubsection{Contact angle}

The contact angle is used to determine the surface energy of the samples, which provides useful information about the samples' wettability and interaction with the environment (e.g., in biological tests, the interaction between the surface and

Initial roughness

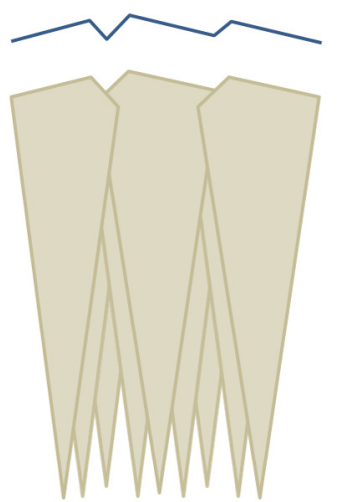

0 at. $\%$ lower roughness

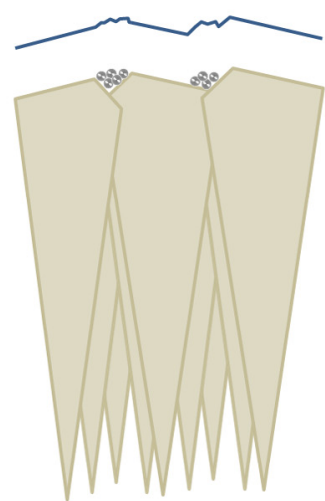

low at. \% higher roughness

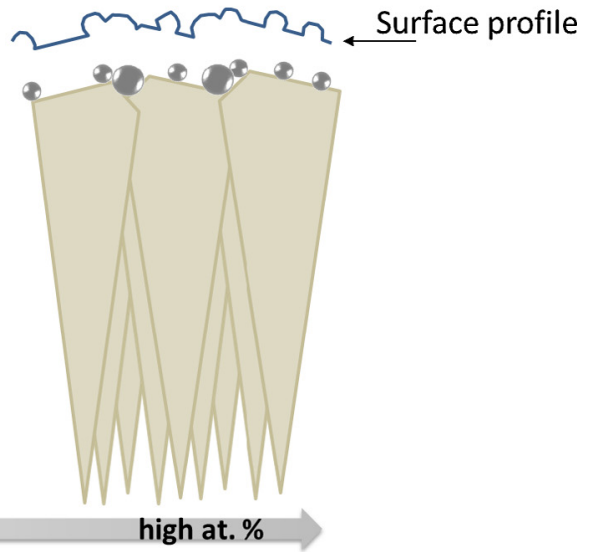

high at. \%

\section{Ag increases}

Fig. 13. Surface roughness scheme as a function of silver content.

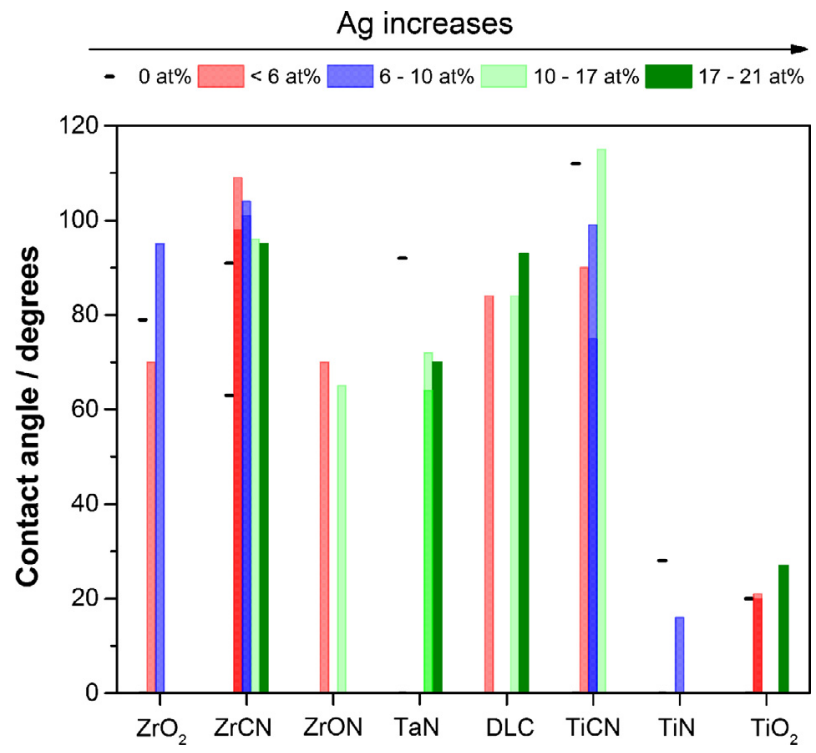

Fig. 14. Contact angles of ceramic-Ag coatings measured with water, reported for $\mathrm{ZrO}_{2}-\mathrm{Ag}$ [17], $\mathrm{ZrCN}-\mathrm{Ag}$ [41,137], $\mathrm{ZrON}-\mathrm{Ag}$ [105], TaN-Ag [69], DLC-Ag [19], TiCN-Ag [4,26], TiN-Ag [12], and $\mathrm{TiO}_{2}-\mathrm{Ag}[11]$. 
the cells or biomolecules). The wettability is mainly dependent on the chemical and topographical properties of the surface. Thus, the matrix roughness and type are expected to control the hydrophobicity of the coatings. The materials are usually considered hydrophilic when the contact angle with water is $<65^{\circ}$ and hydrophobic for values above this contact angle [136]. From a chemical perspective, silver surfaces are hydrophobic in nature, independent of their roughness; however, in ceramic matrices, the contact angle depends on the nature of the matrix (nitride, carbonitride, carbide, oxide) and the transition metal.

The roughness of ceramic-Ag coatings is altered by the silver content and its ability to form particles on the film surface. Unfortunately, the roughness cannot always be controlled, which hinders analyses of its individual influence on the wettability of the coatings. Thus, it would be inaccurate to generalize the effect of silver on the contact angle of the matrices. Fig. 14 summarizes the contact angle values measured for several ceramic-Ag coatings as a function of the silver content (divided into five groups) [17,19,26,41,69,86,105]. No distinguishable tendency is observed as silver is incorporated: both decreases and increases in the hydrophobic character are observed. The highest contact angles are reported for ZrCN and TiCN, attaining values closed to $120^{\circ}$, whereas $\mathrm{TiN}$ and $\mathrm{TiO}_{2}$ have the lowest values.

\section{Functional properties}

Ceramic-Ag coatings have been studied for a vast number of applications, taking advantage of their functional properties, such as optical properties by exploiting the surface plasmon resonance effect of silver nanoparticles; electrical properties due to the chemical stability and electrical conductivity of silver; enhanced mechanical and tribological performance based on the nanocomposite nature and self-lubricating abilities of silver; and antimicrobial properties by incorporating silver nanoparticles into a large number of materials. In the following sections, these properties are analyzed, focusing on the effects of the chemical and physical properties of silver and the matrices described in the previous sections.

\subsection{Biological properties}

\subsubsection{Biocompatibility}

Nanotoxicity is of great interest among the scientific community because nanomaterials are recognized as an important part of developing technology with applications across all economic sectors. Research in nanotoxicity encompasses fields ranging from occupational toxicology to ecotoxicology, including immunotoxicity and medical toxicity, among others.

In particular, the toxicity of nanoparticles can vary depending on their size, shape, surface area, surface reactivity, and solubility [138], thus impeding the establishment of simple methodologies to define their toxicity levels in certain environments. Silver nanoparticles, for instance, behave differently depending on the synthesis methods and the environment surrounding the nano-metal. The toxicity assessment of silver nanoparticles depends on the dispersion matrix (liquid or solid), capping agent and size, among other factors [139]. In this review, the majority of the reports utilized the same technique for producing the silver nanoparticles, and consequently, the ceramic matrix and morphology of the coatings/nanoparticles are expected to determine the changes in the toxicity and biocompatibility of the coatings.

Numerous studies have considered the possibility of applying ceramic-Ag coatings to bioapplications such as medical devices, including joint prostheses, vascular and ureteral catheters, dental prostheses, screws, and surgical tools [1-7,9,12, $13,15,17,19,20,22,38,69,89,105,140]$. By contrast, few studies have reported on the toxicity and/or biocompatibility of ceramic-Ag films deposited by MS and have mainly performed cytotoxicity assessments.

These reports agree that, below a certain value of silver content, the cytotoxicity levels of ceramic-Ag coatings are insignificant. The absolute amount of silver necessary to produce cytotoxicity has not been clearly defined and is dependent on the matrix. For instance, no significant cytotoxicity is observed on ZrON-Ag films for human gingival fibroblasts for surfaces with $<12$ at.\% of silver [105] or TaN-Ag films with $<21$ at.\% of silver [69]. For TiCN-Ag films, low cytotoxicity ( $<20$ at.\%) has been reported in coatings with silver content up to 27 at.\%, and $<10 \%$ of fibroblast 3 T3 cells die when the silver is maintained below 20 at.\% [89], similar to $\mathrm{TiO}_{2}-\mathrm{Ag}$ films [14,15]. However, although the samples are not cytotoxic, some groups have demonstrated that, at certain silver contents ( $>4$ at.\%), a significant inhibitory effect of osteoblastic differentiation occurs in TiCaPCON-Ag [38].

There are three major concerns about ceramic-Ag coatings that require further study: the release of silver ions in biological environments; the migration of silver nanoparticles from ceramic-Ag coatings to the environment due to the mobility of the silver in the matrices; and, finally, the interaction between the ceramic-Ag films and cells. Among these factors, silver ion release is the most studied and is covered in a separate section of this review, whereas systematic research remains lacking for the other two issues.

\subsubsection{Antimicrobial properties}

The antimicrobial effect of silver has been extensively reported for different types of materials containing silver nanoparticles and for a large number of applications. Several authors have incorporated silver nanoparticles into ceramic matrices by MS with the aim of offering a local effect as a bactericidal agent while providing the surface enhanced functional features (i.e., mechanical, electrochemical and tribological) from the ceramic matrix. One of the major advantages of ceramic-Ag coat- 
ings is the release of the antibacterial agent directly at the site where the effect is required, which minimizes the risk of reaching concentrations that can cause harmful side reactions.

There is no agreement regarding how silver kills bacteria, but two main factors responsible for the antimicrobial capabilities of silver have been extensively reported: (i) the amount of silver ions released and (ii) the silver nanoparticles' activity, which depends on their sizes and shapes. These factors are directly related to the mechanisms controlling bacterial spreading because (i) $\mathrm{Ag}^{+}$interacts with the cell thiol groups by binding to the main functional groups in some components, such as enzymes, thus preventing bacterial division and damaging the cell envelope [141], while (ii) the nanoparticles disrupt the cell membrane, killing the bacterium [142].

Different methodologies and microorganisms have been employed to assess the antimicrobial properties of ceramic-Ag coatings, depending on the application intended for the films and the variety of incubation broths, times, temperatures and initial microbe concentrations used in the assays. Therefore, these variations impede a proper comparison to make general conclusions about such behavior. The variability in the tests is exemplified in Table 3, which summarizes the conditions used in most of the reports reviewed in this document.

Despite these difficulties, a common behavior observed in the literature is the relationship between the amount of silver on the coating surface and antibacterial ability. Kelly et al. [2], for instance, reported the antibacterial effects of ZrN-Ag, TiN$\mathrm{Ag}$ and $\mathrm{CrN}-\mathrm{Ag}$ against Pseudomonas aeruginosa and Staphylococcus aureus. An increase in silver on the surface caused a decrease in colony-forming units for all matrices. In TaN-Ag [5], among samples containing 1.6, 3.4 and 10 at.\% of silver, only the sample with 10 at.\% displayed antibacterial effects against Escherichia coli. However, after annealing treatment, all samples (1.6 and 3.4 at.\%) exhibited antibacterial efficacy due to silver agglomeration on the surface activated by temperature. Similarly, Huang et al. [69] demonstrated that adherent bacteria are reduced on TaN-Ag films with silver aggregates on the surface (24 at.\% of silver). Viability tests of these coatings revealed no bacteria in the vicinity of the samples, in contrast to films without visible silver on the surface (14-17 at.\% of silver), which exhibited bacterial activity [69]. Similar results have been reported for TaON-Ag and $\mathrm{ZrN}-\mathrm{Ag}$ samples $[3,6]$.

These results suggest that the segregation and agglomeration of silver on the surface improve antibacterial behavior, which in turns indicates that the deposition parameters influencing this agglomeration, such as the deposition/annealing temperatures, silver content, and bias potential, among others, can be used to tune the coating's antibacterial behavior. Note that the agglomeration of silver on the surface does not per se imply an increase in overall silver ion release, as thoroughly discussed in a subsequent section, and thus, the direct interaction of silver with the bacterial cell should also be relevant to defining the mechanisms of silver acting against bacteria.

The amount of silver on the surface, however, cannot be regarded as the sole parameter controlling the antibacterial effect on ceramic-Ag films. Factors such as silver ion release and the affinity between the matrix and the silver must also be considered. Silver ion release has been recursively employed to explain the antibacterial effect of ceramic-Ag coatings, but no undisputed correlation exists. In some studies of $\mathrm{TiO}_{2}-\mathrm{Ag}$ [14,15] and $\mathrm{SiO}_{2}-\mathrm{Ag}$ [16], a direct correlation between the antibacterial effect and $\mathrm{Ag}^{+}$release was observed for $S$. aureus, whereas, in many other studies, this relationship was only hypothesized.

Tomislav et al. [13], by contrast, demonstrated in a systematic study that the $\mathrm{Ag}^{+}$concentration required to kill bacteria is higher than the concentration released from MS coatings; in their study, $\mathrm{AgNO}_{3}$ was diluted, and the minimal inhibitory concentration (MIC) and the minimal bactericidal concentration (MBC) were determined. The results were dependent on the fluid, but in general, more than $1000 \mathrm{ppb}$ was required for both the MIC and MBC tests for antimicrobial effects on E. coli, $S$. aureus, $P$. aeruginosa and Candida albicans [13]. However, a careful analysis of all of these results is required. For example, in the case of silver ions released directly in the region of interest (i.e., the surface in contact with the bacteria), the instantaneous silver ion concentration may be larger than the MIC or MIB values observed for $\mathrm{AgNO}_{3}$, which might explain the results. Consequently, it is not possible to confidently discard both silver ion release and silver agglomeration as crucial parameters in the antibacterial effect of the coatings.

5.1.2.1. Antibacterial effect activation. The absence of an antibacterial effect in some as-deposited ceramic-Ag coatings, such as TiCN-Ag [4] and $\mathrm{ZrCN}-\mathrm{Ag}$ [91], and some MeON [7-9] has proven the necessity of an additional process to activate or enhance the antibacterial effect of these ceramic-Ag coatings, such as the use of visible light radiation during bacterial culture to activate photocatalytic processes of the films. This method has mainly been reported for transition metal oxynitrides with silver nanoparticles (MeON-Ag) such as for $\mathrm{Me}=\mathrm{Ta}$ [7], $\mathrm{Zr}$ [8] and $\mathrm{Ti}$ [9]. However, this method has also been reported for TiN-Ag [10], the surface of which is commonly oxidized to form $\mathrm{TiO}_{2}$, and for $\mathrm{TiO}_{2}$ [11], a well-known photocatalytic material. Additionally, the use of strong oxidants, such as a $5 \%(\mathrm{w} / \mathrm{v}) \mathrm{NaClO}$ solution, to induce changes in the shape, size and distribution of the silver nanoparticles, as well as changes in the amount of silver on the surface, gives rise to the antibacterial effect of ZrCN-Ag coatings [143].

\subsection{Electrochemical properties}

The electrochemical characterization of ceramic-Ag coatings has provided insights on their ability to withstand certain liquid environments and on the prediction of their behavior and lifetime in harsh environments. A variety of tests can be considered; the most common are the potentiodynamic test (PT) and electrochemical impedance spectroscopy (EIS). The majority of studies reporting the electrochemical behavior of ceramic-Ag films have been conducted in saline solution iso- 
Table 3

Antibacterial tests of ceramic-Ag films, summarizing the microorganisms, initial concentration and other test parameters.

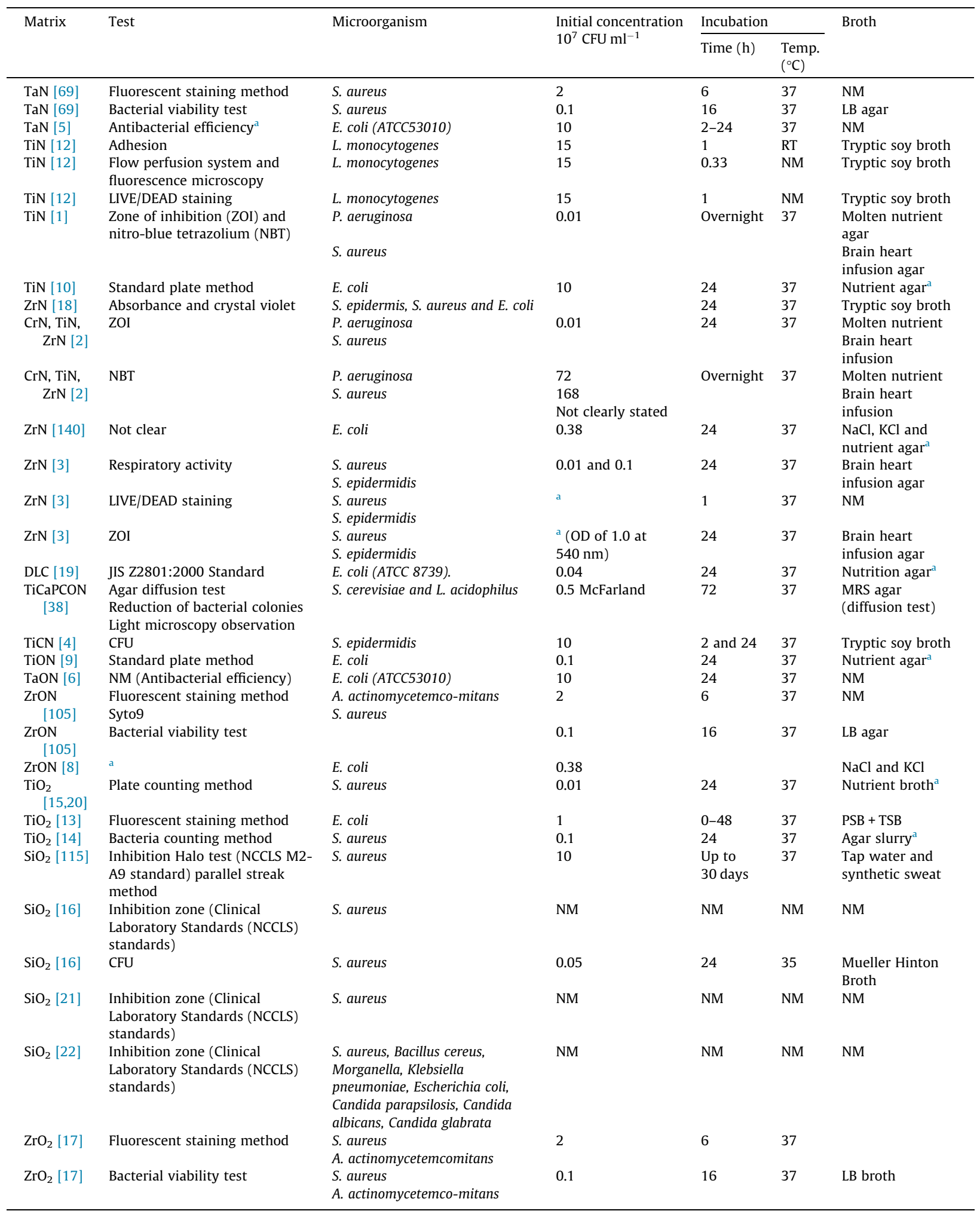

$\mathrm{NM}=$ Not mentioned.

a Not specified. 
tonic to seawater or human body fluids. The electrochemical results are strongly dependent on the substrate and environment selected for the assays, which in turn are designed based on the function of the final application of the system. Table 4 shows a summary of the test conditions for such evaluation.

In addition to the substrate and the electrolyte, the electrochemical behavior of the coatings is delimited by their morphology and phase composition. Columnar, granular and featureless coating growth, for example, modify the diffusion paths for the electrolyte to penetrate and interact with the films (cf. Fig. 15a), thus altering their electrochemical response. The boundary regions (column or grain boundaries) in these coatings might act as passivation zones, improving the corrosion behavior of the material or behaving as diffusion paths when the material is chemically inert, depending on the electrochemical activity of the phases. As a result, the morphology and phase composition of ceramic-Ag coatings have a synergistic effect on the electrochemical properties of the coatings.

As discussed in previous sections, ceramic-Ag films can form separate phases, usually including a combination of one crystalline and/or amorphous ceramic phase and nanocrystalline silver. The electrochemical character of each phase defines the electrochemical process, the corrosion rate, and, consequently, the deterioration of the films. In an electrochemical process, silver may be more or less active than the ceramic matrix, thus altering the corrosion rate of the coatings. For example, if both phases are conductive, formation of a galvanic couple is expected upon immersion in an electrolyte, i.e., a-C-Ag or TiN-Ag films. For ceramic phases with larger reduction potentials than silver, the corrosion rate of the system is expected to increase due to silver oxidation, whereas for phases with lower reduction potentials, oxidation of the matrix is predicted, as schematized in Fig. 15b.

Such behavior has been demonstrated when studying the corrosion potential and/or the open circuit potential (OCP) of ceramic-Ag coatings. This potential behaves as predicted by the mixing potential theory, in which the resulting OCP for two conductive phases in electrical contact is located between the OCP of each phase. In the majority of cases, the matrix possesses a lower OCP than that of silver, such as for ZrN [18], some DLC [29] and ZrCN [40]. Consequently, the corrosion potential of the films tends to increase when silver is incorporated into the coatings. Conversely, for matrices with higher reduction potentials, such as those in [39], the OCP decreases when silver is introduced into the system. This variation is not monotonic with silver incorporation because the OCP is an intensive property that is independent of the phase quantity.

To fully characterize the corrosion resistance of the coatings, the rate at which the material reacts with the electrolyte is determined. The corrosion rate is directly proportional to the density current for the potentiodynamic test, as deduced by Faraday's law [144], or the inverse of the polarization resistance in EIS. These quantities are usually reported to increase as the silver content increases in the films [18,38,39], in association with the incorporation of a more electrochemically active phase $(\mathrm{Ag})$ compared to the ceramic counterpart. In $\mathrm{Cl}$-containing electrolytes, such as $\mathrm{NaCl}$, oxidation of silver is expected due to the high affinity of $\mathrm{Ag}$ to form $\mathrm{AgCl}$; however, no evidence for the precipitation of this phase can be found in the literature.

This tendency is no longer observed for low silver contents in some systems, for which an improvement in the corrosion resistance of the coatings has also been reported. Dhandapani et al. [29], for instance, observed a decrease in the current density as the silver increased in the DLC matrix up to $\sim 8$ at.\%, followed by deterioration of the corrosion resistance; the improvements in the corrosion resistance were hypothetically attributed to the increase in the $\mathrm{sp}^{2} / \mathrm{sp}^{3} \mathrm{ratio} \mathrm{A}$ reduction of the corrosion current has also been observed for a $\mathrm{ZrCN}-\mathrm{Ag}$ coating with silver values below 8-9 at.\% [40,137]. This behavior was more evident for well-packed column morphologies and for $\mathrm{ZrCN}-\mathrm{Ag}$ without amorphous phases, corroborating the synergetic effect of the composition and morphology of the coatings.

\subsubsection{Silver ion release}

Silver ion release is governed by the electrochemical activity of the coatings and is one of the main factors influencing the antibacterial behavior of the coatings, as described in previous sections.

A correlation between silver ion release and the coating's silver content is usually addressed, but the results contradict this simplistic view. Song et al. [15], for example, have shown that higher silver release is observed for lower silver contents

Table 4

Electrochemical test parameters used for ceramic-Ag films.

\begin{tabular}{|c|c|c|c|c|c|c|}
\hline Matrix & Test & Reference electrode & Auxiliary electrode & Area $\left(\mathrm{cm}^{2}\right)$ & Electrolyte & Substrate \\
\hline DLC [29] & $\begin{array}{l}\text { PT } \\
\text { EIS }\end{array}$ & SCE & NM & NM & $3.5 \% \mathrm{NaCl}$ & SS316L \\
\hline TiCaPCON [38] & PT & $\mathrm{Ag} / \mathrm{AgCl}$ & Pt & 1 & Saline solution $\left(37^{\circ} \mathrm{C}\right)$ & $\mathrm{Si}$ \\
\hline TiN [74] & $\begin{array}{l}\text { Cyclic Voltammetry } \\
\text { EIS }\end{array}$ & SCE & $\mathrm{Pt}$ & NM & Sweat solution $(4.7 \mathrm{pH})$ & Glass \\
\hline ZnS [120] & Photocurrent & $\mathrm{Ag} / \mathrm{AgCl}$ & Pt & 1 & $\mathrm{~K}_{2} \mathrm{SO} 3 \mathrm{Na}_{2} \mathrm{~S}$ & NM \\
\hline $\mathrm{ZrCN}[41]$ & $\begin{array}{l}\text { PT } \\
\text { EIS }\end{array}$ & SCE & $\mathrm{Pt}$ & 0.44 & $\mathrm{NaCl} 0.9 \%\left(37^{\circ} \mathrm{C}\right)$ & SS316L \\
\hline $\mathrm{ZrCN}[40]$ & $\begin{array}{l}\text { PT } \\
\text { EIS }\end{array}$ & SCE & $\mathrm{Pt}$ & 1.7 & $\mathrm{NaCl} 0.9 \%\left(37^{\circ} \mathrm{C}\right)$ & SS316L \\
\hline $\mathrm{ZrCN}[137]$ & EIS & SCE & Pt & 0.44 & $\mathrm{HBSS}+10 \mathrm{~g} / 1 \mathrm{BSA}\left(37^{\circ} \mathrm{C}\right)$ & SS316L \\
\hline $\mathrm{ZrN}[18]$ & PT & SCE & Graphite & 1 & $3.5 \% \mathrm{NaCl}\left(37^{\circ} \mathrm{C}\right)$ & NM \\
\hline
\end{tabular}


a)

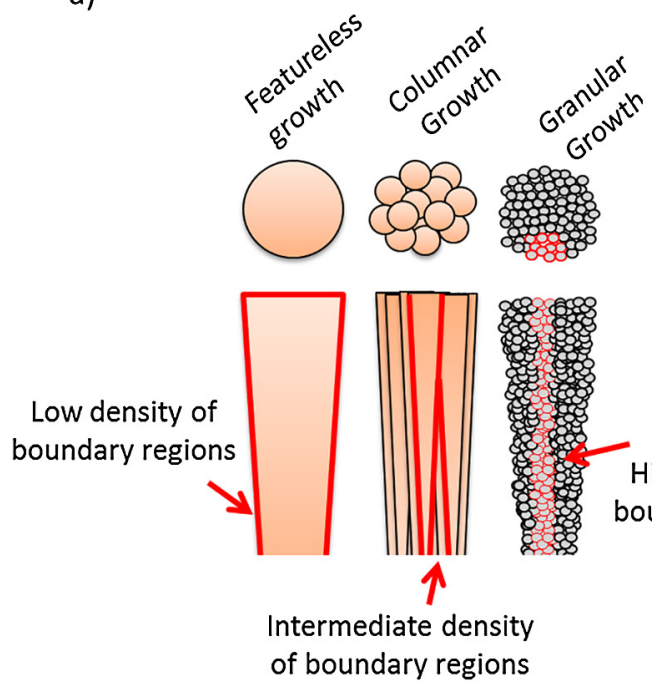

b)

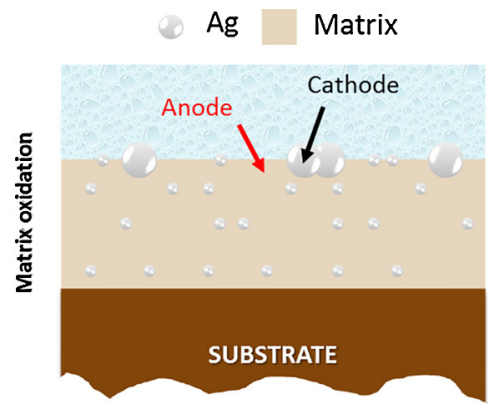

High density of boundary regions

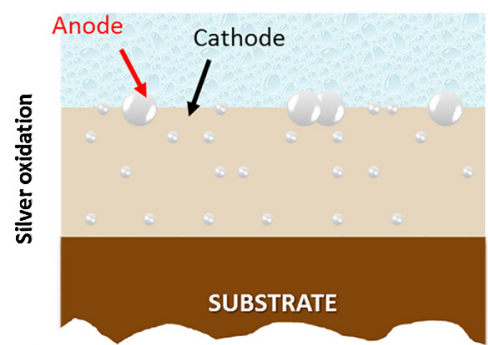

Fig. 15. (a) Scheme of the effect of coating morphology on the ionic and electrolyte diffusion path [137]; (b) phase distribution effect on corrosion resistance (adapted from the corresponding reference).

in $\mathrm{TiO}_{2}-\mathrm{Ag}$ systems, whereas Jamuna et al. [14] reported that in $\mathrm{TiO}_{2}-\mathrm{Ag}$ systems, an increase in the silver content promotes the release of more ions into the medium. These results indicate that silver ion release is controlled not only by the silver content but also by parameters such as the electrochemical galvanic couple formed between the silver and the matrix, the silver nanoparticle size, the electrolyte composition, or the initial oxidized state of silver.

Consider, for instance, the case of galvanic couples formed between the ceramic matrix and silver nanoparticles (see Fig. 16). A silver ionization enhancement is predictable when $\mathrm{Ag}$ acts as the anode of the electrochemical reaction due to its tendency to oxidize [127,145]. By contrast, silver nanoparticles behaving as the cathode of the reaction promote the oxidation of the matrix. An example supporting this analysis is $\mathrm{Zr}-\mathrm{C}-\mathrm{N}-\mathrm{Ag}$, in which, regardless of the amount of silver, $\mathrm{Ag}$ release in the $\mathrm{Zr}-\mathrm{C}-\mathrm{N}$ films mainly depends on the distribution of the phases present in the material. When silver is surrounded by ZrCN crystalline phases, the release is lower than when silver is surrounded by amorphous carbon phases [127].

Although the effect of the size of the Ag nanoparticles on ion release is a consequence of the surface area/volume ratio of the silver nanoparticles, evaluating its effect on ceramic-Ag coatings is not a trivial task. Because the size of the silver

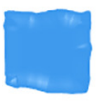

Ceramic phase with lower reduction potential than $\mathrm{Ag}$
Silver Nanoparticles
Ceramic phase with

higher reduction

potential than $\mathrm{Ag}$

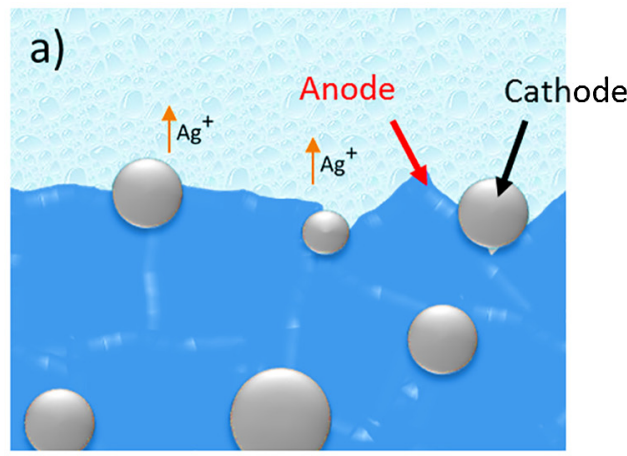

Lower silver release

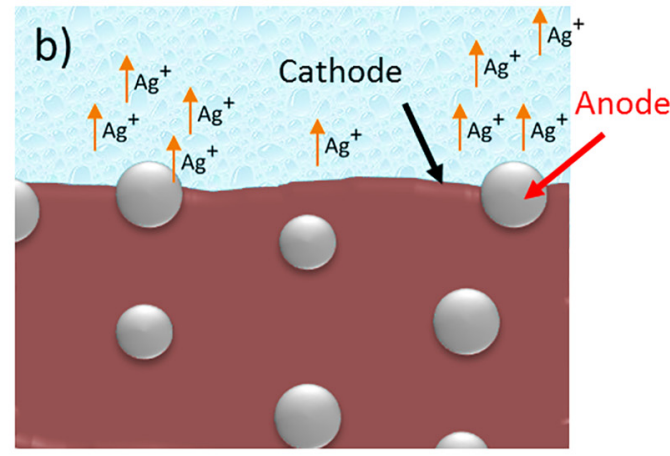

Higher silver release

Fig. 16. Schematic of silver ion release as a function of the phase. 
nanoparticles is dependent on several production parameters that can affect the chemical and morphological characteristics of the coatings, targeted changes in particle size without modifying other properties in the coatings are unlikely to be attained without using special components such as cluster guns. Indirectly, this dependency has been demonstrated by annealing the samples, which produces a decrease in silver ion release attributed to the increase in the silver nanoparticle size [16].

Metal ion release is also dependent on the electrolyte in which the films are immersed due to the different electrochemical reactions promoted by the components of the electrolytes [91]. Silver nanoparticles, for example, show affinity to proteins, sulfites, phosphates and other electrolyte constituents [141,146-149]. Therefore, to elucidate the silver ionization behavior of the ceramic-Ag coatings in specific applications, it is essential to mimic the environment. Unfortunately, the reactivity and/or precipitation of silver compounds may prevent the correct determination of silver ion release in complex environments, and thus, most reports assess $\mathrm{Ag}^{+}$ion release in simple solutions, such as distilled water, low-concentration $\mathrm{NaCl}$ or acidic environments. However, the results must be compared carefully with those occurring in environments characteristic of the final application (e.g., antibacterial tests).

Independent of the electrolyte, a common tendency has been observed. Silver is rapidly released in the first hours of immersion, reaching a plateau-like behavior after a certain period of time $\left(t_{0}\right)$ with very low amounts of silver ion release thereafter, as schematized in Fig. 17 [13,14,41].

Such behavior may be attributed to two phenomena:

(a) The formation of passive films on the surface of the material or on the silver crystals, which prevents silver release. In theory, for $\mathrm{Cl}$-containing electrolytes, a passive film may form due to the formation of $\mathrm{AgCl}$; however, no evidence of such formation has been provided in the literature. Other passivating materials, such as silver oxides and sulfides, can also be considered [10].

(b) The release of chemisorbed silver ions from the silver nanoparticles' surfaces, which decreases with time with the progressive decrease in their total amount. This behavior has been observed in composite samples [41,150] and in pure nanoparticles in natural water [151].

These two scenarios are optimal for short-term antibacterial applications because the silver release in the first hours will control the possible bacterial adhesion while maintaining low silver release to reduce undesired toxicity effects. However, to exploit these materials for long-term applications, solutions should be provided to maintain silver ion release for the duration of the application.

A direct comparison between silver ion release and the antibacterial effect cannot be performed because, in most reports, different electrolytes are used in antibacterial and silver ion release tests. Furthermore, the dimensions of the samples are often not provided. For example, the silver release in a maximum period of 30 days has been reported to be on the order of ppb; however, neither the size of the immersed sample, which is necessary to determine the silver release per sample area, nor the total amount of silver released in grams was specified.

From a pollution perspective, the low silver release and the reduction of the silver after a few hours of immersion represent advantages of ceramic-Ag coatings when $\mathrm{Ag}$ release is undesirable, such as in filters or bearing surfaces in contact

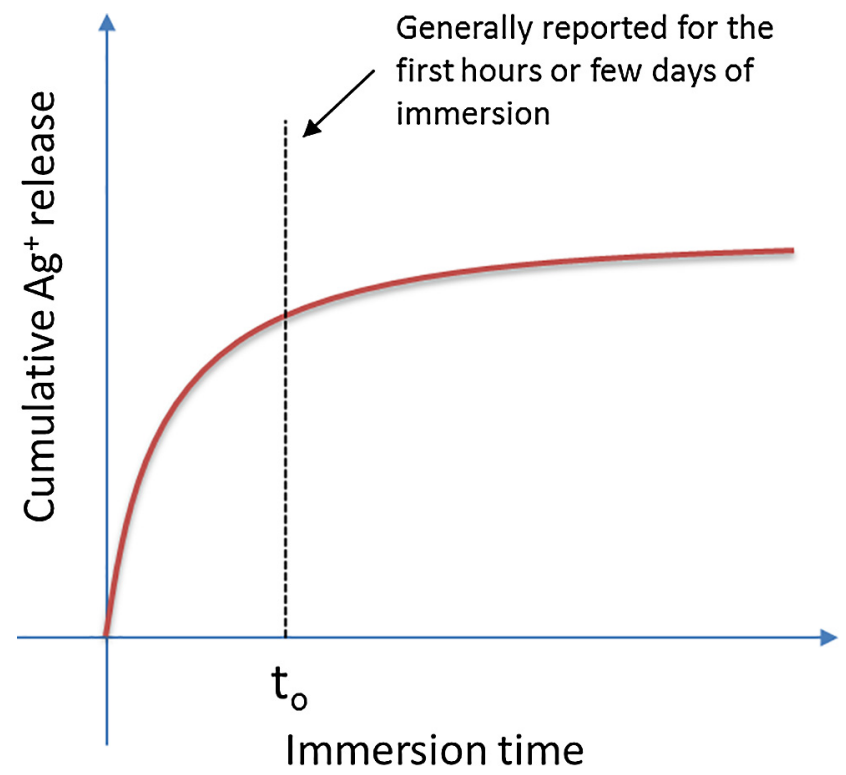

Fig. 17. Schematic of silver ion release as a function of the immersion time of ceramic-Ag in an electrolyte. 
with fluids. In other cases, the low silver activity can also be exploited as a self-controlling release mechanism if the release is meticulously activated by processing (i.e., electrically, mechanically, or chemically).

In conclusion, to better understand the behavior of ceramic-Ag coatings immersed in an electrolyte, more studies are required, particularly concerning the $\mathrm{Ag}^{+}$dependency of the matrix ( $\mathrm{MeN}, \mathrm{MeCN}$, a-C, oxides, etc.), the electrolyte and the importance of controlling the kinetics of the Ag release process. Only with a deeper understanding can the use of these coatings for applications involving silver ion release be envisaged.

\subsection{Optical properties}

One of the main applications for ceramic-Ag coatings is based on the surface plasmon resonance effect (SPR) exhibited by silver nanoparticles, as thoroughly studied by Jain et al. [152]. SPR may be interpreted as a collective oscillation of the metal's conduction electrons in resonance due to interaction with incident light, which arises from the quantum confinement effect. SPR is used in solar energy conversion systems and sensor/actuator development, particularly if the silver nanoparticles possess the ability to absorb radiation with wavelengths in the range of visible light. To enhance the SPR effect, the silver particles' size and concentration and the dielectric behavior of the matrix should be carefully controlled. The fabrication process is the key factor to control the position, shape and width of the surface plasmon resonance peaks and to achieve the desired optical properties by adjusting the sputtering parameters. In other words, depending on the morphological and chemical properties of ceramic-Ag, the radiation absorption can be tuned to modify the deposition parameters of the coatings. The silver power density [49], number of targets [99], bias potential [99], substrate arrangement and deposition temperature can determine the size, shape and ordering of the metal nanoparticles in the dielectric matrix, as previously discussed, which in turn control the SPR response. Moreover, the effect is potentiated by the low affinity between the silver and the matrices, allowing the formation of two separate phases.

In ceramic-Ag films, SPR has been reported for a variety of matrices, with resonance bands ranging from 387 to $610 \mathrm{~nm}$ in wavelength [44-46,48-51,63,99,102], as detailed in Table 5. The nanoparticles' size distribution in the ceramic matrix determines the broadness or sharpness of the absorption peaks, and these differences can be attributed to the large distribution of silver particle sizes and shapes [44]. In addition, a blue shift of the absorption peak is observed for lower silver contents $[44,46]$, which is attributable to the decrease in particle size.

The intensity of the absorption is also dependent on the silver content [116]. The absence of SPR has been reported for low silver contents, indicating that a threshold concentration is required to produce absorption [46]. Other authors have reported a decrease in both the transmittance $[92,109,121]$ and the optical band gap $[6,7,109]$ of coatings with increasing silver content, in agreement with the increase in absorption.

One of the major issues regarding ceramic-Ag coatings is the instability of silver nanoparticles on the surface of the coatings. Silver nanoparticles tend to segregate and agglomerate on the surfaces of coatings, altering the SPR response as a function of time, which is undesirable for optical/optoelectronic devices. To avoid this effect, alternative methods have been proposed, including changing the stoichiometry of the matrix and silver content and applying a diffusion barrier layer to control silver segregation, as mentioned in previous sections. Tu et al. [48], for instance, have demonstrated that the addition of $\mathrm{Al}$ to $\mathrm{Al}_{2} \mathrm{O}_{3}$ coatings promotes the control of silver nanoparticle growth when films are thermally treated; a shift in the absorption peak to higher or lower wavelengths was observed depending on the content of Al and the annealing temperature.

\subsection{Electrical properties}

A limited number of studies have examined the electrical and piezoelectric properties of the ceramic-Ag coatings produced by MS. The electrical behavior of the films is highly dependent on the silver content. For low metallic phase contents, the resistivity of the films is not altered or increases slightly [73], behaving as an impurity. After the silver content reaches a threshold value, the resistivity decreases [70,73,83,109,121], in some cases abruptly, with coatings adopting a metallic

Table 5

Radiation absorption of ceramic-Ag coatings in the UV-visible spectra attributed to SPR.

\begin{tabular}{ll}
\hline Matrix & Absorption peak (nm) \\
\hline $\mathrm{Al}_{2} \mathrm{O}_{3}[49]$ & 610 \\
$\mathrm{Al}_{2} \mathrm{O}_{3}[48]$ & 387 \\
$\mathrm{AlN}[63]$ & 460 \\
$\mathrm{Bi}_{2} \mathrm{O}_{3}[44]$ & $560-650$ \\
$\mathrm{ZnS}[121]$ & $444-468$ \\
$\mathrm{DLC}[46,102]$ & $400-500$ \\
$\mathrm{SiO}_{2}[117]$ & Asymmetric peaks from 350 to 550 \\
$\mathrm{SIO}_{2}[50]$ & 415 \\
$\mathrm{SiO}_{2}[21]$ & $396-398$ \\
$\mathrm{SiO}_{2}[22]$ & 439 \\
\hline
\end{tabular}


behavior. Such conductivity is associated with interconnections between the silver nanoparticles in the grain boundaries of the matrices that create electrical paths in the coatings, reaching a percolation threshold and reducing the electrical resistance.

Piezoresistive properties, by contrast, have been reported for C-based coatings (a-C-Ag and DLC-Ag). Incorporating silver into these ceramic coatings produces changes in the piezoresistive response. This property is commonly quantified by determining the gauge factor, i.e., the ratio between the changes in the material resistivity and the deformation. Both an increase [99] and a decrease [46] in this factor have been reported with increasing silver content, indicating that silver content is not the controlling parameter. Instead, Tamulevicius et al. [46] attributed the effect of silver on the $\mathrm{sp}^{2} / \mathrm{sp}^{3}$ bond ratio as being responsible for piezoelectric variations. Thus, the silver content and other production parameters of the coatings, such as the reactive gas, bias voltage and power density current, might be used to adjust the $\mathrm{sp}^{2} / \mathrm{sp}^{3}$ ratio and, indirectly, the piezoelectric properties in C-based-Ag coatings.

\subsection{Mechanical properties}

Coatings such as TiN and $\mathrm{CrN}$ have been used in industrial applications for more than three decades due to their higher hardness compared to base materials such as high-speed steel and cemented carbide employed in cutting tools [153]. The success of these coatings has led to the use of a large family of carbides, carbonitrides and carbon-based coatings to enhance the mechanical properties of base materials. The mechanical properties of these coatings are mainly determined by the intrinsic characteristics of the materials in single-crystal forms and their microstructure. As a result, in ceramic-Ag coatings, only the microstructural changes due to silver incorporation are expected to be responsible for modifying the mechanical properties, without significant effects on the matrix lattices, as previously demonstrated. In the following sections, the effect of silver nanoparticles on the mechanical and tribological properties of the coatings will be discussed.

\subsubsection{Residual stress}

The stress in PVD films is usually compressive (Fig. 18) due to either the difference in the thermal expansion coefficients between the substrate and the film or the growing conditions and their effect on the cross-section morphology. Fig. 18a schematically shows a system (coating-substrate) without any residual stress; a red square indicates the changes that occur when residual compressive stress is present (Fig. 18b). When the film is compressed, following the direction parallel to the substrate, the rectangle expands in the perpendicular direction. This can occur during cooling after deposition (or thermal treatment) if the substrate contracts more than the film.

When silver is incorporated into coatings, the compressive stress can be released due to the plastic deformation of the soft metallic phase [65] located between the columns or grain boundaries, as schematically shown in Fig. 19, thus promoting strain-induced segregation. In fact, this effect is the reason behind incorporating silver into DLC coatings, which helps increase the mechanical stability of the coatings by reducing the compressive stress, thereby enhancing film adhesion.

\subsubsection{Hardness}

In general, for any type of matrix, an increase in silver produces a reduction of the hardness and Young's modulus of the coatings, as shown in Figs. 20-22. Some researchers have shown that for low silver content, the hardness of MeN can increase, which can be explained by the grain refinement of the structure. This refinement hinders dislocation motion and prevents crack development at the interfaces. The silver content threshold at which this trend is verified depends on the type of matrices, which has been reported as $<5$ at.\% for $\mathrm{CrN}$ [27], between 5 and 12 at.\% for $\mathrm{ZrN} \mathrm{[76]} \mathrm{and} \mathrm{between} 2$ and 15 at.\% for TaN [32,69]. As the silver content continuously increases, more silver segregates to the grain boundaries, enhancing the ductility in those regions and facilitating both grain boundary sliding and the reduction of the residual stress of the coatings, with the consequent deterioration of the system's hardness.

In C-based ceramic-Ag coatings, the hardness depends on the ratio between $\mathrm{sp}^{2}$ and $\mathrm{sp}^{3}$ carbon bonds, which can be altered as silver is added to the films (see the above discussion of Raman and XPS results). Thus, the hardness is expected to decrease with the increasing $\mathrm{sp}^{2} / \mathrm{sp}^{3}$ ratio that occurs as the silver content increases $[28,29,93,103,104]$ (Fig. 21). However, some reports have stated that for low silver contents (between 3 and 10 at.\%), the hardness exhibits the opposite trend [29,103], in agreement with the increment of $\mathrm{sp}^{3}$ bonds in the films observed by Raman spectroscopy.

The analysis of hardness for $\mathrm{MeCN}-\mathrm{Ag}$ films is more complex because when silver is added to MeCN matrices, an amorphous carbon phase can form [4,26,42,90,130], as previously discussed. Therefore, a mixture of crystalline MeCN, amorphous carbon and silver nanocrystalline phases is created, each with specific mechanical properties that determine the final hardness of the system. Studies of $\mathrm{MeCN}$ coatings with and without amorphous carbon phases have demonstrated that silver has a greater effect than the amorphous carbon phases on the reduction of the system hardness. This phenomenon may be explained by the lower interaction between the silver and the matrices ( $M e C N$ and a-C) compared to the carbon, which can interact with the Me atoms in the matrix, forming a nanocomposite-like material. Thus, silver may promote the sliding of the grain boundaries more easily, reducing the hardness of the system. 
a)

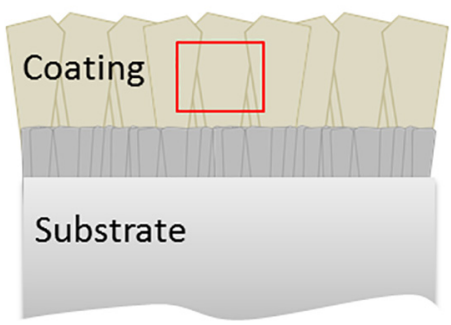

b)

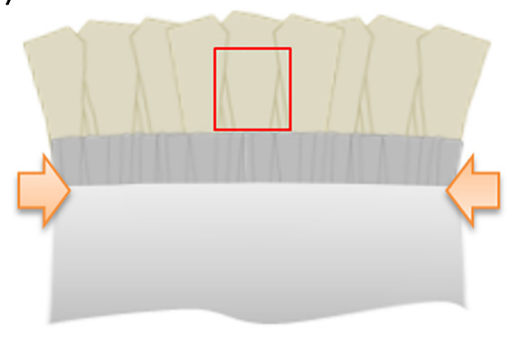

Fig. 18. Compressive stress of PVD coatings: (a) coating without stress and (b) coating with compressive stress.

a)

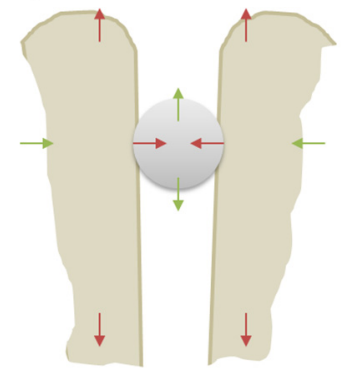

Before releasing the stress b)

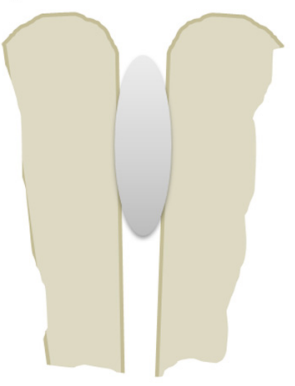

After releasing the stress

Fig. 19. Scheme of the effect of silver on the compressive residual stress of ceramic-Ag coatings.

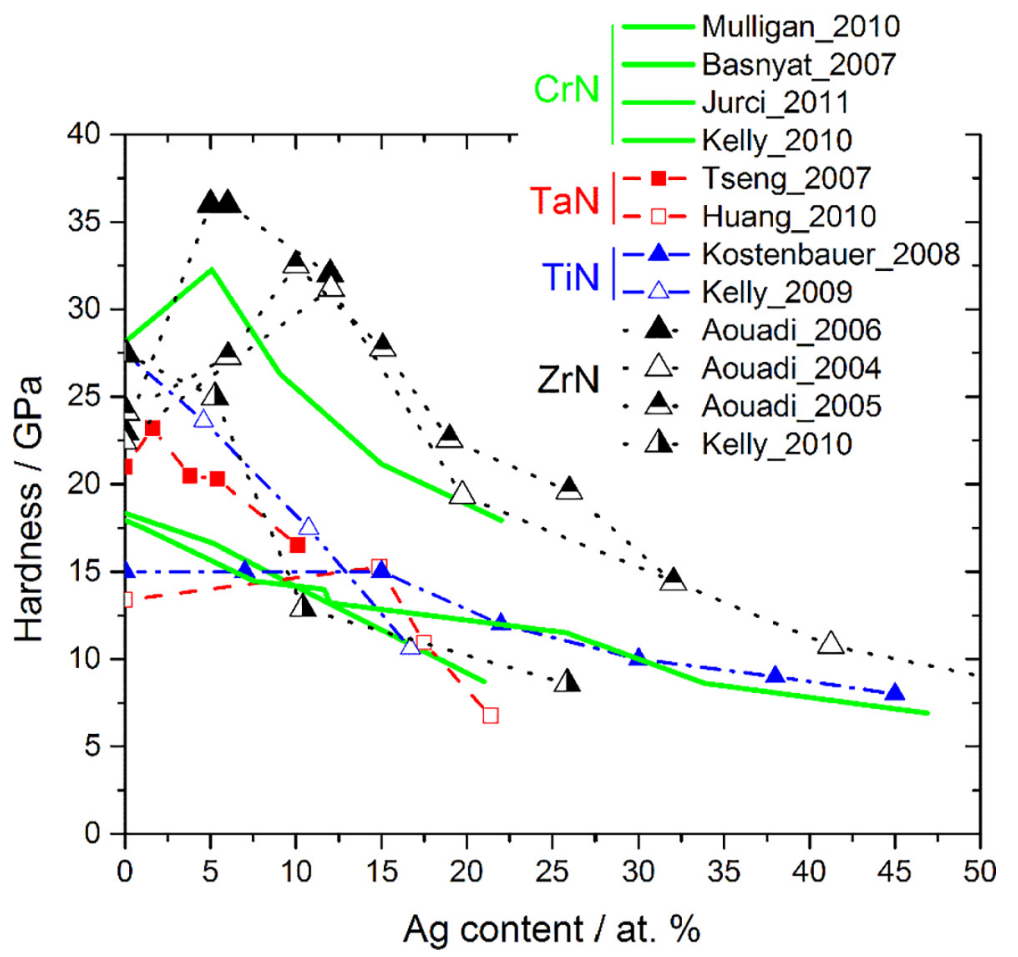

Fig. 20. Hardness of MeN-Ag coatings as a function of the silver content $[1,2,18,27,30,32,35,37,45,64,69,71,77,78,106]$. For hardness values reported in HK, a conversion factor was used to approximate the values in GPa $(100 \mathrm{HK} / \mathrm{GPa})$. 
Finally, oxides such as yttria-stabilized zirconia exhibit the same behavior reported in previous systems [111,112], in which the hardness of the films is reduced as the silver content is increased. An unusual behavior is observed in $\mathrm{WS}_{2}-\mathrm{Ag}_{\mathrm{g}} \mathrm{ys}^{-}$ tems, in which the hardness increases as silver is incorporated. In these films, the microstructure is the dominant factor controlling the hardness of the films because, when the silver is added, the film densifies, and thus, the reduction of the porosity helps prevent plastic deformation due to indentations [123].

An increase in the deposition temperature can give rise to higher hardness of the films. Some authors have explained this trend by the segregation of $\mathrm{Ag}$ phases originating from pure, silver-free $M e \mathrm{~N}$ phases, which possess higher hardness

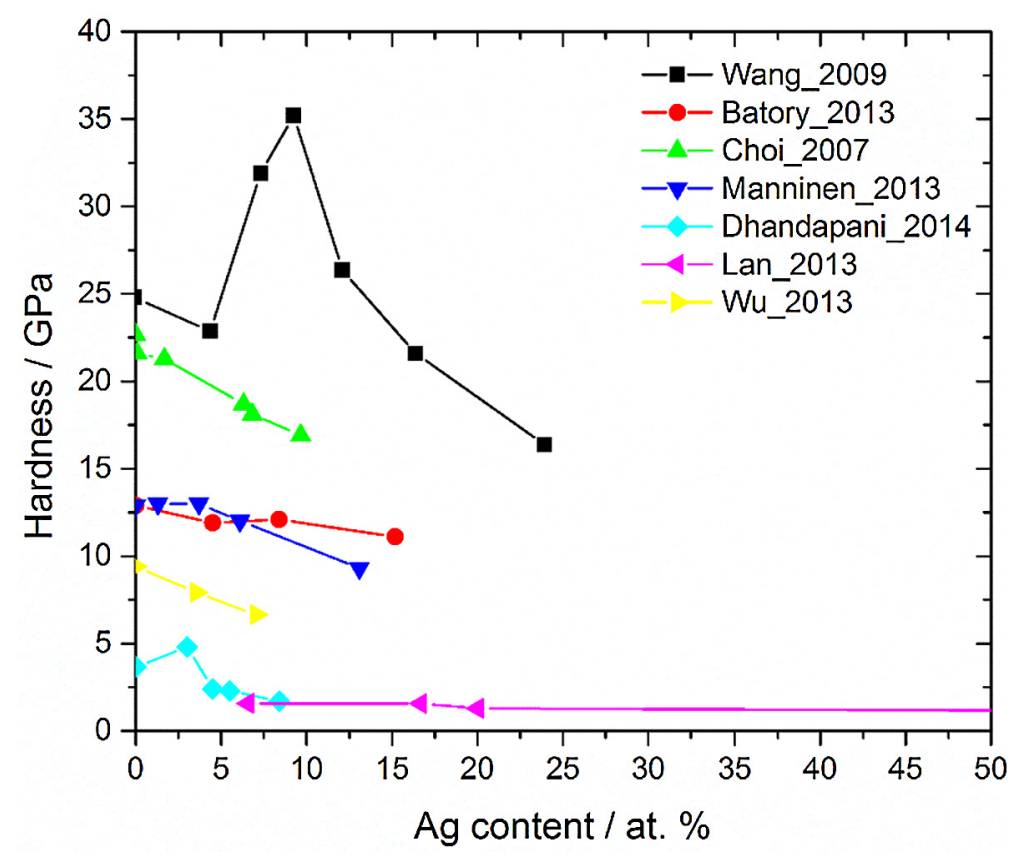

Fig. 21. Hardness of C-based Ag coatings as a function of the silver content $[19,28,29,93,95,103,104]$.

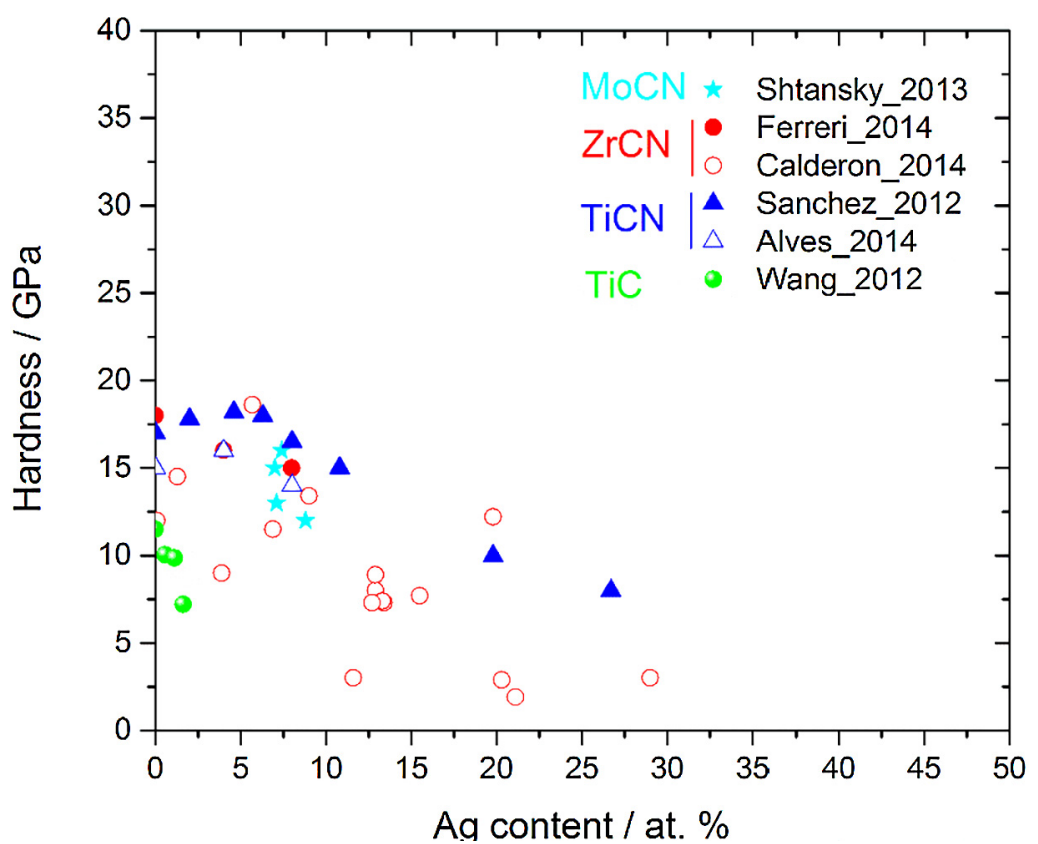

Fig. 22. Hardness of MeCN-Ag and MeC-Ag coatings as a function of the silver content $[4,26,42,85,90]$. 
[32,64,71]. However, difficulties have been reported for measuring the hardness of the system after high temperature deposition or thermal treatment because silver segregates to the surface and the resultant Ag-rich regions can give misleading values [35].

\subsection{Tribological properties}

The combination of a hard material with enhanced wear resistance and silver as a solid lubricant with high thermochemical stability is one of the main purposes of depositing ceramic-Ag coatings. The majority of tribological studies available in the literature are concerned with sliding in dry conditions. However, due to the potential of these films for other applications in which different environments can be present, such as simulated human body fluids in biomedical devices, other testing conditions have also been reported. In these cases, the tribological testing procedure permits the evaluation of the ability of these coatings to support saline and biological environments and the simultaneously exploration of the known antimicrobial performance of silver, both fundamental requirements for many biomedical devices.

The tribological performance of ceramic-Ag films depends not only on the silver content but also on the ceramic matrix and the testing conditions (e.g., the lubricant and counterpart). Hence, the tribological behavior of ceramic-Ag films, grouped by nitrides, carbides, carbonitrides, C-based and oxides coatings, is summarized in Tables 6 and 7.

\subsubsection{Coefficient of friction (COF)}

5.6.1.1. Transition metal nitride matrices $(M e N)$. All of the studies reported in this review regarding the tribological properties of $\mathrm{MeN}-\mathrm{Ag}$ coatings were performed in dry conditions. Under these conditions, the segregation of silver to the surface is one of the key parameters controlling the self-lubricating features of ceramic-Ag coatings. Therefore, the deposition and annealing conditions, as well as the tribological test parameters, which influence the segregation activity, must be considered. As previously discussed, when annealing treatments are applied, silver is allowed to segregate to the surface, forming islands that can act as a lubricant during tribological testing at high temperatures [23,31-33,37,75]. In these cases, the reduction of the COF is attributed to the low shear strength of $\mathrm{Ag}$ at high temperatures. Even at room temperature testing, reduction of the COF has been reported for larger silver contents compared to the COF of the pure $M e N$ matrix $[2,25,27,32,33,68]$ due to the formation of silver agglomerates on the coating surface. However, for very large contents of silver and high silver segregation, higher COFs have been reported [27], which may be associated with the unstable porous matrix (Fig. 11) that remains underneath the top layer due to silver diffusion and segregation. Thus, mechanical loading can make the pores collapse and can disintegrate the topmost layer of the film, increasing the COF.

Table 6

Tribological test conditions, COF and wear rate reported for composite coatings of the MeN-Ag type. All data were obtained under dry conditions.

\begin{tabular}{|c|c|c|c|c|c|c|c|}
\hline Matrix & Test & Counterpart & Temperature $\left({ }^{\circ} \mathrm{C}\right)$ & $\begin{array}{l}\text { Humidity } \\
(\%)\end{array}$ & $\begin{array}{l}\text { Applied } \\
\text { load }(\mathrm{N})\end{array}$ & COF & $\begin{array}{l}\text { Wear rate }{ }^{\mathrm{b}} \times 10^{-6} \\
\left(\mathrm{~mm}^{3} \mathrm{~N}^{-1} \mathrm{~m}^{-1}\right)\end{array}$ \\
\hline $\mathrm{CrN}[25]$ & $\begin{array}{l}\text { Reciprocating } \\
\text { multipass scratching }\end{array}$ & Rockwell indenter & RT & $40-45$ & 1 & $0.04-0.11$ & $0.4-0.19 \mu \mathrm{m} / 100$ cycles \\
\hline $\mathrm{CrN}[23]$ & Ball on disk & Alumina & 550 & $35-45$ & 5 & $0.20-0.40$ & $3.2-10.2$ \\
\hline $\mathrm{CrN}[23]$ & Ball on disk & Alumina & 450,550 and 650 & NM & 5 & $0.16-0.54$ & $4-47$ \\
\hline $\mathrm{CrN}[23]$ & Ball on disk & Alumina & RT & $35-45$ & 5 & $0.50-0.80$ & $7-100$ \\
\hline CrN [23] & Ball on disk & $100 \mathrm{Cr} 6$ steel & RT & $35-45$ & 15 & $0.47-0.8$ & $2.3-9.9$ \\
\hline $\mathrm{CrN}[23]$ & Ball on disk & Alumina & $25-700$ & & 15 & $0.05-0.80$ & NA \\
\hline $\mathrm{CrN}[31]$ & Ball on disk & $100 \mathrm{Cr} 6$ steel & RT, 400 and 600 & NM & 2 & $0.23-0.75$ & NM \\
\hline $\mathrm{CrN}[27]$ & Ball on disk & Alumina & RT & 40 & 2 & $0.23-0.83$ & $0.054-0.4$ \\
\hline $\mathrm{CrN}[37]$ & Pin on disk & Alumina & RT and 500 & NM & 1 & $0.17-0.39$ & $(7.4-289.4) \times 10^{-7}$ \\
\hline $\mathrm{CrN}[30]$ & $\begin{array}{l}\text { Reciprocating } \\
\text { ball on disk }\end{array}$ & S45C steel & NM & NM & 100 & $0.30-0.65^{a}$ & $0.4-0.72 \mathrm{um}$ \\
\hline MoN [34] & Ball on disk & $\begin{array}{l}\text { Alumina, } 440 \mathrm{C} \\
\text { steel, } \mathrm{Si}_{3} \mathrm{~N}_{4}\end{array}$ & RT & 50 - Dry $\mathrm{N}_{2}$ & 1 & $0.28-1.06$ & $300-800$ \\
\hline MoN [34] & Ball on disk & $\mathrm{Si}_{3} \mathrm{~N}_{4}$ & 350 and 600 & 50 - Dry $\mathrm{N}_{2}$ & 1 & $0.10-0.80$ & $8-500$ \\
\hline MoN [66] & Ball on disk & $\mathrm{Si}_{3} \mathrm{~N}_{4}$ & RT, 350 and 600 & Dry & 1 & $0.10-0.80$ & $0.8-90$ \\
\hline MoN [67] & Ball on disk & Alumina & RT, 100, 250, 400 & 50 & 1 & $0.30-0.80$ & NM \\
\hline NbN [68] & Ball on disk & $\mathrm{Si}_{3} \mathrm{~N}_{4}$ & RT, 350 and 750, 1000 & 60 & 1 & $0.27-0.35$ & NM \\
\hline TaN [33] & Pin on disk & Alumina & NM & NM & $1-5$ & $0.70-1.20$ & $(0.7-6) \times N$ \\
\hline TiN [35] & Ball on disk & Alumina & RT, 200, 300 and 500 & $30-40$ & 1 & $0.15-0.70$ & NM \\
\hline TiN [1] & $\begin{array}{l}\text { Thrust washer } \\
\text { wear testing }\end{array}$ & $100 \mathrm{Cr} 6$ steel & NM & NM & 20 & $0.31-0.36$ & NM \\
\hline VN [75] & Ball on disk & $\mathrm{Si}_{3} \mathrm{~N}_{4}$ & RT, 350, 700 and 1000 & 60 & 2 & $0.12-0.9$ & NM \\
\hline $\mathrm{ZrN}[18]$ & Ball on disk & 440C steel & RT & 50 & 5 & NM & $1.8 \times 10^{-3} \mathrm{~mm}^{3}$ \\
\hline $\mathrm{ZrN}[45]$ & Ball on disk & 440C steel & RT & 50 & 5 & $0.65-0.09$ & $27 \times 10^{-3} \mathrm{~mm}^{3}$ \\
\hline $\mathrm{ZrN}$ & Thrust washer & $100 \mathrm{Cr} 6$ steel & RT & NM & NM & $0.11-0.19$ & NM \\
\hline $\mathrm{CrN}$ & wear testing & & & & & $0.13-0.17$ & \\
\hline TiN [2] & & & & & & $0.16-0.17$ & \\
\hline
\end{tabular}

a Approximated value; $\mathrm{NM}=$ not mentioned; $\mathrm{RT}=$ Room temperature.

b Different wear rate units are given when no information is provided in $\mathrm{mm}^{3} \mathrm{~N}^{-1} \mathrm{~m}^{-1}$. 
Table 7

Tribological test conditions, COF values and wear rates reported for MeC, MeCN and DLC coatings.

\begin{tabular}{|c|c|c|c|c|c|c|c|c|}
\hline & Test & Lubricant & Counter body & $\mathrm{T}\left({ }^{\circ} \mathrm{C}\right)$ & Humidity (\%) & $\begin{array}{l}\text { Applied } \\
\text { load }(\mathrm{N})\end{array}$ & COF & $\begin{array}{l}\text { Wear rate } \\
\times 10^{-6}\left(\mathrm{~mm}^{3} \mathrm{~N}^{-1} \mathrm{~m}^{-1}\right)\end{array}$ \\
\hline C-based [96] & Ball on disk & Dry & AISI 52100 steel & RT & $40-50$ & 5 & $0.25-0.70$ & NM \\
\hline C-based [28] & Pin on disk & Dry & Zirconia & RT & 40 & $\begin{array}{l}10 \\
18\end{array}$ & $0.06-0.20$ & $0.05-0.20$ \\
\hline C-based [101] & $\begin{array}{l}\text { Reciprocating } \\
\text { pin on disk }\end{array}$ & Dry & AISI 52100 steel & RT & 30 & 1 & $0.20-0.30$ & NM \\
\hline C-based [29] & $\begin{array}{l}\text { Reciprocating } \\
\text { test }\end{array}$ & NM & Alumina & RT & 40 & 0.01 & $0.16-0.60$ & $\begin{array}{l}0.002-19.60 \mu \mathrm{m}^{3} / \\
\text { cycle } \mathrm{mN}\end{array}$ \\
\hline C-based [104] & Ball on disk & Vacuum & GCr15 steel & RT & NA & 5 & 0.005 & NM \\
\hline $\mathrm{SiC}[79]$ & Ball on flat & Dry & 440C steel & NM & Vacuum & 1 & $0.12-0.39$ & NM \\
\hline $\mathrm{TiC}[80]$ & Ball on flat & Dry & 440C steel & RT & Vacuum & 1 & $0.25-0.75$ & NM \\
\hline $\mathrm{TiC}[81]$ & Ball on flat & Dry & GCr15 steel & RT & NM and Vacuum & 1 & $0.04-0.30$ & $0.10-0.80$ \\
\hline $\mathrm{HfC}$ [79] & Ball on flat & Dry & $440 C$ & NM & Vacuum & 1 & $0.17-0.45$ & NM \\
\hline MoCN [85] & Ball on disk & Dry & $\begin{array}{l}\text { Alumina and } \\
\text { cemented carbide }\end{array}$ & $\begin{array}{l}\text { RT, } 500 \\
\text { and } 700\end{array}$ & 60 & 1 & $\begin{array}{l}0.25- \\
0.90^{\mathrm{a}}\end{array}$ & NM \\
\hline TiCN [26] & Pin on disk & $\begin{array}{l}\text { Dry, HBSS, } \\
\text { HBSS + BSA }\end{array}$ & Alumina & RT & 35 & 2 & NM & $0.15-0.21$ \\
\hline ZrCN [130] & $\begin{array}{l}\text { Reciprocating } \\
\text { pin on disk }\end{array}$ & HBBS + BSA & UHMWPE & 37 & NM & 10 & $0.07-0.15$ & $1.38-2.08$ \\
\hline TiCN [89] & $\begin{array}{l}\text { Reciprocating } \\
\text { pin on disk }\end{array}$ & $\begin{array}{l}\text { Fetal bovine } \\
\text { serum }\end{array}$ & Alumina & NM & NM & 0.5 & $0.30^{\mathrm{a}}$ & $1.00-9.00$ \\
\hline
\end{tabular}

a Approximated value; NM = not mentioned; RT = Room temperature.

b Different wear rate units are given when no information is provided in $\mathrm{mm}^{3} \mathrm{~N}^{-1} \mathrm{~m}^{-1}$.

The deposition temperature is another important variable for the silver segregation. Some studies have described a very simple mathematical relationship between the deposition temperature and the testing temperature to control the diffusion of silver to the surface to act as a self-lubricating material. For example, Mulligan et al. [23,24] proposed that the difference between the deposition temperature $\left(T_{d}\right)$ and test temperature $\left(T_{t}\right)\left(T_{t}-T_{d}\right)$ functions as a parameter to evaluate the efficiency of the silver lubrication. They observed a lubricant effect of silver when tests were performed at temperatures higher than the deposition temperature $\left(T_{t}>T_{d}\right)$; however, this lubricant effect was observed only for a certain number of cycles until the silver was depleted, and consequently, the COF returned to $\mathrm{MeN}$ values. When the test temperature was lower than the deposition temperature $\left(\mathrm{T}_{t}<\mathrm{T}_{\mathrm{d}}\right)$, the coefficient of friction was constant and below or above the MeN COF, depending on the amount of silver, as schematized in Fig. 23.

When tests are performed at high temperature, some matrices can react with silver to form complex oxides, such as silver molybdate (in MoN-Ag films) [34,66,106] or silver niobate (for NbN-Ag) [68], which are responsible for the reduction of the COF. Moreover, these complex oxides can prevent the depletion of silver, which will be incorporated into the lubricious oxides, allowing maintenance of a constant COF at low values for a much larger number of cycles.

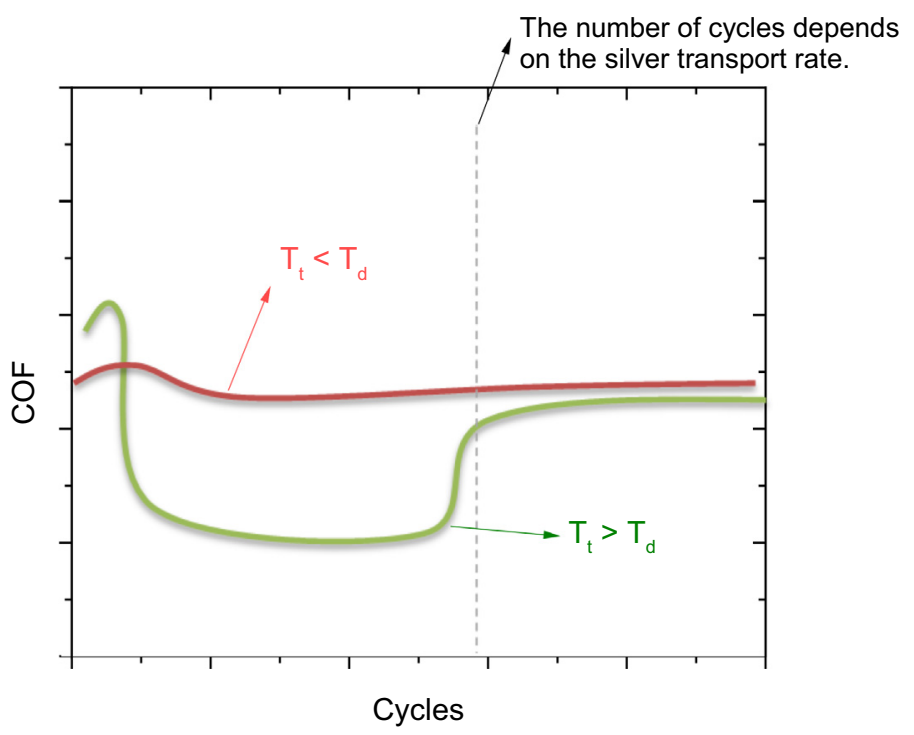

Fig. 23. Scheme of the dependence of the COF on the test and deposition temperatures. 
Fig. 24 summarizes the influence of the testing temperature and silver content on the friction coefficient of MeN-Ag coatings. Although different counterparts, normal loads and test temperatures have been used, the graph provides indicative ranges of values for the COF achieved in these systems.

5.6.1.2. Carbon-containing matrices ( $\mathrm{MeC}-\mathrm{Ag}, \mathrm{MeCN}-\mathrm{Ag}$ and $\mathrm{a}-\mathrm{C}-\mathrm{Ag}$ ). For a-C-Ag films, the literature results are summarized in Table 7. No unanimous trends for the influence of silver incorporation can be concluded. Some studies have reported that the COF of C-based-Ag coatings is always higher than that of pure a-C coatings [28], independent of the silver content, whereas others have reported a reduction of the COF for low silver contents ( $<4.5$ at.\%) [29]. For high silver content films, significant instabilities in the COF are observed due to the segregation of silver and the consequent degradation of the film related to the porous structure remaining beneath $[28,29,101]$.

The COF results for $\mathrm{MeC}$ and $\mathrm{MeCN}$ matrices are also summarized in Table 7. A threshold silver content is necessary to promote sufficient silver agglomeration on the material surface to reduce the COF at room temperature [79,84]. As for DLC, the beneficial effect of silver is only observed up to a certain content, and further increments in the silver content produce a deterioration of the COF in some systems [79,81]. The reduction of the friction coefficient may also be due to the increase in the amount of amorphous carbon induced by the incorporation of $\mathrm{Ag}$ [26,85], which is known to act as a selflubricating material.

$\mathrm{MeCN}-\mathrm{Ag}$ systems have also been tested in lubricated environments using albumin-containing solutions. In these studies, the incorporation of silver did not produce an evident lubrication enhancement, but the COF was reduced due to the formation of a protective protein layer on the sliding contact $[26,130]$. Although this lubricant itself is mainly responsible for the lubrication, these systems are known to function in a boundary lubrication regime; thus, the presence of self-lubricating phases $(\mathrm{a}-\mathrm{C}$ ) between surface asperities in close contact may reduce the COF.

Fig. 25 summarizes the COFs reported for the a-C-Ag, MeC-Ag and MeCN-Ag coatings reported in Table 7. In general, MeN$\mathrm{Ag}$ has higher COF values, demonstrating the influence of the carbon phases on the friction behavior of the systems.

5.6.1.3. Oxides and other matrices. A reduction in the COF was also observed due to the incorporation of silver into oxide matrices [112,118]. Two systems are highlighted.

For yttria-stabilized zirconia (YSZ) with silver at temperatures between $300{ }^{\circ} \mathrm{C}$ and $500{ }^{\circ} \mathrm{C}$, increasing the silver content results in a reduction of the COF. At higher temperatures $\left(700^{\circ} \mathrm{C}\right)$, the COF stabilizes at 0.8 . The diffusion of silver forms a lubricious layer on the contact region, decreasing the friction. At higher temperatures $\left(700{ }^{\circ} \mathrm{C}\right)$, the silver becomes very soft and is easily pushed out of the sliding contact, reducing its ability to lubricate [112]. To avoid the rapid depletion of silver, Hu et al. [111] produced a multilayered system with TiN as a barrier layer, enabling the control of the silver diffusion.

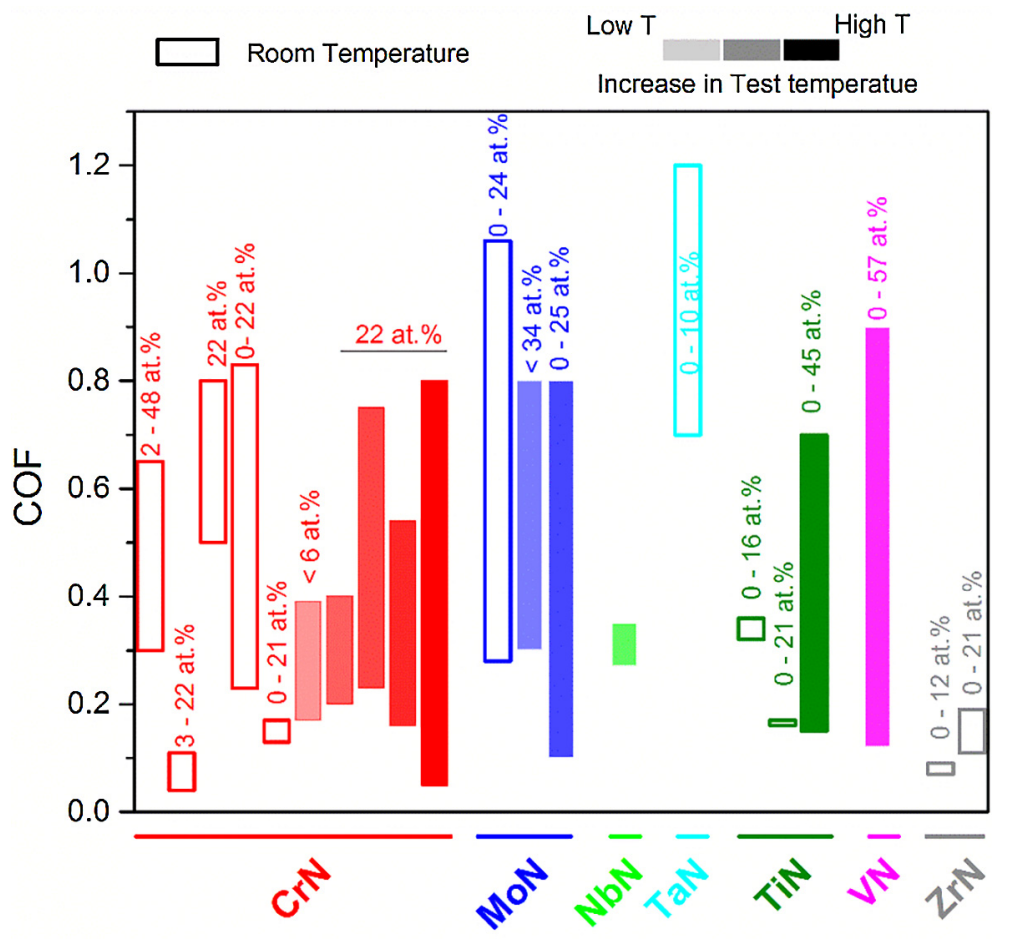

Fig. 24. COF values reported in the literature (Table 6) for different MeN-Ag coatings. Different columns for the same material correspond to different references. The intensity of the color for each column reflects low (less intense color) to high (more intense color) testing temperatures. The atomic percentages located over the columns represent the range of silver content in the studies. 


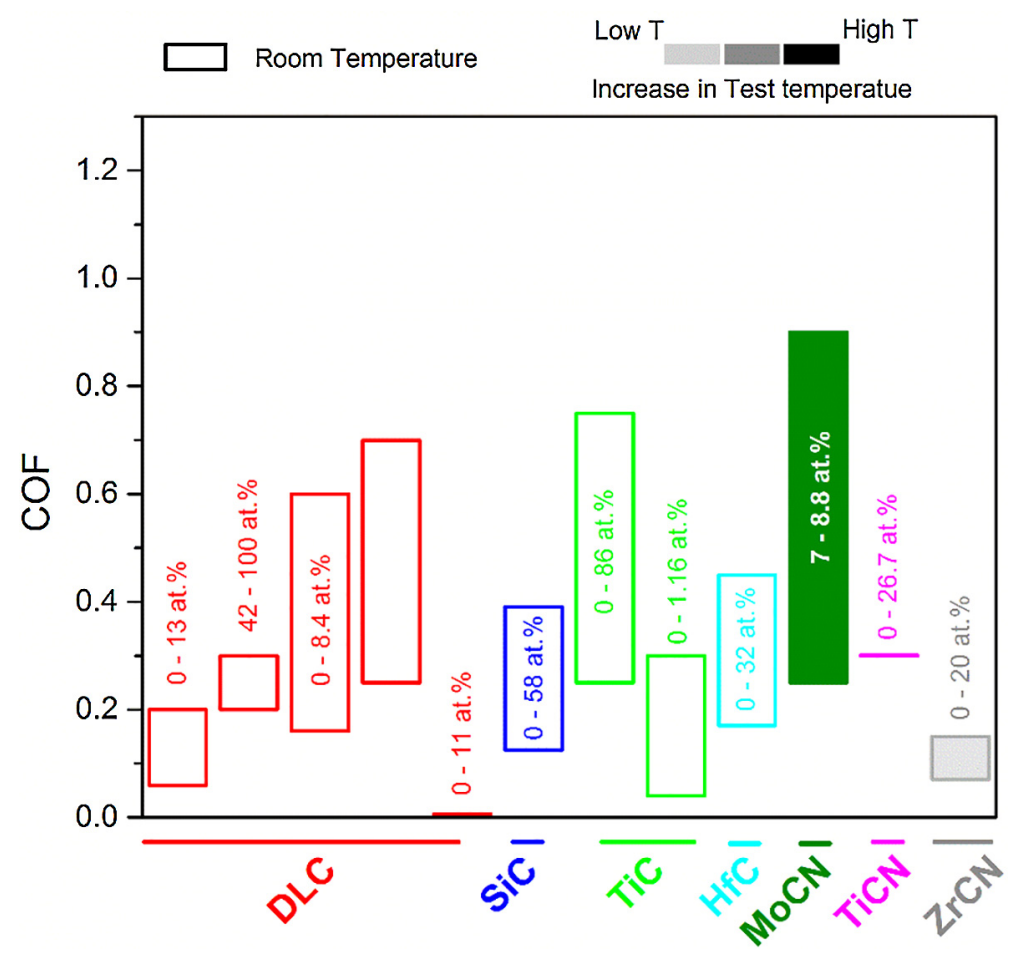

Fig. 25. COFs reported in the literature (Table 7) for DLC-Ag, MeC-Ag and MeCN-Ag coatings. Different columns for the same material correspond to different references. The intensity of the color for each column reflects low (less intense color) to high (more intense color) testing temperatures. The atomic percentages located over the columns represent the range of silver content in the studies.

$\mathrm{WS}_{2}$-Ag films with 40 at.\% of silver improved the tribological behavior compared to pure $\mathrm{WS}_{2}$ under air and vacuum conditions. The incorporation of silver improved the mechanical properties of $\mathrm{WS}_{2}$, and thus, the wear track showed less debris and higher resistance to crack nucleation and propagation [122]. The COF started at similar values but decreased abruptly for the films containing silver after a low number of cycles $(<1000)$. In humid air, lower COFs were maintained for all silver contents compared to the COF of $\mathrm{WS}_{2}$, but the COFs were higher when tests were performed under vacuum [36,123].

\subsubsection{Wear}

Similar to the coefficient of friction, the wear rate of the coatings depends on the ability of silver to segregate, form a lubricant layer and endure for a certain number of cycles on the surface. The morphological characterization of ceramicAg films has shown that silver segregation to the coating surface is governed by a variety of parameters, such as the deposition temperature, annealing temperature, silver content, and bias potential, among others, and therefore, the wear rate is expected to demonstrate these dependencies.

Silver functions as a solid lubricant on the surface of the material, reducing the wear when dry tests are performed; however, certain conditions must be satisfied to obtain this lubrication. First, silver must segregate to the surface, spontaneously or externally activated (i.e., by temperature), and thus, in systems with low silver segregation, the wear rate is not modified or even increased when silver is added due to the hardness reduction. For high silver segregation, the wear rate depends on the Ag depletion time because, after the solid lubricant (silver) is worn out, a more unstable porous structure underneath the surface is created, causing failure and increasing the wear rate of the system [23,24], as shown schematically in Fig. 26. Hence, an equilibrium among the silver content, silver mobility and the stability of the matrix must be reached to be able to exploit these self-assembled silver nanoparticles in a self-lubricating system.

In the literature, the wear rate depends on the silver content, the testing temperature and their influence on the stability of the coatings. The wear rate is reduced [25,26] or increased [4,26-29] by introducing silver into the system. Kelly et al., for example, demonstrated that ZrN-Ag and TiN-Ag showed no wear when $\mathrm{Ag}=0$ at.\% but became worn out at higher silver content, whereas $\mathrm{CrN}$ showed low values of wear for silver content $<11$ at.\% that increased at higher Ag contents [2]. In other studies, $\mathrm{ZrN}-\mathrm{Ag}$ and TaN-Ag wear rates were reduced compared to those of the pure nitrides [32,33,154], although the decrease was not monotonic with the incorporation of silver.

In relation to the effect of the testing temperature increment, in some cases, a reduction of the wear rates is achieved due to efficient lubrication by silver [31-34]. However, in other cases, an increase in the wear rate is observed due to the loss of the integrity of the coatings $[23,35,36]$. The values of the wear rate vary from $10^{-13}$ to $10^{-3} \mathrm{~mm}^{3} \mathrm{~N}^{-1} \mathrm{~m}^{-1}$. A summary of the tribological results is shown in Tables 6 and 7 . 


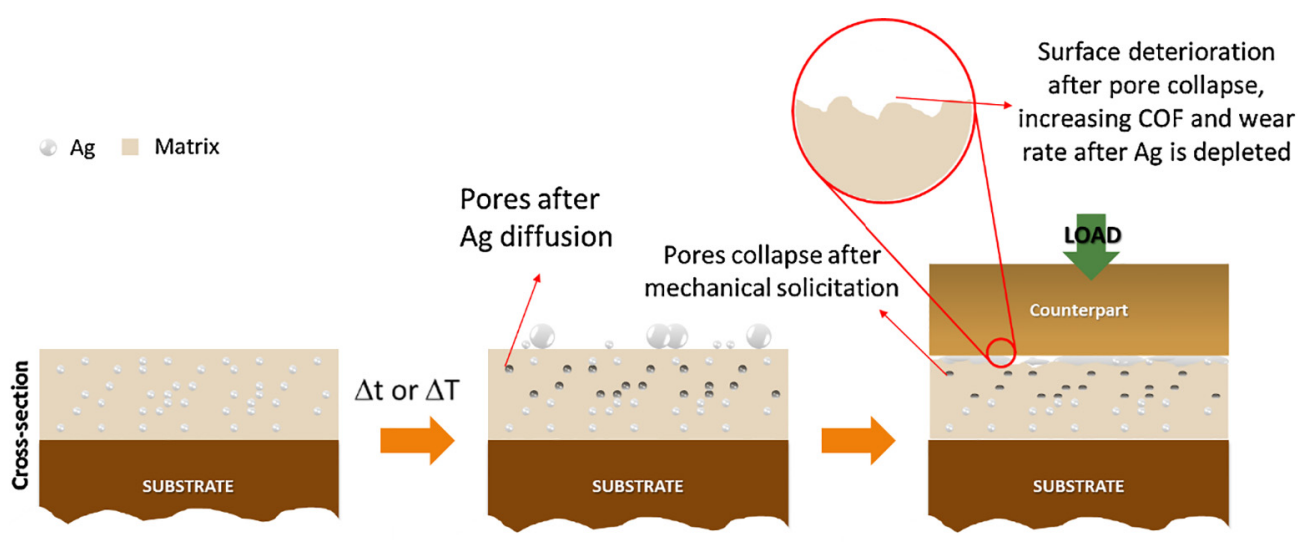

Fig. 26. Coating evolution scheme after silver segregation in a tribological test.

\section{Conclusions and further prospects}

The previous sections have demonstrated the potential of ceramic-Ag coatings for exploitation in a large variety of applications. In general, the silver phase is identified as one of the dominant parameters affecting the properties of the materials. However, a variety of variables belonging to the MS process can permit careful adjustment of the composition, morphology and additional features of the coatings to control their functional performance. However, the countless possibilities to produce a specific ceramic-Ag coating hinder direct comparisons of the developed materials described in the literature. For example, ceramic matrices with equal compositions can be produced in a variety of morphologies that alter the fundamental behavior of the system. Therefore, there is still a need to perform systematic studies entirely focused on the effect of the matrix composition on functional properties such as SPR, silver ion release, antimicrobial ability and, from a more fundamental point of view, the segregation of silver. The latter characteristic has been identified as a general shortcoming of these systems in optical applications and mechanical technologies because the optical and mechanical properties are altered by silver segregation and agglomeration. By contrast, in other fields, such as biomedical and self-lubricating applications, silver segregation may enhance the performance of the system, emphasizing the necessity of establishing a kinetic model of this process. Thus, it is imperative to understand how silver segregation is affected by the matrix composition and to properly define ranges in which the properties of the coatings can be tuned by modifying the silver amount and coating features. In particular, the precise amount of silver that will enhance existing properties or trigger new properties is unknown. In the case of biological applications, for instance, an increase in the silver content triggers undesired reactions, causing toxicity. This behavior has also been observed for other properties, where an excess of silver promotes film corrosion, mechanical instability, increased wear and COF, and a loss of SPR, demonstrating the need to designate a limit on the silver content for each of these properties and its dependence on the matrix chemistry, morphology and architecture.

MS is primarily used at the industrial scale, and some approaches have been developed to make this technique costeffective and highly competitive at that scale. However, the limiting factor to transfer ceramic-Ag coating technologies to industry seems to be entirely related to the definition of the above-mentioned characteristics, as well as a complete understanding of silver segregation behavior. As a result, a synergetic effort between experimental and simulation studies on the fundamental behavior of these systems should be encouraged, aimed at understanding the reasons for silver segregation in different environments (dry and vacuum environments, different levels of humidity, etc.) and the variables that control this process.

\section{Acknowledgments}

This research is partially sponsored by FEDER funds through the program COMPETE-Programa Operacional Factores de Competitividade and by Portuguese national funds through FCT-Fundação para a Ciência e a Tecnologia, under the projects ANTIMICROBCOAT - PTDC/CTM/102853/2008 and in the framework of the Strategic Projects PEST-C/FIS/UI607/2011", PESTC/EME/UI0285/2011 and SFRH/BD/80947/2011. The authors would like to thank the "Surface Modification and Functionalization - Research Group (SMF)" for advice during the development of this review.

\section{References}

[1] Kelly PJ, Li H, Whitehead KA, Verran J, Arnell RD, Iordanova I. A study of the antimicrobial and tribological properties of TiN/Ag nanocomposite coatings. Surf Coat Technol 2009;204:1137-40.

[2] Kelly PJ, Li H, Benson PS, Whitehead KA, Verran J, Arnell RD, et al. Comparison of the tribological and antimicrobial properties of CrN/Ag, ZrN/Ag, TiN/ Ag, and TiN/Cu nanocomposite coatings. Surf Coat Technol 2010;205:1606-10. 
[3] Wickens DJ, West G, Kelly PJ, Verran J, Lynch S, Whitehead KA. Antimicrobial activity of nanocomposite zirconium nitride/silver coatings to combat external bone fixation pin infections. Int J Artif Organs 2012;35:817-25.

[4] Isabel C, Mariana H, João Carlos O, Cristiana Filipa Almeida A, Ana Paula P, Sandra C. Influence of surface features on the adhesion of Staphylococcus epidermidis to Ag-TiCN thin films. Sci Technol Adv Mater 2013;14:035009.

[5] Hsieh JH, Tseng CC, Chang YK, Chang SY, Wu W. Antibacterial behavior of TaN-Ag nanocomposite thin films with and without annealing. Surf Coat Technol 2008;202:5586-9.

[6] Hsieh JH, Chang CC, Li C, Liu SJ, Chang YK. Effects of Ag contents on antibacterial behaviors of TaON-Ag nanocomposite thin films. Surf Coat Technol 2010;205(Suppl. 1):S337-40.

[7] Hsieh JH, Chang CC, Chang YK, Cherng JS. Photocatalytic and antibacterial properties of TaON-Ag nanocomposite thin films. Thin Solid Films 2010;518:7263-6.

[8] Rtimi S, Pascu M, Sanjines R, Pulgarin C, Ben-Simon M, Houas A, et al. ZrNO-Ag co-sputtered surfaces leading to E. coli inactivation under actinic light: Evidence for the oligodynamic effect. Appl Catal B 2013;138-139:113-21.

[9] Rtimi S, Baghriche O, Sanjines R, Pulgarin C, Bensimon M, Kiwi J. TiON and TiON-Ag sputtered surfaces leading to bacterial inactivation under indoor actinic light. J Photochem Photobiol A 2013;256:52-63.

[10] Rtimi S, Baghriche O, Sanjines R, Pulgarin C, Ben-Simon M, Lavanchy JC, et al. Photocatalysis/catalysis by innovative TiN and TiN-Ag surfaces inactivate bacteria under visible light. Appl Catal B 2012:123-124:306-15.

[11] Navabpour P, Ostovarpour S, Hampshire J, Kelly P, Verran J, Cooke K. The effect of process parameters on the structure, photocatalytic and selfcleaning properties of $\mathrm{TiO}_{2}$ and $\mathrm{Ag}-\mathrm{TiO}_{2}$ coatings deposited using reactive magnetron sputtering. Thin Solid Films 2014;571(Part 1):75-83.

[12] Skovager A, Whitehead K, Wickens D, Verran J, Ingmer H, Arneborg N. A comparative study of fine polished stainless steel, TiN and TiN/Ag surfaces: adhesion and attachment strength of Listeria monocytogenes as well as anti-listerial effect. Colloids Surf B 2013;109:190-6.

[13] Hrkac T, Röhl C, Podschun R, Zaporojtchenko V, Strunskus T, Papavlassopoulos H, et al. Huge increase of therapeutic window at a bioactive silver/ titania nanocomposite coating surface compared to solution. Mater Sci Eng C 2013;33:2367-75.

[14] Jamuna-Thevi K, Bakar SA, Ibrahim S, Shahab N, Toff MRM. Quantification of silver ion release, in vitro cytotoxicity and antibacterial properties of nanostuctured $\mathrm{Ag}$ doped $\mathrm{TiO}_{2}$ coatings on stainless steel deposited by RF magnetron sputtering. Vacuum 2011;86:235-41.

[15] Song D-H, Uhm S-H, Kim S-E, Kwon J-S, Han J-G, Kim K-N. Synthesis of titanium oxide thin films containing antibacterial silver nanoparticles by a reactive magnetron co-sputtering system for application in biomedical implants. Mater Res Bull 2012;47:2994-8.

[16] Ferraris M, Perero S, Miola M, Ferraris S, Gautier G, Maina G, et al. Chemical, mechanical, and antibacterial properties of silver nanocluster-silica composite coatings obtained by sputtering. Adv Eng Mater 2010;12:B276-82.

[17] Huang H-L, Chang Y-Y, Weng J-C, Chen Y-C, Lai C-H, Shieh T-M. Anti-bacterial performance of Zirconia coatings on Titanium implants. Thin Solid Films 2013;528:151-6.

[18] Kertzman Z, Marchal J, Suarez M, Staia MH, Filip P, Kohli P, et al. Mechanical, tribological, and biocompatibility properties of ZrN-Ag nanocomposite films. J Biomed Mater Res Part A 2008;84A:1061-7.

[19] Lan W-C, Ou S-F, Lin M-H, Ou K-L, Tsai M-Y. Development of silver-containing diamond-like carbon for biomedical applications. Part I: Microstructure characteristics, mechanical properties and antibacterial mechanisms. Ceram Int 2013;39:4099-104.

[20] Song D-H, Uhm S-H, Lee S-B, Han J-G, Kim K-N. Antimicrobial silver-containing titanium oxide nanocomposite coatings by a reactive magnetron sputtering. Thin Solid Films 2011;519:7079-85.

[21] Ferraris M, Balagna C, Perero S, Miola M, Ferraris S, Baino F, et al. Silver nanocluster/silica composite coatings obtained by sputtering for antibacterial applications. IOP Conf Ser: Mater Sci Eng 2012;40:012037.

[22] Balagna C, Perero S, Ferraris S, Miola M, Fucale G, Manfredotti C, et al. Antibacterial coating on polymer for space application. Mater Chem Phys 2012;135:714-22.

[23] Mulligan CP, Blanchet TA, Gall D. CrN-Ag nanocomposite coatings: high-temperature tribological response. Wear 2010;269:125-31.

[24] Mulligan CP, Blanchet TA, Gall D. CrN-Ag nanocomposite coatings: tribology at room temperature and during a temperature ramp. Surf Coat Technol 2010;204:1388-94.

[25] Mulligan CP, Gall D. CrN-Ag self-lubricating hard coatings. Surf Coat Technol 2005;200:1495-500.

[26] Alves CFA, Oliveira F, Carvalho I, Piedade AP, Carvalho S. Influence of albumin on the tribological behavior of Ag-Ti (C, N) thin films for orthopedic implants. Mater Sci Eng C 2014;34:22-8.

[27] Basnyat P, Luster B, Kertzman Z, Stadler S, Kohli P, Aouadi S, et al. Mechanical and tribological properties of CrAlN-Ag self-lubricating films. Surf Coat Technol 2007;202:1011-6.

[28] Manninen NK, Ribeiro F, Escudeiro A, Polcar T, Carvalho S, Cavaleiro A. Influence of Ag content on mechanical and tribological behavior of DLC coatings. Surf Coat Technol 2013;232:440-6.

[29] Vs Dhandapani, Thangavel E, Arumugam M, Shin KS, Veeraraghavan V, Yau SY, et al. Effect of Ag content on the microstructure, tribological and corrosion properties of amorphous carbon coatings on 316L SS. Surf Coat Technol 2014;240:128-36.

[30] Yao SH, Su YL, Kao WH. Effect of Ag/W addition on the wear performance of CrN coatings prepared by RF unbalanced magnetron sputtering. Mater Sci Eng A 2005;398:88-92.

[31] Incerti L, Rota A, Valeri S, Miguel A, García JA, Rodríguez RJ, et al. Nanostructured self-lubricating CrN-Ag films deposited by PVD arc discharge and magnetron sputtering. Vacuum 2011;85:1108-13.

[32] Tseng CC, Hsieh JH, Wu W, Chang SY, Chang CL. Emergence of Ag particles and their effects on the mechanical properties of TaN-Ag nanocomposite thin films. Surf Coat Technol 2007;201:9565-70.

[33] Tseng CC, Hsieh JH, Wu W, Chang SY, Chang CL. Surface and mechanical characterization of TaN-Ag nanocomposite thin films. Thin Solid Films 2008;516:5424-9.

[34] Aouadi S, Paudel Y, Luster B, Stadler S, Kohli P, Muratore C, et al. Adaptive $\mathrm{Mo}_{2} \mathrm{~N} / \mathrm{MoS}_{2} / \mathrm{Ag}$ tribological nanocomposite coatings for aerospace applications. Tribol Lett 2008;29:95-103.

[35] Köstenbauer H, Fontalvo G, Mitterer C, Keckes J. Tribological properties of TiN/Ag nanocomposite coatings. Tribol Lett 2008;30:53-60.

[36] Zheng XH, Tu JP, Lai DM, Peng SM, Gu B, Hu SB. Microstructure and tribological behavior of WS2-Ag composite films deposited by RF magnetron sputtering. Thin Solid Films 2008;516:5404-8.

[37] Jurči P, Dlouhý I. Coating of Cr-V ledeburitic steel with CrN containing a small addition of Ag. Appl Surf Sci 2011;257:10581-9.

[38] Shtansky DV, Batenina IV, Kiryukhantsev-Korneev PV, Sheveyko AN, Kuptsov KA, Zhitnyak IY, et al. Ag- and Cu-doped multifunctional bioactive nanostructured TiCaPCON films. Appl Surf Sci 2013;285(Part B):331-43.

[39] Pedrosa P, Alves E, Barradas NP, Martin N, Fiedler P, Haueisen J, et al. Electrochemical behaviour of nanocomposite Agx:TiN thin films for dry biopotential electrodes. Electrochim Acta 2014;125:48-57.

[40] Calderon Velasco S, Lopez V, Almeida Alves CF, Cavaleiro A, Carvalho S. Structural and electrochemical characterization of Zr-C-N-Ag coatings deposited by DC dual magnetron sputtering. Corros Sci 2014;80:229-36.

[41] Calderon VS, Galindo RE, Oliveira JC, Cavaleiro A, Carvalho S. $\mathrm{Ag}^{+}$release and corrosion behavior of zirconium carbonitride coatings with silver nanoparticles for biomedical devices. Surf Coat Technol 2013;222:104-11.

[42] Calderon VS, Oliveira JC, Evaristo M, Cavaleiro A, Carvalho S. Prediction of optimized composition for enhanced mechanical and electrochemical response of Zr-C-N-Ag coatings for medical devices. Appl Surf Sci 2014;320:570-80.

[43] Siozios A, Zoubos H, Pliatsikas N, Koutsogeorgis DC, Vourlias G, Pavlidou E, et al. Growth and annealing strategies to control the microstructure of AlN: Ag nanocomposite films for plasmonic applications. Surf Coat Technol 2014;255:28-36. 
[44] Zhou P, You H-Y, Jia J-H, Li J, Han T, Wang S-Y, et al. Concentration and size dependence of optical properties of Ag: $\mathrm{Bi}_{2} \mathrm{O}_{3}$ composite films by using the co-sputtering method. Thin Solid Films 2004;455-456:605-8.

[45] Aouadi SM, Bohnhoff A, Amriou T, Williams M, Hilfiker JN, Singh N, et al. Vacuum ultra-violet spectroscopic ellipsometry study of single- and multiphase nitride protective films. J Phys: Condens Matter 2006;18:S1691.

[46] Tamulevičius S, Meškinis Š, Šlapikas K, Vasiliauskas A, Gudaitis R, Andrulevičius M, et al. Piezoresistive properties of amorphous carbon based nanocomposite thin films deposited by plasma assisted methods. Thin Solid Films 2013;538:78-84.

[47] Meškinis Š, Vasiliauskas A, Šlapikas K, Gudaitis R, Andrulevičius M, Čiegis A, et al. Bias effects on structure and piezoresistive properties of DLC: Ag thin films. Surf Coat Technol 2014;255:84-9.

[48] Tu CJ, Gao JH, Hui S, Lou D, Zhang HL, Liang LY, et al. Alloyed nanoparticle-embedded alumina nanocermet film: a new attempt to improve the thermotolerance. Appl Surf Sci 2015;331:285-91.

[49] Barshilia HC, Kumar P, Rajam KS, Biswas A. Structure and optical properties of $\mathrm{Ag}-\mathrm{Al}_{2} \mathrm{O}_{3}$ nanocermet solar selective coatings prepared using unbalanced magnetron sputtering. Sol Energy Mater Sol Cells 2011;95:1707-15.

[50] Singh F, Gautam SK, Kulriya PK, Pivin JC. In situ X-ray diffraction study of the growth of silver nanoparticles embedded in silica film by ion irradiation: the effect of volume fraction. Nucl Instrum Meth Phys Res Sect B: Beam Interact Mater Atoms 2013;311:5-9.

[51] Liu M, Bao S, Yang G, Lu L, Cheng S, Qu S, et al. Self-assembled ZnO/Ag nanocomposite thin films with enhanced multiple-phonon resonant Raman scattering. Mater Lett 2014;115:172-5.

[52] Tamulevičius T, Tamulevičienè A, Virganavičius D, Vasiliauskas A, Kopustinskas V, Meškinis Š, et al. Structuring of DLC: Ag nanocomposite thin films employing plasma chemical etching and ion sputtering. Nucl Instrum Meth Phys Res Sect B: Beam Interact Mater Atoms 2014;341:1-6.

[53] Matenoglou GM, Zoubos H, Lotsari A, Lekka CE, Komninou P, Dimitrakopulos GP, et al. Metal-containing amorphous carbon (a-C:Ag) and AlN (AlN:Ag) metallo-dielectric nanocomposites. Thin Solid Films 2009;518:1508-11.

[54] Pardo A, Gómez-Aleixandre C, Celis JP, Buijnsters JG. Friction and wear behavior of plasma assisted chemical vapor deposited nanocomposites made of metal nanoparticles embedded in a hydrogenated amorphous carbon matrix. Surf Coat Technol 2012;206:3116-24.

[55] Serezhkina SV, Potapenko LT, Bokshits YV, Shevchenko GP, Sviridov VV. Preparation of silver nanoparticles in oxide matrices derived by the sol-gel method. Glass Phys Chem 2003:29:484-9.

[56] Frey H, Khan HR. Handbook of thin film technology. Springer; 2010.

[57] Reinecke R, Burkhardt W. Method of coating articles by vaporized coating materials. Google Patents; 1939.

[58] Kelly PJ, Arnell RD. Magnetron sputtering: a review of recent developments and applications. Vacuum 2000;56:159-72.

[59] Mattox DM. Handbook of physical vapor deposition (PVD) processing. William Andrew; 2010.

[60] Manninen NK, Calderón VS, Almeida Alves CF, Carvalho S, Cavaleiro A. Influence of hydrogen incorporation and coating thickness on the corrosion resistance of carbon based coatings deposited by magnetron sputtering. Surf Coat Technol 2015;275:127-32.

[61] Van der Donck T, Muchlado M, Zein Eddine W, Achanta S, Carvalho NJM, Celis JP. Effect of hydrogen content in a-C:H coatings on their tribological behaviour at room temperature up to $150^{\circ} \mathrm{C}$. Surf Coat Technol 2009;203:3472-9.

[62] Onoprienko AA, Danylenko MI. Annealing effects in Ag-doped amorphous carbon films deposited by dc magnetron sputtering. Surf Coat Technol 2012;206:3450-3.

[63] Siozios A, Zoubos H, Pliatsikas N, Koutsogeorgis DC, Vourlias G, Pavlidou E, et al. Growth and annealing strategies to control the microstructure of AlN: Ag nanocomposite films for plasmonic applications. Surf Coat Technol 2014;255:28-36.

[64] Mulligan CP, Blanchet TA, Gall D. CrN-Ag nanocomposite coatings: effect of growth temperature on the microstructure. Surf Coat Technol 2008;203:584-7.

[65] Papi PA, Mulligan CP, Gall D. CrN-Ag nanocomposite coatings: control of lubricant transport by diffusion barriers. Thin Solid Films 2012;524:211-7.

[66] Aouadi SM, Paudel Y, Simonson WJ, Ge Q Kohli P, Muratore C, et al. Tribological investigation of adaptive $\mathrm{Mo}_{2} \mathrm{~N} / \mathrm{MoS}_{2} / \mathrm{Ag}$ coatings with high sulfur content. Surf Coat Technol 2009;203:1304-9.

[67] Gulbiński W, Suszko T. Thin films of $\mathrm{Mo}_{2} \mathrm{~N} / \mathrm{Ag}$ nanocomposite-the structure, mechanical and tribological properties. Surf Coat Technol 2006:201:1469-76.

[68] Stone DS, Migas J, Martini A, Smith T, Muratore C, Voevodin AA, et al. Adaptive NbN/Ag coatings for high temperature tribological applications. Surf Coat Technol 2012;206:4316-21.

[69] Huang H-L, Chang Y-Y, Lai M-C, Lin C-R, Lai C-H, Shieh T-M. Antibacterial TaN-Ag coatings on titanium dental implants. Surf Coat Technol 2010;205:1636-41.

[70] Park I-S, Park S-Y, Jeong G-H, Na S-M, Suh S-J. Fabrication of $\mathrm{Ta}_{3} \mathrm{~N}_{5}-\mathrm{Ag}$ nanocomposite thin films with high resistivity and near-zero temperature coefficient of resistance. Thin Solid Films 2008;516:5409-13.

[71] Tseng CC, Hsieh JH, Jang SC, Chang YY, Wu W. Microstructural analysis and mechanical properties of TaN-Ag nanocomposite thin films. Thin Solid Films 2009;517:4970-4

[72] de los Arcos T, Oelhafen P, Aebi U, Hefti A, Düggelin M, Mathys D, et al. Preparation and characterization of TiN-Ag nanocomposite films. Vacuum 2002;67:463-70.

[73] Pedrosa P, Machado D, Lopes C, Alves E, Barradas NP, Martin N, et al. Nanocomposite Ag:TiN thin films for dry biopotential electrodes. Appl Surf Sci 2013;285(Part A):40-8.

[74] Pedrosa P, Lopes C, Martin N, Fonseca C, Vaz F. Electrical characterization of Ag:TiN thin films produced by glancing angle deposition. Mater Lett 2014;115:136-9.

[75] Aouadi SM, Singh DP, Stone DS, Polychronopoulou K, Nahif F, Rebholz C, et al. Adaptive VN/Ag nanocomposite coatings with lubricious behavior from 25 to $1000{ }^{\circ} \mathrm{C}$. Acta Mater 2010;58:5326-31.

[76] Aouadi SM, Bohnhoff A, Sodergren M, Mihut D, Rohde SL, Xu J, et al. Tribological investigation of zirconium nitride/silver nanocomposite structures. Surf Coat Technol 2006;201:418-22.

[77] Aouadi SM, Debessai M, Filip P. Zirconium nitride/silver nanocomposite structures for biomedical applications. J Vac Sci Technol B 2004;22:1134-40.

[78] Aouadi SM, Shreeman PK, Ge Q Xu J, Mishra SR. Correlation between interfacial electronic structure and mechanical properties of ZrN-Me $(\mathrm{Me}=\mathrm{Ag}$, Au, or Pd) nanocomposite films. Appl Phys Lett 2005;87. 041902-1.

[79] Krzanowski JE, Endrino JL, Nainaparampil JJ, Zabinski JS. Composite coatings incorporating solid lubricant phases. J Mater Eng Perform 2004;13:439-44.

[80] Endrino JL, Nainaparampil JJ, Krzanowski JE. Microstructure and vacuum tribology of TiC-Ag composite coatings deposited by magnetron sputteringpulsed laser deposition. Surf Coat Technol 2002;157:95-101.

[81] Wang Y, Wang J, Zhang G, Wang L, Yan P. Microstructure and tribology of TiC(Ag)/a-C:H nanocomposite coatings deposited by unbalanced magnetron sputtering. Surf Coat Technol 2012;206:3299-308.

[82] Sarius NG, Lauridsen J, Lewin E, Lu J, Högberg H, Öberg Å, et al. Ni and Ti diffusion barrier layers between Ti-Si-C and Ti-Si-C-Ag nanocomposite coatings and Cu-based substrates. Surf Coat Technol 2012;206:2558-65.

[83] Eklund P, Joelsson T, Ljungcrantz H, Wilhelmsson O, Czigány Z, Högberg H, et al. Microstructure and electrical properties of Ti-Si-C-Ag nanocomposite thin films. Surf Coat Technol 2007;201:6465-9.

[84] Endrino JL, Nainaparampil JJ, Krzanowski JE. Magnetron sputter deposition of WC-Ag and TiC-Ag coatings and their frictional properties in vacuum environments. Scripta Mater 2002;47:613-8.

[85] Shtansky DV, Bondarev AV, Kiryukhantsev-Korneev PV, Rojas TC, Godinho V, Fernández A. Structure and tribological properties of MoCN-Ag coatings in the temperature range of $25-700^{\circ} \mathrm{C}$. Appl Surf Sci 2013;273:408-14. 
[86] Carvalho I, Galindo RE, Henriques M, Palacio C, Carvalho S. Influence of culture media on the physical and chemical properties of Ag-TiCN coatings. J Phys D Appl Phys 2014;47:335401.

[87] Escobar Galindo R, Manninen NK, Palacio C, Carvalho S. Advanced surface characterization of silver nanocluster segregation in Ag-TiCN bioactive coatings by RBS, GDOES, and ARXPS. Anal Bioanal Chem 2013;405:6259-69.

[88] Manninen N, Galindo RE, Benito N, Figueiredo N, Cavaleiro A, Palacio C, et al. Ag-Ti (C, N)-based coatings for biomedical applications: influence of silver content on the structural properties. J Phys D Appl Phys 2011;44:375501.

[89] Sánchez-López JC, Abad MD, Carvalho I, Escobar Galindo R, Benito N, Ribeiro S, et al. Influence of silver content on the tribomechanical behavior on Ag-TiCN bioactive coatings. Surf Coat Technol 2012;206:2192-8.

[90] Ferreri I, Lopes V, Calderon VS, Tavares CJ, Cavaleiro A, Carvalho S. Study of the effect of the silver content on the structural and mechanical behavior of Ag-ZrCN coatings for orthopedic prostheses. Mater Sci Eng C 2014;42:782-90.

[91] Calderon VS, Ferreri I, Galindo RE, Henriques M, Cavaleiro A, Carvalho S. Electrochemical vs antibacterial characterization of ZrCN-Ag coatings. Surf Coat Technol 2015;275:357-62.

[92] Ahmed SF, Moon M-W, Lee K-R. Effect of silver doping on optical property of diamond like carbon films. Thin Solid Films 2009;517:4035-8.

[93] Batory D, Reczulska MC, Kolodziejczyk L, Szymanski W. Gradient titanium and silver based carbon coatings deposited on AISI316L. Appl Surf Sci 2013;275:303-10.

[94] Chen S-Y, Ou K-L, Huang W-C, Chu K-T, Ou S-F. Phase transformation of diamond-like carbon/silver composite films by sputtering deposition. Ceram Int 2013;39:2575-80.

[95] Choi HW, Choi J-H, Lee K-R, Ahn J-P, Oh KH. Structure and mechanical properties of Ag-incorporated DLC films prepared by a hybrid ion beam deposition system. Thin Solid Films 2007;516:248-51.

[96] Lungu CP. Nanostructure influence on DLC-Ag tribological coatings. Surf Coat Technol 2005;200:198-202.

[97] Manninen NK, Galindo RE, Carvalho S, Cavaleiro A. Silver surface segregation in Ag-DLC nanocomposite coatings. Surf Coat Technol 2015;267:90-7.

[98] Meškinis Š, Čiegis A, Vasiliauskas A, Tamulevičiené A, Šlapikas K, Juškènas R, et al. Plasmonic properties of silver nanoparticles embedded in diamond like carbon films: influence of structure and composition. Appl Surf Sci 2014;317:1041-6.

[99] Meškinis Š, Vasiliauskas A, Šlapikas K, Gudaitis R, Andrulevičius M, Čiegis A, et al. Bias effects on structure and piezoresistive properties of DLC:Ag thin films. Surf Coat Technol 2014;255:84-9.

[100] Morrison ML, Buchanan RA, Liaw PK, Berry CJ, Brigmon RL, Riester L, et al. Electrochemical and antimicrobial properties of diamondlike carbon-metal composite films. Diam Relat Mater 2006;15:138-46.

[101] Takeno T, Saito H, Goto M, Fontaine J, Miki H, Belin M, et al. Deposition, structure and tribological behavior of silver-carbon nanocomposite coatings. Diam Relat Mater 2013;39:20-6.

[102] Tamulevičius T, Tamulevičienė A, Virganavičius D, Vasiliauskas A, Kopustinskas V, Meškinis Š, et al. Structuring of DLC:Ag nanocomposite thin films employing plasma chemical etching and ion sputtering. Nucl Instrum Meth Phys Res Sect B: Beam Interact Mater Atoms 2014;341:1-6.

[103] Wang C, Yu X, Hua M. Microstructure and mechanical properties of Ag-containing diamond-like carbon films in mid-frequency dual-magnetron sputtering. Appl Surf Sci 2009;256:1431-5.

[104] Wu Y, Chen J, Li H, Ji L, Ye Y, Zhou H. Preparation and properties of Ag/DLC nanocomposite films fabricated by unbalanced magnetron sputtering. Appl Surf Sci 2013;284:165-70.

[105] Chang Y-Y, Huang H-L, Chen Y-C, Weng J-C, Lai C-H. Characterization and antibacterial performance of ZrNO-Ag coatings. Surf Coat Technol 2013;231:224-8.

[106] Bian HQ Ma SY, Li FM, Zhu HB. Influence of ZnO buffer layer on microstructure and Raman scattering of ZnO:Ag film on Si substrate. Superlatt Microstruct 2013;58:171-7.

[107] Duan L, Gao W, Chen R, Fu Z. Influence of post-annealing conditions on properties of ZnO:Ag films. Solid State Commun 2008;145:479-81.

[108] Duan L, Yu X, Ni L, Wang Z. ZnO:Ag film growth on Si substrate with ZnO buffer layer by rf sputtering. Appl Surf Sci 2011;257:3463-7.

[109] Jeong SH, Yoo DG, Kim DY, Lee NE, Boo JH. Physical properties and etching characteristics of metal (Al, Ag, Li) doped ZnO films grown by RF magnetron sputtering. Thin Solid Films 2008;516:6598-603.

[110] Liang Y-C, Deng X-S. Structure dependent luminescence evolution of c-axis-oriented ZnO nanofilms embedded with silver nanoparticles and clusters prepared by sputtering. J Alloy Compd 2013;569:144-9.

[111] Hu JJ, Muratore C, Voevodin AA. Silver diffusion and high-temperature lubrication mechanisms of YSZ-Ag-Mo based nanocomposite coatings. Compos Sci Technol 2007;67:336-47.

[112] Muratore C, Voevodin AA, Hu JJ, Jones JG, Zabinski JS. Growth and characterization of nanocomposite yttria-stabilized zirconia with Ag and Mo. Surf Coat Technol 2005;200:1549-54.

[113] Muratore C, Voevodin AA, Hu JJ, Zabinski JS. Tribology of adaptive nanocomposite yttria-stabilized zirconia coatings containing silver and molybdenum from 25 to $700^{\circ} \mathrm{C}$. Wear 2006;261:797-805.

[114] Ashok Kumar Reddy Y, Sivasankar Reddy A, Sreedhara Reddy P. Effect of oxygen partial pressure on the properties of NiO-Ag composite films grown by DC reactive magnetron sputtering. J Alloy Compd 2014;583:396-403.

[115] Ferraris S, Perero S, Miola M, Vernè E, Rosiello A, Ferrazzo V, et al. Chemical, mechanical and antibacterial properties of silver nanocluster/silica composite coated textiles for safety systems and aerospace applications. Appl Surf Sci 2014;317:131-9.

[116] Nikolaeva M, Sendova-Vassileva M, Malinovska D, Sarov Y, Pivin JC. Ion beam assisted formation of $\mathrm{Ag}$ nanoparticles in $\mathrm{SiO}_{2}$ and their optical properties. Nucl Instrum Meth Phys Res Sect B: Beam Interact Mater Atoms 2002;193:867-70.

[117] Sella C, Chenot S, Reillon V, Berthier S. Influence of the deposition conditions on the optical absorption of Ag-SiO ${ }_{2}$ nanocermet thin films. Thin Solid Films 2009;517:5848-54.

[118] Adochite RC, Munteanu D, Torrell M, Cunha L, Alves E, Barradas NP, et al. The influence of annealing treatments on the properties of Ag:TiO 2 nanocomposite films prepared by magnetron sputtering. Appl Surf Sci 2012;258:4028-34.

[119] Xiong J, Ghori MZ, Henkel B, Strunskus T, Schürmann U, Kienle L, et al. Controlling surface segregation of reactively sputtered Ag/TiO ${ }_{x}$ nanocomposites. Acta Mater 2014;74:1-8.

[120] Huang C-M, Cheng K-W, Jhan Y-R, Chung T-W. Preparation of visible-light-active Ag and In-doped ZnS thin film photoelectrodes by reactive magnetron co-sputtering. Thin Solid Films 2007;515:7935-44.

[121] Song X, Shi S, Cao C, Chen X, Cui J, He G, et al. Effect of Ag-doping on microstructural, optical and electrical properties of sputtering-derived ZnS films. J Alloy Compd 2013;551:430-4.

[122] Wang Q, Tu JP, Zhang SC, Lai DM, Peng SM, Gu B. Effect of Ag content on microstructure and tribological performance of WS2-Ag composite films. Surf Coat Technol 2006;201:1666-70.

[123] Xu S, Gao X, Hu M, Sun J, Wang D, Zhou F, et al. Morphology evolution of Ag alloyed WS2 films and the significantly enhanced mechanical and tribological properties. Surf Coat Technol 2014;238:197-206.

[124] Krzanowski JE. Phase formation and phase separation in multiphase thin film hard coatings. Surf Coat Technol 2004;188-189:376-83.

[125] Meškinis Š, Vasiliauskas A, Šlapikas K, Niaura G, Juškènas R, Andrulevičius M, et al. Structure of the silver containing diamond like carbon films: study by multiwavelength Raman spectroscopy and XRD. Diam Relat Mater 2013;40:32-7.

[126] Calderon VS, Cavaleiro A, Carvalho S. Chemical and structural characterization of ZrCNAg coatings: XPS, XRD and Raman spectroscopy. Appl Surf Sci 2015;346:240-7.

[127] Calderon VS, Ferreri I, Henriques M, De Hosson JTM, Cavaleiro A, Carvalho S. Nano-galvanic coupling for enhanced $\mathrm{Ag}^{+}$release in $\mathrm{ZrCN}-\mathrm{Ag}_{\mathrm{g}}$ films: antibacterial application. Surf Coat Technol 2016;298:1-6. 
[128] Machado D, Pedrosa P, Fonseca C, Martin N, Vaz F. Structural and morphological changes in Ag:TiN nanocomposite films promoted by in-vacuum annealing. J Nano Res 2013;25:67-76.

[129] Garcia-Zarco O, Rodil SE, Camacho-López MA. Deposition of amorphous carbon-silver composites. Thin Solid Films 2009;518:1493-7.

[130] Calderon VS, Sánchez-López JC, Cavaleiro A, Carvalho S. Biotribological behavior of $\mathrm{Ag}_{\mathrm{Z}} \mathrm{ZrC}_{\mathrm{x}} \mathrm{N}_{1-\mathrm{x}}$ coatings against UHMWPE for joint prostheses devices. J Mech Behav Biomed Mater 2015;41:83-91.

[131] Lauridsen J, Eklund P, Jensen J, Furlan A, Flink A, Andersson AM, et al. Effects of A-elements (ASi, Ge or Sn) on the structure and electrical contact properties of Ti-A-C-Ag nanocomposites. Thin Solid Films 2012;520:5128-36.

[132] Mulligan CP, Papi PA, Gall D. Ag transport in CrN-Ag nanocomposite coatings. Thin Solid Films 2012;520:6774-9.

[133] Marques SM, Manninen NK, Ferdov S, Lanceros-Mendez S, Carvalho S. $\mathrm{Ti}_{1-\mathrm{x}} \mathrm{Ag}_{\mathrm{x}}$ electrodes deposited on polymer based sensors. Appl Surf Sci 2014;317:490-5.

[134] Chakravadhanula VSK, Mishra YK, Kotnur VG, Avasthi DK, Strunskus T, Zaporotchenko V, et al. Microstructural and plasmonic modifications in Ag$\mathrm{TiO}_{2}$ and $\mathrm{Au}-\mathrm{TiO}_{2}$ nanocomposites through ion beam irradiation. Beilstein J Nanotechnol 2014;5:1419-31.

[135] Mulligan CP, Blanchet TA, Gall D. Control of lubricant transport by a CrN diffusion barrier layer during high-temperature sliding of a CrN-Ag composite coating. Surf Coat Technol 2010;205:1350-5.

[136] Lei Jiang LF. Bioinspired intelligent nanostructured interfacial materials. Singapore: World scientific publishing; 2010.

[137] Calderon VS, Cavaleiro A, Carvalho S. Electrochemical response of ZrCN-Ag-a(C, N) coatings in simulated body fluids. Electrochim Acta 2015.

[138] Kuempel ED, Geraci CL, Schulte PA. Risk assessment and risk management of nanomaterials in the workplace: translating research to practice. Ann Occup Hyg 2012;56:491-505.

[139] de Lima R, Seabra AB, Durán N. Silver nanoparticles: a brief review of cytotoxicity and genotoxicity of chemically and biogenically synthesized nanoparticles. J Appl Toxicol 2012;32:867-79.

[140] Baghriche O, Kiwi J, Pulgarin C, Sanjinés R. Antibacterial Ag-ZrN surfaces promoted by subnanometric ZrN-clusters deposited by reactive pulsed magnetron sputtering. J Photochem Photobiol A 2012;229:39-45.

[141] Jung WK, Koo HC, Kim KW, Shin S, Kim SH, Park YH. Antibacterial activity and mechanism of action of the silver ion in Staphylococcus aureus and Escherichia coli. Appl Environ Microbiol 2008;74:2171-8.

[142] Sondi I, Salopek-Sondi B. Silver nanoparticles as antimicrobial agent: a case study on E. coli as a model for Gram-negative bacteria. J Colloid Interface Sci 2004;275:177-82.

[143] Ferreri I, Calderon VS, Escobar Galindo R, Palacio C, Henriques M, Piedade AP, et al. Silver activation on thin films of Ag-ZrCN coatings for antimicrobial activity. Mater Sci Eng C 2015;55:547-55.

[144] Stansbury EE, Buchanan RA. Fundamentals of electrochemical corrosion. ASM International; 2000.

[145] Manninen NK, Calderon VS, Carvalho I, Henriques M, Cavaleiro A, Carvalho S. Antibacterial Ag/a-C nanocomposite coatings: the influence of nanogalvanic a-C and Ag couples on Ag ionization rates. Appl Surf Sci 2016;377:283-91.

[146] Liu J, Sonshine DA, Shervani S, Hurt RH. Controlled release of biologically active silver from nanosilver surfaces. ACS Nano 2010;4:6903-13.

[147] Monteiro-Riviere NA, Samberg ME, Oldenburg SJ, Riviere JE. Protein binding modulates the cellular uptake of silver nanoparticles into human cells: implications for in vitro to in vivo extrapolations? Toxicol Lett 2013;220:286-93.

[148] Ravindran A, Singh A, Raichur AM, Chandrasekaran N, Mukherjee A. Studies on interaction of colloidal Ag nanoparticles with bovine serum albumin (BSA). Colloids Surf B 2010;76:32-7.

[149] Gnanadhas DP, Thomas MB, Thomas R, Raichur AM, Chakravortty D. Interaction of silver nanoparticles with serum proteins affects their antimicrobial activity in vivo. Antimicrob Agents Chemother 2013;57:4945-55.

[150] Akhavan O, Ghaderi E. Capping antibacterial Ag nanorods aligned on Ti interlayer by mesoporous $\mathrm{TiO}_{2}$ layer. Surf Coat Technol 2009;203:3123-8.

[151] Dobias J, Bernier-Latmani R. Silver release from silver nanoparticles in natural waters. Environ Sci Technol 2013;47:4140-6.

[152] Jain P, Huang X, El-Sayed I, El-Sayed M. Review of some interesting surface plasmon resonance-enhanced properties of noble metal nanoparticles and their applications to biosystems. Plasmonics 2007;2:107-18.

[153] Bunshah RF. Handbook of hard coatings; 2001.

[154] Aouadi SM, Shreeman PK, Ge Q Xu J, Mishra SR. Correlation between interfacial electronic structure and mechanical properties of ZrN-Me (Me.Ag, $\mathrm{Au}$, or Pd) nanocomposite films. Appl Phys Lett 2005;87. 